\title{
CLINICAL PRACTICE GUIDELINES FOR THE PERIOPERATIVE NUTRITIONAL, METABOLIC, AND NONSURGICAL SUPPORT OF THE BARIATRIC SURGERY PATIENT-2013 UPDATE: COSPONSORED BY AMERICAN ASSOCIATION OF CLINICAL ENDOCRINOLOGISTS, THE OBESITY SOCIETY, AND AMERICAN SOCIETY FOR METABOLIC \& BARIATRIC SURGERY^
}

\author{
Jeffrey I. Mechanick, MD ${ }^{1,}{ }^{*}$, Adrienne Youdim, MD $^{2}$, Daniel B. Jones, MD, MS ${ }^{3}$, W. Timothy \\ Garvey, MD ${ }^{4}$, Daniel L. Hurley, MD ${ }^{5}$, M. Molly McMahon, MD ${ }^{5}$, Leslie J. Heinberg, PhD $^{6}$, \\ Robert Kushner, MD ${ }^{7}$, Ted D. Adams, PhD, MPH ${ }^{8}$, Scott Shikora, MD ${ }^{9}$, John B. Dixon, \\ MBBS, PhD ${ }^{10}$, and Stacy Brethauer, MD ${ }^{11}$ \\ ${ }^{1}$ Co-Chair, Icahn School of Medicine at Mount Sinai, New York, New York \\ ${ }^{2}$ Co-Chair, Cedars Sinai Medical Center, Los Angeles, California \\ ${ }^{3}$ Co-Chair, Harvard Medical School, Beth Israel Deaconess Medical Center, Boston, \\ Massachusetts
}

\footnotetext{
^ These Guidelines are endorsed by the European Association for the Study of Obesity (EASO), International Association for the Study of Obesity (IASO), International Society for the Perioperative Care of the Obese Patient (ISPCOP), Society American Gastrointestinal Endoscopic Surgeons (SAGES), American College of Surgery (ACS), and International Federation for the Surgery of Obesity and Metabolic Disorders (IFSO).

Copyright $\odot 2013$ AACE.

*Address correspondence to Dr. Jeffrey I. Mechanick, Icahn School of Medicine at Mount Sinai, 1192 Park Avenue, New York, NY 10128. jeffreymechanick@gmail.com.

DISCLOSURES

Jeffrey I. Mechanick, MD: Abbott Nutrition, honoraria for lectures and program development. Daniel B. Jones, MD, MS: Allurion, consultant. W. Timothy Garvey, MD: Merck, speakers list; Daiichi-Sanyo, Vivus, Alkermes, Liposcience, Tethys Bioscience, advisory boards; Merck, Amylin, Weight Watchers, research. Scott Shikora, MD: Baxter Healthcare, consultant; EnteroMedics, consultant; GI Dynamics, stock options for previous consultant work. John B. Dixon, MBBS, PhD, FRACGP, FRCPEdin: Consultant for Allergan Inc. and Bariatric Advantage Inc.; Scientific Advisory Board for OPTIFAST(R), Nestle Australia; developed educational material and is on the speakers' bureau for iNova Pharmaceuticals; Institutions receive research assistance from Allergan Inc. and Nestle Australia. Robin Blackstone, MD: Enteromedics PI and Johnson and Johnson, consultant. Alan Garber, MD: Novo Nordisk, Daiichi Sankyo, Merck, Takeda, Santarus, LipoScience, Boehringer Ingelheim, Tethys, Lexicon, Vivus, consultant; Novo Nordisk, Daiichi Sankyo, Merck, Takeda, LipoScience, Boehringer Ingelheim, advisory board; Merck, Novo Nordisk, Santarus, Daiichi Sankyo, Speakers Bureau. Stacy Brethauer, MD: Ethicon Endo-Surgery, consultant and Advisory Board member. David B. Sarwer, PhD: Allergan, BaroNova, EnteroMedics, Ethicon Endo-Surgery, Galderma, consultant. Bruce Wolfe, MD: EnteroMedics, investigator. Adrienne Youdim, MD; Daniel L. Hurley, MD; M. Molly McMahon, MD; Leslie J. Heinberg, PhD; Robert Kushner, MD; Ted Adams, PhD, MPH; George Blackburn, MD, PhD; and Christopher D. Still, DO, report no potential conflicts of interest. DISCLAIMER

American Association of Clinical Endocrinologists, The Obesity Society, and American Society for Metabolic \& Bariatric Surgery Medical Guidelines for Clinical Practice are systematically developed statements to assist health-care professionals in medical decision making for specific clinical conditions. Most of the content herein is based on literature reviews. In areas of uncertainty, professional judgment was applied. These guidelines are a working document that reflects the state of the field at the time of publication. Because rapid changes in this area are expected, periodic revisions are inevitable. We encourage medical professionals to use this information in conjunction with their best clinical judgment. The presented recommendations may not be appropriate in all situations. Any decision by practitioners to apply these guidelines must be made in light of local resources and individual patient circumstances.
} 
${ }^{4}$ Primary Writer, AACE, University of Alabama at Birmingham, Birmingham VA Medical Center, Birmingham, Alabama

${ }^{5}$ Primary Writer AACE, Division of Endocrinology, Diabetes, Metabolism, and Nutrition, Mayo

Clinic, Rochester, Minnesota

${ }^{6}$ Primary Writer TOS, Cleveland Clinic Lerner College of Medicine, BMI Director of Behavioral Services, Cleveland, Ohio

${ }^{7}$ Primary Writer TOS, Northwestern University, Feinberg School of Medicine, Chicago, Illinois

${ }^{8}$ Primary Writer TOS, Health \& Fitness Institute, Intermountain Healthcare and Cardiovascular Genetics Division, University of Utah School of Medicine, Salt Lake City, Utah

${ }^{9}$ Primary Writer ASMBS, Harvard Medical School, Center for Metabolic Health and Bariatric Surgery, Brigham and Women's Hospital, Boston, Massachusetts

${ }^{10}$ Primary Writer ASMBS, Professor and Head of Clinical Obesity Research, Baker IDI Heart and Diabetes Institute, Head of Obesity Research, Monash University, Melbourne, Australia

${ }^{11}$ Primary Writer ASMBS, Bariatric and Metabolic Institute, Cleveland Clinic, Cleveland, Ohio

\section{Abstract}

The development of these updated guidelines was commissioned by the AACE, TOS, and ASMBS Board of Directors and adheres to the AACE 2010 protocol for standardized production of clinical practice guidelines (CPG). Each recommendation was re-evaluated and updated based on the evidence and subjective factors per protocol. Examples of expanded topics in this update include: the roles of sleeve gastrectomy, bariatric surgery in patients with type-2 diabetes, bariatric surgery for patients with mild obesity, copper deficiency, informed consent, and behavioral issues. There are 74 recommendations (of which 56 are revised and 2 are new) in this 2013 update, compared with 164 original recommendations in 2008. There are 403 citations, of which 33 $(8.2 \%)$ are EL 1, $131(32.5 \%)$ are EL 2, $170(42.2 \%)$ are EL 3, and 69 (17.1\%) are EL 4. There is a relatively high proportion (40.4\%) of strong (EL 1 and 2) studies, compared with only $16.5 \%$ in the 2008 AACE- TOS-ASMBS CPG. These updated guidelines reflect recent additions to the evidence base. Bariatric surgery remains a safe and effective intervention for select patients with obesity. A team approach to perioperative care is mandatory with special attention to nutritional and metabolic issues.

\section{INTRODUCTION}

Obesity continues to be a major public health problem in the United States, with more than one-third of adults considered obese in 2009-2010, as defined by a body mass index (BMI) $230 \mathrm{~kg} / \mathrm{m}^{2}$ (1 [EL 3, SS]). Obesity has been associated with an increased hazard ratio for allcause mortality (2 [EL 3, SS]), as well as significant medical and psychological comorbidity. Indeed, obesity is not only a chronic medical condition but should be regarded as a bona fide disease state (3 [EL 4, NE]). Nonsurgical management can effectively induce $5 \%-10 \%$ weight loss and improve health in severely obese individuals (4 [EL 1, RCT]) resulting in cardiometabolic benefit. Bariatric surgery procedures are indicated for patients 
with clinically severe obesity. Currently, these procedures are the most successful and durable treatment for obesity. Furthermore, although overall obesity rates and bariatric surgery procedures have plateaued in the United States, rates of severe obesity are still increasing and now there are approximately 15 million people in the United States with a BMI $\geq 40 \mathrm{~kg} / \mathrm{m}^{2}$ (1 [EL 3, SS]; 5 [EL 3, SS]). Only $1 \%$ of the clinically eligible population receives surgical treatment for obesity (6 [EL 3, SS]). Given the potentially increased need for bariatric surgery as a treatment for obesity, it is apparent that clinical practice guidelines (CPG) on the subject keep pace and are kept current.

Since the 2008 TOS/ASMBS/AACE CPG for the perioperative nutritional, metabolic, and nonsurgical support of the bariatric surgery patient (7 [EL 4; CPG]), significant data have emerged regarding a broader range of available surgeries for the treatment of obesity. A PubMed computerized literature search (performed on December 15, 2012) using the search term "bariatric surgery" reveals a total of 14,287 publications with approximately 6,800 citations from 2008 to 2012. Updated CPG are therefore needed to guide clinicians in the care of the bariatric surgery patient. What are the salient advances in bariatric surgery since 2008? The sleeve gastrectomy (SG; laparoscopic SG [LSG]) has demonstrated benefits comparable to other bariatric procedures and is no longer considered investigational (8 [EL 4 , NE]). A national risk-adjusted database positions SG between the laparoscopic adjustable gastric band (LAGB) and laparoscopic Roux-en-Y gastric bypass (RYGB) in terms of weight loss, co-morbidity resolution, and complications (9 [EL 2, PCS]). The number of SG procedures has increased with greater third-party pay or coverage (9 [EL 2, PCS]). Other unique procedures are gaining attention, such as gastric plication, electrical neuromodulation, and endoscopic sleeves, but these procedures lack sufficient outcome evidence and therefore remain investigational and outside the scope of this CPG update.

There is also emerging data on bariatric surgery in specific patient populations, including those with mild to moderate obesity, type 2 diabetes (T2D) with class I obesity (BMI 30$34.9 \mathrm{~kg} / \mathrm{m}^{2}$ ), and patients at the extremes of age. Clinical studies have demonstrated shortterm efficacy of LAGB in mild to moderate obesity (10 [EL 1, RCT]; 11 [EL 2, PCS]; 12 [EL 2, PCSA]; 13 [EL 3, SS]), leading the Food and Drug Administration (FDA) to approve the use of LAGB for patients with a BMI of 30 to $35 \mathrm{~kg} / \mathrm{m}^{2}$ with T2D or other obesityrelated co-morbidities (14 [EL 4, NE]). Although controversial, this position was incorporated by the International Diabetes Federation, which proposed eligibility for bariatric procedures in a subset of patients with T2D and a BMI of $30 \mathrm{~kg} / \mathrm{m}^{2}$ with suboptimal glycemic control despite optimal medical management (15 [EL 4, NE]). Thus, the term metabolic surgery has emerged to describe procedures intended to treat T2D as well as reduce cardiometabolic risk factors. In 1 study, metabolic surgery was shown to induce T2D remission in up to $72 \%$ of subjects at 2 years; however, this number was reduced to $36 \%$ at 10 years (16 [EL 2, PCS]). In a more recent study, patients who underwent RYGB sustained diabetes remission rates of $62 \%$ at 6 years (17 [EL 2, PCS]). The overall long-term effect of bariatric surgery on T2D remission rates is currently not well studied. Additionally, for patients who have T2D recurrence several years after surgery, the legacy effects of a remission period on their long-term cardiovascular risk is not known. The mechanism of T2D remission has not been completely elucidated but appears to include an 
incretin effect (SG and RYGB procedures) in addition to caloric restriction and weight loss. These findings potentially expand the eligible population for bariatric and metabolic surgery.

Another area of recent interest is the use of bariatric surgery at the extremes of age. Historically, the 1991 National Institutes of Health (NIH) consensus criteria stipulated that treatment of obesity with bariatric surgery is limited to adults (18 [EL 4, NE]). Until 2003, $<.7 \%$ of bariatric procedures were performed in adolescents (age <20 years) (19 [EL 3, SS]). However, in academic centers alone, the number of bariatric procedures in adolescents nearly doubled from 2002-2006 to >100 cases per year in 2007-2009 (20 [EL 3, SS]). Morbidity and mortality in this 2007-2009 cohort were $2.9 \%$ and $0 \%$, respectively (20 [EL $3, \mathrm{SS}])$.

Advanced age $>45$ years has also been cited as a risk factor for bariatric surgery in some series; however, the data have been conflicting. Prospective data collected from a single academic center demonstrated that patients age $\geq 55$ years had a 3 -fold mortality compared with younger patients (21 [EL 3, SS]). However, recent American College of Surgeons National Surgical Quality Improvement Program (ACS NSQIP) data of 48,378 patients failed to reveal advanced age to be associated with statistically significant mortality compared with controls (22 [EL 3, SS]). Although many bariatric programs have established arbitrary cutoff levels for age at $65-70$ years, other programs primarily consider overall health risks and physiological status.

The Obesity Surgery Mortality Risk Score (OS-MRS) by DeMaria et al. $(23,24)$ identified 5 preoperative risk factors that predicted increased risk of 30-day morbidity and mortality after RYGB. These included advanced age ( $\geq 45$ years), "super-obesity" (BMI $\geq 50 \mathrm{~kg} / \mathrm{m}^{2}$ ), hypertension, male gender, and pulmonary embolism (PE) or surrogate (23 [EL 3, SS]; 24 [EL 3, SS]). However, a more recent multicenter study of 4,776 patients who underwent bariatric surgery failed to replicate the OS-MRS (25 [EL 2, PCS]). The Longitudinal Assessment of Bariatric Surgery (LABS) data did find that a history of thrombophilia (deep venous thrombosis [DVT] and PE), obstructive sleep apnea (OSA), or functional status to be independently predictive of 30-day adverse outcomes, including death (25 [EL 2, PCS]). Age and gender, however, were not predictors of death in the LABS analysis (25 [EL 2, PCS]). Moreover, 30-day mortality for RYGB and LAGB occurred in only .3\% of procedures, less than had been reported previously (25 [EL 2, PCS]).

Despite the known complications of bariatric surgery, overall mortality has improved since 2008. Data reported from the Swedish Obese Subjects (SOS) study, a large prospective observational study of $>2000$ patients who underwent bariatric surgery, demonstrated a mortality hazard ratio (HR) of .71, 10 years following bariatric surgery compared with matched obese controls (17 [EL 2, PCS]). More recent data from this cohort followed for up to 20 years demonstrated a HR of .47 in cardiovascular death (including stroke and myocardial infarction) among surgical subjects compared with obese controls (26 [EL 2, PCS]). In another cohort, all-cause mortality was reduced by $40 \% 7$ years after RYGB, compared with the control group, and cause-specific mortality in the surgery group 
decreased by $56 \%$ for coronary artery disease, by $92 \%$ for T2D, and by $60 \%$ for cancer ( 27 [EL 2, RCCS]).

As the prevalence of obesity has grown in the United States, so too has the number of bariatric operations for the surgical treatment of obesity. Promising pharmacological (including biological) treatments are on the horizon, but at present, bariatric surgery remains superior to nonsurgical treatments in terms of short-term benefits in surrogate markers of metabolic disease. Durability of benefit in terms of pertinent clinical outcomes will be the endpoints of current prospective trials. An enriched evidence base, expanding eligible patient populations, and safer, innovative surgical treatments for obesity will likely result in a greater number of obese patients undergoing surgery.

This CPG update aims to keep pace with the evidence-based literature, and along with the accompanying checklist (28 [EL 4]), assist physicians and allied health professionals with both routine and difficult clinical decision making.

\section{Methods}

The Boards of Directors for the American Association of Clinical Endocrinologists (AACE), The Obesity Society (TOS), and the American Society for Metabolic \& Bariatric Surgery (ASMBS) approved this update of the 2008 AACE, TOS, and ASMBS Medical Guidelines for Clinical Practice for the Perioperative Nutritional, Metabolic, and Nonsurgical Support of the Bariatric Surgery Patient (2008 AACE-TOS-ASMBS CPG; 7). These CPG expired in 2011 per the National Guideline Clearinghouse (http://www.guideline.gov/content.aspx? id=13022\&search=bariatric+aace) (29 [EL 4, NE]). Selection of the co-chairs, primary writers, and reviewers, as well as the logistics for creating this evidence-based CPG were conducted in strict adherence with the AACE Protocol for Standardized Production of Clinical Practice Guidelines-2010 Update (30 [EL 4, CPG]); Tables 1-4. This updated CPG methodology has the advantage of greater transparency, diligence, and detail for mapping the strength of evidence and expert opinion into a final graded recommendation. Nevertheless, as with all white papers, there is an element of subjectivity that must be recognized by the reader when interpreting the information.

The Executive Summary is reorganized by clinical questions and provides updated recommendation numbers $(\mathrm{R} 1, \mathrm{R} 2, \mathrm{R} 3, \ldots \mathrm{R} 100)$ with original recommendation numbers in parentheses, and an appended "-r," indicating substantive content or grading revision, or "“NEW," indicating new content. In many cases, recommendations have been condensed for clarity and brevity. In other cases, recommendations have been expanded for more clarity for complex decision making. The relevant evidence base, supporting tables, and figures for the updated recommendations follow the Executive Summary. The reader is encouraged to refer to the 2008 AACE-TOS-ASMBS CPG (7 [EL 4, CPG]) for background material not covered in this update.

\section{EXECUTIVE SUMMARY}

There are 74 recommendations in this 2013 update, compared with 164 original recommendations in 2008. There are 56 revised recommendations and 2 new 
recommendations (R30 and R59) in this 2013 update. Consensus among primary writers was obtained for each of the recommendations.

\section{Q1. Which patients should be offered bariatric surgery?}

R1(1)-r. Patients with a BMI $\geq 40 \mathrm{~kg} / \mathrm{m}^{2}$ without coexisting medical problems and for whom bariatric surgery would not be associated with excessive risk should be eligible for 1 of the procedures (Grade A; BEL 1).

R2(2/3)-r. Patients with a BMI $235 \mathrm{~kg} / \mathrm{m}^{2}$ and 1 or more severe obesity-related comorbidities, including T2D, hypertension, hyperlipidemia, obstructive sleep apnea (OSA), obesity-hypoventilation syndrome (OHS), Pickwickian syndrome (a combination of OSA and OHS), nonalcoholic fatty liver disease (NAFLD) or nonalcoholic steatohepatitis (NASH), pseudotumor cerebri, gastroesophageal reflux disease (GERD), asthma, venous stasis disease, severe urinary incontinence, debilitating arthritis, or considerably impaired quality of life, may also be offered a bariatric procedure. Patients with BMI of 30-34.9 $\mathrm{kg} / \mathrm{m}^{2}$ with diabetes or metabolic syndrome may also be offered a bariatric procedure, although current evidence is limited by the number of subjects studied and lack of long-term data demonstrating net benefit.

- Grade A, BEL 1 for BMI $\geq 35 \mathrm{~kg} / \mathrm{m}^{2}$ and therapeutic target of weight control and improved biochemical markers of cardiovascular disease [CVD] risk

- Grade B, BEL 2 for BMI $\geq 30 \mathrm{~kg} / \mathrm{m}^{2}$ and therapeutic target of weight control and improved biochemical markers of CVD risk

- Grade C, BEL 3 for BMI $330 \mathrm{~kg} / \mathrm{m}^{2}$ and therapeutic target of glycemic control in T2D and improved biochemical markers of CVD risk.

R3(4)-r. There is insufficient evidence for recommending a bariatric surgical procedure specifically for glycemic control alone, lipid lowering alone, or cardiovascular disease risk reduction alone, independent of BMI criteria (Grade D).

\section{Q2. Which bariatric surgical procedure should be offered?}

$\mathbf{R 4}(5 / 6 / 7)$ )r. The best choice for any bariatric procedure (type of procedure and type of approach) depends on the individualized goals of therapy (e.g., weight loss and/or metabolic [glycemic] control), available local-regional expertise (surgeon and institution), patient preferences, and personalized risk stratification (Grade D). At this time, there is still insufficient evidence to generalize in favor of one bariatric surgical procedure for the severely obese population (Grade D). In general, laparoscopic bariatric procedures are preferred over open bariatric procedures due to lower early postoperative morbidity and mortality (Grade B; BEL 2). Laparoscopic adjustable gastric banding (LAGB), laparoscopic sleeve gastrectomy (LSG), laparoscopic Roux-en-Y gastric bypass (RYGB), and laparoscopic biliopancreatic diversion BPD, BPD/duodenal switch (BPD-DS), or related procedures are primary bariatric and metabolic procedures that may be performed in patients requiring weight loss and/or metabolic control (Grade A; BEL 1). Physicians should exercise caution when recommending BPD, BPD-DS, or related procedures because of the greater associated nutritional risks related to the increased length of bypassed small intestine 
(Grade A; BEL 1). Investigational procedures may be considered for selected patients based on available institutional review board (IRB) approved protocols, suitability for clinical targets and individual patient factors, and only after a careful assessment balancing the importance for innovation, patient safety, and demonstrated effectiveness (Grade D).

\section{Q3. How should potential candidates for bariatric surgery be managed preoperatively?}

R5(8). All patients should undergo preoperative evaluation for obesity-related comorbidities and causes of obesity, with special attention directed to those factors that could affect a recommendation for bariatric surgery (see Preoperative Checklist in Table 5) (Grade A; BEL 1).

R6(9). The preoperative evaluation must include a comprehensive medical history, psychosocial history, physical examination (see Table 16 in ref [6]), and appropriate laboratory testing to assess surgical risk (Table 6) (Grade A; BEL 1).

R7(10). The medical necessity for bariatric surgery should be documented (Grade D).

$\mathbf{R 8}(11 / 12)$-r. Because informed consent is a dynamic process, there should be a thorough discussion with the patient regarding the risks and benefits, procedural options, choices of surgeon and medical institution, and the need for long-term follow-up and vitamin supplementation (including costs required to maintain appropriate followup) (Grade D). Patients should also be provided with educational materials and access to preoperative educational sessions at prospective bariatric surgery centers (Grade D). Consent should include experience of the surgeon with the specific procedure offered and whether the hospital has an accredited bariatric surgery program (Grade D).

R9(13)-r. Financial information should be provided, and the bariatric surgery program should be able to provide all necessary clinical material for documentation so that thirdparty payor criteria for reimbursement are met (Grade D).

R10(14)-r. Preoperative weight loss can reduce liver volume and may help improve the technical aspects of surgery in patients with an enlarged liver or fatty liver disease and is therefore encouraged before bariatric surgery (Grade B; BEL 1; downgraded due to inconsistent results). Preoperative weight loss or medical nutritional therapy may also be used in selected cases to improve comorbidities, such as reasonable preoperative glycemic targets (Grade D).

\section{Q4. What are the elements of medical clearance for bariatric surgery?}

R11(15-17)-r. Preoperative glycemic control should be optimized using a diabetes comprehensive care plan, including healthy dietary patterns, medical nutrition therapy, physical activity, and as needed, pharmacotherapy (Grade A; BEL 1). Reasonable targets for preoperative glycemic control, which may be associated with improved bariatric surgery outcomes, include a hemoglobin $\mathrm{A}_{1 \mathrm{c}}$ value of $6.5 \%-7.0 \%$ or less, a fasting blood glucose level of $\unlhd 10 \mathrm{mg} / \mathrm{dL}$, and a 2-hour postprandial blood glucose concentration of $₫ 40 \mathrm{mg} / \mathrm{dL}$ (http://www.aace.com/sites/default/files/DMGuidelinesCCP.pdf) (Grade A; BEL 1). More liberal preoperative targets, such as an $\mathrm{A}_{1 \mathrm{c}}$ of $7 \%-8 \%$, should be considered in patients with 
advanced microvascular or macrovascular complications, extensive comorbid conditions, or long-standing diabetes in which the general goal has been difficult to attain despite intensive efforts (Grade A; BEL 1). In patients with $\mathrm{A}_{1 \mathrm{c}}>8 \%$ or otherwise uncontrolled diabetes, clinical judgment determines the need for bariatric surgery (Grade D).

R12(18/19)-r. Routine screening for primary hypothyroidism before bariatric surgery is not recommended (Grade D). Patients at risk for primary hypothyroidism should have screening serum thyroid-stimulating hormone (TSH) level (Grade B; BEL 2). Patients found to be hypothyroid should be treated with L-thyroxine monotherapy (Grade A; BEL 1).

R13(20/21)-r. A fasting lipid panel should be obtained in all patients with obesity (Grade A; BEL 1). Treatment should be initiated according to the National Cholesterol Education Program Adult Treatment Panel III guidelines (see http://www.nhlbi.nih.gov/guidelines/ cholesterol/ and https://www.aace.com/files/lipid-guidelines.pdf) (Grade D).

R14(22-24)-r. Candidates for bariatric surgery should avoid pregnancy preoperatively and for 12 to 18 months postoperatively (Grade D). Women who become pregnant after bariatric surgery should be counseled and monitored for appropriate weight gain, nutritional supplementation, and for fetal health (Grade C; BEL 3). All women of reproductive age should be counseled on contraceptive choices following bariatric surgery (Grade D). Patients with RYGB or malabsorptive procedures should be counseled in nonoral contraceptive therapies (Grade D). Patients who do become pregnant following bariatric surgery should have nutritional surveillance and laboratory screening for deficiency every trimester, including iron, folate and $\mathrm{B}_{12}$, calcium, and fat soluble vitamins (Grade D). Patients who become pregnant post-LAGB should have band adjustments as necessary for appropriate weight gain for fetal health (Grade B; BEL 2).

R15(25). Estrogen therapy should be discontinued before bariatric surgery (1 cycle of oral contraceptives in premenopausal women; 3 weeks of hormone replacement therapy in postmenopausal women) to reduce the risks for postoperative thromboembolic phenomena (Grade D).

R16(26). Women with PCOS should be advised that their fertility status might be improved postoperatively (Grade D).

R17(28). Case-by-case decisions to screen for rare causes of obesity should be based on specific historical and physical findings (Grade D).

R18(29-31). Noninvasive cardiac testing beyond an electrocardiogram is determined on the basis of the individual risk factors and findings on history and physical examination (Grade B). Patients with known heart disease may require a formal cardiology consultation before bariatric surgery (Grade D). Patients at risk for heart disease should undergo evaluation for perioperative b-adrenergic blockade (Grade A; BEL 1).

R19(32/33)-r. In patients considered for bariatric surgery, chest radiograph and standardized screening for obstructive sleep apnea (with confirmatory polysomnography if screening tests 
are positive) should be considered. (Grade C, BEL 3). Patients with intrinsic lung disease or disordered sleep patterns should have a formal pulmonary evaluation, including arterial blood gas measurement, when knowledge of the results would alter patient care (Grade C; BEL 3).

R20(34/157)-r. Tobacco use should be avoided at all times by all patients. In particular, patients who smoke cigarettes should stop, preferably at least 6 weeks before bariatric surgery (Grade A; BEL 2, upgraded by consensus). Also, tobacco use should be avoided after bariatric surgery given the increased risk for of poor wound healing, anastomotic ulcer, and overall impaired health (Grade A; BEL 1).

R21(35/36)-r. Patients with a history of deep venous thrombosis (DVT) or cor pulmonale should undergo an appropriate diagnostic evaluation for DVT (Grade D). A prophylactic vena caval filter may present a greater risk than benefit in patients with a history of prior PE or DVT given the risks of filter-related complications including thrombosis (Grade C; BEL 3).

R22(37). Clinically significant gastrointestinal symptoms should be evaluated before bariatric surgery with imaging studies, upper gastrointestinal (UGI) series, or endoscopy (Grade D).

R23(38)-r. Abdominal ultrasound is not recommended as a routine screen for liver disease (Grade C, BEL 3). Abdominal ultrasound is indicated to evaluate symptomatic biliary disease and elevated liver function tests. In patients with increased liver function tests ( 2 to 3 times the upper limit of normal), abdominal ultrasonography and a viral hepatitis screen may be considered (Grade D). Consideration can be made for liver biopsy at the time of surgery to document steatohepatitis and/or cirrhosis that may otherwise be unknown due to normal appearance and/or liver function tests (Grade D).

R24(39)-r. Routine screening for the presence of Helicobacter pylori before bariatric surgery may be considered in high-prevalence areas (Grade C; BEL 3).

R25(40)-r. Before bariatric surgery, prophylactic treatment for gouty attacks should be considered in patients with a history of gout (Grade C, BEL 3).

R26(41). There are insufficient data to warrant preoperative assessment of bone mineral density with dual-energy $\mathrm{x}$-ray absorptiometry (DXA) outside formal CPG recommendations by the National Osteoporosis Foundation (www.nof.org) (Grade D).

R27(42/43)-r. A psychosocial-behavioral evaluation, which assesses environmental, familial, and behavioral factors, should be required for all patients before bariatric surgery (Grade C; BEL 3). Any patient considered for bariatric surgery with a known or suspected psychiatric illness, or substance abuse, or dependence, should undergo a formal mental health evaluation before performance of the surgical procedure (Grade C; BEL 3). Following RYGB, high-risk groups should eliminate alcohol consumption due to impaired alcohol metabolism and risk of alcohol use disorder postoperatively (Grade C; BEL 3). 
R28(44)-r. All patients should undergo evaluation of their ability to incorporate nutritional and behavioral changes before and after bariatric surgery (Grade C; BEL 3).

R29(45)-r. All patients should undergo an appropriate nutritional evaluation, including micronutrient measurements, before any bariatric surgical procedure. In comparison with purely restrictive procedures, more extensive perioperative nutritional evaluations are required for malabsorptive procedures (Grade A; BEL 1).

R30(NEW). Patients should be followed by their primary care physician and have age and risk appropriate cancer screening before surgery. Grade C; BEL 3).

\section{Q5. How can early postoperative care be optimized?}

R31(46-53/90/91)-r. A low-sugar clear liquid meal program can usually be initiated within 24 hours after any of the bariatric procedures, but this diet and meal progression should be discussed with the surgeon and guided by the registered dietician (RD) (Grade C; BEL 3). A consultation for postoperative meal initiation and progression should be arranged with a dietician who is knowledgeable of the postoperative bariatric diet. (Grade A, BEL 1). Patients should receive education in a protocol-derived staged meal progression based on their surgical procedure (Grade D). Patients should be counseled to eat 3 small meals during the day and chew small bites of food thoroughly before swallowing (Grade D). Patients should adhere with principles of healthy eating, including at least 5 daily servings of fresh fruits and vegetables (Grade D). Protein intake should be individualized, assessed, and guided by an RD, in reference to gender, age, and weight (Grade D). A minimal protein intake of $60 \mathrm{~g} / \mathrm{d}$ and up to $1.5 \mathrm{~g} / \mathrm{kg}$ ideal body weight per day should be adequate; higher amounts of protein intake — up to $2.1 \mathrm{~g} / \mathrm{kg}$ ideal body weight per day—need to be assessed on an individualized basis (Grade D). Concentrated sweets should be eliminated from the diet after RYGB to minimize symptoms of the dumping syndrome, as well as after any bariatric procedure to reduce caloric intake (Grade D). Crushed or liquid rapid-release medications should be used instead of extended-release medications to maximize absorption in the immediate postoperative period (Grade D).

R32(54/89/93)-r. After consideration of risks and benefits, patients with, or at risk for, demonstrable micronutrient insufficiencies or deficiencies should be treated with the respective micronutrient (Grade A, BEL 2, upgraded by consensus). Minimal daily nutritional supplementation for patients with RYGB and LSG all in chewable form initially (i.e., 3 to 6 months), should include 2 adult multivitamin plus mineral (each containing iron, folic acid, and thiamine) supplements (Grade B, BEL 2), 1200 to $1500 \mathrm{mg}$ of elemental calcium (in diet and as citrated supplement in divided doses) (Grade B, BEL 2), at least 3000 international units of vitamin D (titrated to therapeutic 25-hydroxyvitamin D levels $>30 \mathrm{ng} / \mathrm{ml}$ ) (Grade A, BEL 1), and vitamin $\mathrm{B}_{12}$ (parenterally as sublingual, subcutaneous, or intramuscular preparations, or orally, if determined to be adequately absorbed) as needed to maintain B12 levels in the normal range (Grade B; BEL 2). Total iron provided should be $45-60 \mathrm{mg}$ via multivitamins and additional supplements. Minimal daily nutritional supplementation for patients with LAGB should include 1 adult multivitamin plus mineral (including iron, folic acid, and thiamine) (Grade B, BEL 2), 1200 to $1500 \mathrm{mg}$ of elemental 
calcium (in diet and as citrated supplement in divided doses) (Grade B, BEL 2), at least 3000 international units of vitamin D (titrated to therapeutic 25-dihydroxyvitamin D levels). Alternatively, in lieu of routine screening with relatively costly biochemical testing, the above routine micronutrient supplementation may be initiated preoperatively (Grade D).

R33(55)-r. Fluids should be consumed slowly, preferably at least 30 minutes after meals to prevent gastrointestinal symptoms, and in sufficient amounts to maintain adequate hydration (more than 1.5 liters daily) (Grade D).

R34(56/92)-r. Nutrition support (enteral nutrition [EN; tube feeds] or parenteral nutrition $[\mathrm{PN}])$ should be considered in bariatric surgery patients at high nutritional risk (e.g., Nutrition Risk Score [NRS 2002] 33); PN should be considered in those patients who are unable to meet their needs using their gastrointestinal tract for at least 5-7 days with noncritical illness or 3-7 days with critical illness (Grade D). In patients with severe protein malnutrition and/or hypoalbuminemia, not responsive to oral or EN protein supplementation, PN should be considered (Grade D).

R35(57)-r. In patients with T2D, periodic fasting blood glucose concentrations should be determined (Grade A; BEL 1). Preprandial, 2-hour postprandial, and bedtime reflectance meter glucose (RMG; "fingerstick") determinations in the home setting should also be encouraged, depending on the patient's ability to test, the level of glycemic control targeted, use of oral agents or insulin, and overall care plan (Grade A; BEL 1). RMG determinations should also be performed if symptoms of hypoglycemia occur (Grade A; BEL 1).

R36(58-61)-r. In patients with diabetes, the use of all insulin secretagogues (sulfonylureas and meglitinides) should be discontinued and insulin doses should be adjusted postoperatively (due to low calorie intake) to minimize the risk for hypoglycemia (Grade D). Antidiabetic medications should be withheld if the T2D is in remission following bariatric surgery (Grade D). Metformin may be continued postoperatively until prolonged clinical resolution of diabetes is demonstrated by normalized glycemic targets (including fasting and postprandial blood glucose and $\mathrm{HbA}_{1 \mathrm{c}}$ ). Insulin therapy, using a rapid-acting insulin analogue (insulin lispro, aspart, or glulisine) before meals and a basal long-acting insulin analogue (insulin glargine or detemir) should be used to attain glycemic targets $(140-180 \mathrm{mg} / \mathrm{dL})$ in nonintensive care unit hospitalized patients (Grade D). In the intensive care unit, intravenous regular insulin, as part of a standard intensive insulin therapy protocol, should be used to control hyperglycemia to a $140-180 \mathrm{mg} / \mathrm{dL}$ blood glucose target (Grade D). Antidiabetic medications that improve insulin sensitivity (metformin), as well as incretin-based therapies, should be considered in outpatients not reaching glycemic targets.

(Grade D). Endocrinology consultation should be considered for patients with uncontrolled hyperglycemia (Grade D).

R37(62)-r. Patients with high perioperative risk for myocardial infarction should be managed in a monitored telemetry setting for at least the first 24 hours postoperatively (Grade D). 
R38(64)-r. Pulmonary management includes aggressive pulmonary toilet and incentive spirometry, oxygen supplementation to avoid hypoxemia, and early institution of continuous positive airway pressure (CPAP) when clinically indicated (Grade C, BEL 3).

R39(65/66)-r. Prophylaxis against deep venous thrombosis (DVT) is recommended for all patients (Grade B; BEL 2). Prophylactic regimens after bariatric surgery include sequential compression devices (Grade C; BEL 3), as well as subcutaneously administered unfractionated heparin or low-molecular-weight heparin given within 24 hours after bariatric surgery (Grade B; BEL 2). Extended chemoprophylaxis after hospital discharge should be considered for high-risk patients, such as those with history of DVT (Grade C, BEL 3). Early ambulation is encouraged (Grade C; BEL 3).

$\mathbf{R 4 0 ( 6 7 - 7 1 ) - r . ~ R e s p i r a t o r y ~ d i s t r e s s ~ o r ~ f a i l u r e ~ t o ~ w e a n ~ f r o m ~ v e n t i l a t o r y ~ s u p p o r t ~ s h o u l d ~ r a i s e ~}$ suspicion and prompt an evaluation for an acute postoperative complication, such as pulmonary embolus (PE) or anastomotic leak (Grade D). In the clinically stable patient, UGI studies (water-soluble contrast followed by thin barium) or computed tomography (CT) may be considered to evaluate for anastomotic leaks in suspected patients (Grade C; BEL 3). Exploratory laparotomy or laparoscopy is justified in the setting of high clinical suspicion for anastomotic leaks despite a negative study (Grade C; BEL 3). The presence of a new sustained pulse rate of more than 120 beats/min for longer than 4 hours, tachypnea, hypoxia, or fever, should raise concern for an anastomotic leak (Grade D). A selected Gastrografin upper gastrointestinal (UGI) study in the absence of abnormal signs or symptoms may be considered to identify any subclinical leaks before discharge of the patient from the hospital, although routine studies are not cost effective. (Grade C; BEL 3). C-reactive protein (CRP) testing should be considered if a postoperative leak is suspected.

R41(72-75)-r. Patients should have adequate padding at pressure points during bariatric surgery (Grade D). When rhabdomyolysis (RML) is suspected, creatine kinase (CK) levels should be determined, urine output monitored, and adequate hydration ensured (Grade C;

BEL 3). The risk for RML increases as BMI increases (particular with BMI $>55-60 \mathrm{~kg} / \mathrm{m}^{2}$ ); therefore, screening CK levels may be tested in these higher risk groups (Grade D).

\section{Q6. How can optimal follow-up of bariatric surgery be achieved?}

R42(78-83/85/88)-r. The frequency of follow up depends on the bariatric procedure performed and the severity of co-morbidities (Grade D). Following LAGB, frequent nutritional follow-up and/or band adjustments are important for maximal weight loss (Grade C; BEL 3). Significant weight regain or failure to lose weight should prompt evaluation for (a) decreased patient adherence with lifestyle modification, (b) evaluation of medications associated with weight gain or impairment of weight loss, (c) development of maladaptive eating behaviors, (d) psychological complications, and (e) radiographic or endoscopic evaluation to assess pouch enlargement, anastomotic dilation, formation of a gastrogastric fistula among patients who underwent a RYGB, or inadequate band restriction among patients who underwent a LAGB (Grade B; BEL 2). Interventions should first include a multidisciplinary approach, including dietary change, physical activity, behavioral modification with frequent follow up; and then if appropriate, pharmacologic therapy and/or 
surgical revision (Grade B; BEL 2). In those patients with or without complete resolution of their T2D, dyslipidemia, or hypertension, continued surveillance and management should be guided by current clinical practice guidelines for those conditions (Grade D). Routine metabolic and nutritional monitoring is recommended after all bariatric surgical procedures (Grade A; BEL 1).

R43(84)-r. Patients who have undergone RYGB, BPD, or BPD/DS and who present with postprandial hypoglycemic symptoms that have not responded to nutritional manipulation should undergo an evaluation to differentiate noninsulinoma pancreatogenous hypoglycemia syndrome (NIPHS) from factitious or iatrogenic causes, dumping syndrome, and insulinoma (Grade C; BEL 3). In patients with NIPHS, therapeutic strategies include dietary changes (low carbohydrate diet), octreotide, diazoxide, acarbose, calcium channel antagonists, gastric restriction, and reversal procedures, with partial or total pancreatectomy reserved for the rare recalcitrant cases (Grade C; BEL 3).

R44(86)-r. Patients should be advised to incorporate moderate aerobic physical activity to include a minimum of 150 minutes per week and goal of 300 minutes per week, including strength training 2 to 3 times per week (see ACSM Position Statement July 2011 http:// www.acsmmsse.org/) (Grade A; BEL 1).

R45(87)-r. All patients should be encouraged to participate in ongoing support groups after discharge from the hospital (Grade B; BEL 2).

R46(94/95/100)-r. In patients who have undergone RYGB, BPD, or BPD/DS, treatment with oral calcium citrate and vitamin $\mathrm{D}$ (ergocalciferol [vitamin $\mathrm{D}_{2}$ ] or cholecalciferol [vitamin $\mathrm{D}_{3}$ ]), is indicated to prevent or minimize secondary hyperparathyroidism without inducing frank hypercalciuria (Grade C; BEL 3). In cases of severe vitamin D malabsorption, oral doses of vitamin $D_{2}$ or $D_{3}$ may need to be as high as 50,000 units 1 to 3 times weekly to daily, and more recalcitrant cases may require concurrent oral administration of calcitriol (1,25-dihydroxyvitamin D) (Grade D). Hypophosphatemia is usually due to vitamin D deficiency, and oral phosphate supplementation should be provided for mild to moderate hypophosphatemia (1.5 to $2.5 \mathrm{mg} / \mathrm{dL}$ ) (Grade D).

R47(96). In patients with RYGB, BPD, or BPD/DS, bone density measurements with use of axial (spine and hip) dual-energy x-ray absorptiometry (DXA) may be indicated to monitor for osteoporosis at baseline and at about 2 years (Grade D).

R48(97/98)-r. Bisphosphonates may be considered in bariatric surgery patients with osteoporosis only after appropriate therapy for calcium and vitamin D insufficiency (Grade C; BEL 3). Evaluation should include serum parathyroid hormone (PTH), total calcium, phosphorus, 25-hydroxyvitamin D, and 24-hour urine calcium levels (Grade C; BEL 3). If therapy is indicated, then intravenously administered bisphosphonates should be used, as concerns exist about adequate oral absorption and potential anastomotic ulceration with orally administered bisphosphonates (Grade C; BEL 3). Recommended intravenous dosages of bisphosphonates include zoledronic acid, $5 \mathrm{mg}$ once a year, or ibandronate, $3 \mathrm{mg}$ every 3 months (Grade D). If concerns about absorption or potential anastomotic ulceration 
are obviated, oral bisphosphonate administration can be provided; the recommended dosages are alendronate, $70 \mathrm{mg} / \mathrm{wk}$; risedronate, $35 \mathrm{mg} / \mathrm{wk}$ or $150 \mathrm{mg} / \mathrm{mo}$; or ibandronate, 150 $\mathrm{mg} / \mathrm{mo}$ (Grade C; BEL 3).

R49(101/102)-r. Management of oxalosis and calcium oxalate stones includes avoidance of dehydration (Grade D), a low oxalate meal plan (Grade D), oral calcium (Grade B, BEL 1, downgraded due to small evidence base), and potassium citrate therapy (Grade B, BEL 1, downgraded due to small evidence base). Probiotics containing Oxalobacter formigenes may be used as they have been shown to improve renal oxalate excretion and improve supersaturation levels (Grade C; BEL 3).

R50(103/107)-r. There is insufficient evidence to support routine screening for essential fatty acid, vitamin $\mathrm{E}$, or vitamin $\mathrm{K}$ deficiencies (Grade D).

R51(104/105)-r. Routine screening for vitamin A deficiency, which may present as ocular complications, is recommended after purely malabsorptive bariatric procedures, such as $\mathrm{BPD}$ or BPD/DS, and supplementation alone or in combination with other fat-soluble vitamins (D, E, and K) may be indicated in this setting. (Grade C; BEL 3).

R52(108). In the presence of an established fat-soluble vitamin deficiency with hepatopathy, coagulopathy, or osteoporosis, assessment of a vitamin $\mathrm{K}_{1}$ level should be considered (Grade D).

R53(76/77/109-112)-r. Anemia without evidence of blood loss warrants evaluation of nutritional deficiencies, as well as age appropriate causes during the late postoperative period (Grade D). Iron status should be monitored in all bariatric surgery patients (Grade D). Treatment regimens include oral ferrous sulfate, fumarate, or gluconate to provide up to 150-200 mg of elemental iron daily (Grade A; BEL 1). Vitamin C supplementation may be added simultaneously to increase iron absorption (Grade C; BEL 3). Intravenous iron infusion (preferably with ferric gluconate or sucrose) may be needed for patients with severe intolerance to oral iron or refractory deficiency due to severe iron malabsorption (Grade D).

R54(113-116)-r. Baseline and postoperative evaluation for vitamin $B_{12}$ deficiency is recommended in all bariatric surgery and annually in those with procedures that exclude the lower part of the stomach (e.g., LSG, RYGB) (Grade B; BEL 2). Oral supplementation with crystalline vitamin $B_{12}$ at a dosage of $1000 \mu \mathrm{g}$ daily or more may be used to maintain normal vitamin $B_{12}$ levels (Grade A; BEL 1). Intranasally administered vitamin $B_{12}, 500$ $\mu \mathrm{g}$ weekly, may also be considered (Grade D). Parenteral (intramuscular or subcutaneous) $\mathrm{B}_{12}$ supplementation, $1000 \mu \mathrm{g} / \mathrm{mo}$ to $1000-3000 \mu \mathrm{g}$ every 6 to 12 months, is indicated if $\mathrm{B}_{12}$ sufficiency cannot be maintained using oral or intranasal routes (Grade C; BEL 3).

R55(117)-r. Folic acid supplementation $(400 \mu \mathrm{g} / \mathrm{d})$ should be part of a routine mineralcontaining multivitamin preparation (Grade B; BEL 2) and should be supplemented in all women of childbearing age to reduce the risk of fetal neural tube defects (Grade A; BEL 1).

R56(119)-r. Nutritional anemias resulting from malabsorptive bariatric surgical procedures might also involve deficiencies in vitamin $\mathrm{B}_{12}$, folate, protein, copper, selenium, and zinc 
and should be evaluated when routine screening for iron deficiency anemia is negative (Grade C; BEL 3).

R57(120/121)-r. There is insufficient evidence to support routine selenium screening or supplementation after bariatric surgery (Grade D). However, selenium levels should be checked in patients with a malabsorptive bariatric surgical procedure who have unexplained anemia or fatigue, persistent diarrhea, cardiomyopathy, or metabolic bone disease (Grade C; BEL 3).

R58(122/123)-r. Routine screening for zinc deficiency should occur after malabsorptive bariatric surgical procedures (Grade C; BEL 3) and should be routinely supplemented following BPD/BPDDS (Grade C; BEL 3). Zinc deficiency should be considered in patients with hair loss, pica, significant dysgeusia, or in male patients with hypogonadism or erectile dysfunction (Grade D).

R59(NEW). Copper supplementation ( $2 \mathrm{mg} / \mathrm{d}$ ) should be included as part of routine multivitamin with mineral preparation (Grade D). Routine copper screening is not indicated following bariatric surgery but should be evaluated in patients with anemia, neutropenia, myeloneuropathy, and impaired wound healing (Grade D). In severe deficiency, treatment can be initiated with IV copper ( 2 to $4 \mathrm{mg} / \mathrm{d}$ ) $\times 6$ days (Grade D). Subsequent treatment or treatment of mild to moderate deficiency can usually be achieved with oral copper sulfate or gluconate 3 to $8 \mathrm{mg} / \mathrm{d}$ until levels normalize and symptoms resolve (Grade D). Patients being treated for zinc deficiency or using supplemental zinc for hair loss should receive 1 $\mathrm{mg}$ of copper for each 8 to $15 \mathrm{mg}$ of zinc as zinc replacement can cause copper deficiency (Grade C; BEL 3).

R60(124-129)-r. Thiamine supplementation should be included as part of routine multivitamin with mineral preparation (Grade D). Routine thiamine screening is not recommended following bariatric surgery (Grade C; BEL 3). Screening for thiamine deficiency and/or empiric thiamine supplementation should be considered in postbariatric surgery patients with rapid weight loss, protracted vomiting, parenteral nutrition, excessive alcohol use, neuropathy or encephalopathy, or heart failure (Grade D). Patients with severe thiamine deficiency (suspected or established) should be treated with intravenous thiamine, $500 \mathrm{mg} / \mathrm{d}$, for 3 to 5 days, followed by $250 \mathrm{mg} / \mathrm{d}$ for 3 to 5 days or until resolution of symptoms, and then to consider treatment with $100 \mathrm{mg} / \mathrm{d}$, orally, usually indefinitely or until risk factors have resolved (Grade C; BEL 3). Mild deficiency can be treated with intravenous thiamine, $100 \mathrm{mg} / \mathrm{d}$, for 7-14 days (Grade C; BEL 3). In recalcitrant or recurrent cases of thiamine deficiency without 1 of the above risks, the addition of antibiotics for small intestine bacterial overgrowth should be considered (Grade C; BEL 3).

R61(130)-r. Lipid levels and need for lipid-lowering medications should be periodically evaluated (Grade D). The effect of weight loss on dyslipidemia is variable and incomplete; therefore, lipid-lowering medications should not be stopped unless clearly indicated (Grade C; BEL 3). 
R62(131)-r. The need for antihypertensive medications should be evaluated repeatedly (Grade D). Because the effect of weight loss on blood pressure is variable, incomplete, and at times transient, antihypertensive medications should not be stopped unless clearly indicated (Grade D).

R63(132-135/138)-r. Persistent and severe gastrointestinal symptoms (e.g., nausea, vomiting, abdominal pain, diarrhea, and constipation) warrant evaluation (Grade C; BEL 3). Upper endoscopy with small bowel biopsies and aspirates remains the "gold standard" in the evaluation of celiac disease and bacterial overgrowth (Grade C; BEL 3). Screening with a stool specimen should be obtained if the presence of Clostridium difficile colitis is suspected (Grade C; BEL 3). Persistent steatorrhea after BPD/BPDDS should prompt an evaluation for nutrient deficiencies (Grade C; BEL 3).

R64(136/137)-r. Nonsteroidal antiinflammatory drugs should be completely avoided after bariatric surgery, if possible, because they have been implicated in the development of anastomotic ulcerations/perforations. (Grade C; BEL 3) and alternative pain medication should be identified before bariatric surgery (Grade D).

R65(139-141)-r. Endoscopy may be the preferred procedure for gastrointestinal symptoms suggestive of stricture or foreign body (e.g., suture, staple) as it can be both diagnostic and therapeutic (endoscopic dilation or foreign body removal) (Grade C; BEL 3). Evaluation can also include $\mathrm{H}$ pylori testing as a possible contributor to persistent gastrointestinal symptoms after bariatric surgery (Grade D). Anastomotic ulcers should be treated with $\mathrm{H}_{2}$ receptor blockers, proton pump inhibitors (PPI), sucralfate, and if $\mathrm{H}$ pylori is identified, triple therapy to include antibiotics, bismuth, and PPI (Grade C; BEL 3).

R66(142)-r. Patients who previously underwent a RYGB with a nonpartitioned stomach who develop a gastrogastric fistula or herniation with symptoms of weight regain, marginal ulcer, stricture or gastroesophageal reflux, may benefit from a revisional procedure (Grade C; BEL 3).

R67(143/144). Persistent vomiting, regurgitation, and UGI obstruction after LAGB should be treated with immediate removal of fluid from the adjustable band (Grade D). Persistent symptoms of gastroesophageal reflux, regurgitation, chronic cough, or recurrent aspiration pneumonia after LAGB raise concern for the band being too tight or the development of an abnormally large gastric pouch above the band or esophageal dilation. These symptoms should prompt immediate referral to a bariatric surgeon (Grade D).

R68(145/146)-r. Ultrasound should be used to evaluate patients with right upper quadrant pain for cholecystitis (Grade D). Prophylactic cholecystectomy may be considered with RYGB to prevent gallbladder complications (Grade B; BEL 2). Oral administration of ursodeoxycholic acid, at least $300 \mathrm{mg}$ daily in divided doses, significantly decreases gallstone formation after RYGB and may be considered for use in patients after bariatric surgery who have not had a cholecystectomy (Grade A; BEL 1).

R69(147/148)-r. Although uncommon, suspected bacterial overgrowth in the biliopancreatic limb after BPD or BPD/DS should be treated empirically with metronidazole or rifaximin 
(Grade C; BEL 3). For antibiotic-resistant cases of bacterial overgrowth, probiotic therapy with Lactobacillus plantarum 299v and Lactobacillus GG may be considered (Grade D).

R70(149-152). Definitive repair of asymptomatic abdominal wall hernias can be deferred until weight loss has stabilized and nutritional status has improved, to allow for adequate healing (12 to 18 months after bariatric surgery) (Grade D). Symptomatic hernias that occur after bariatric surgery require prompt surgical evaluation (Grade C; BEL 3). Patients with sudden onset, severe cramping periumbilical pain or recurrent episodes of severe abdominal pain anytime after weight loss surgery should be evaluated with an abdominal and pelvic CT scan to exclude the potentially life-threatening complication of a closed loop bowel obstruction (Grade D). Exploratory laparotomy or laparoscopy is indicated in patients who are suspected of having an internal hernia because this complication can be missed with upper gastrointestinal (UGI) x-ray studies and CT scans (Grade C; BEL 3).

R71(153-156)-r. Body-contouring surgery may be performed after bariatric surgery to manage excess tissue that impairs hygiene, causes discomfort, and is disfiguring (Grade C; BEL 3). This surgery is best pursued after weight loss has stabilized (12 to 18 months after bariatric surgery) (Grade D).

\section{Q7. What are the criteria for hospital admission after bariatric surgery?}

R72(158-162)-r. Severe malnutrition should prompt hospital admission for initiation of nutritional support (Grade D). The initiation and formulation of enteral (tube feeding) or parenteral nutrition should be guided by current clinical practice guidelines (Grade D). Hospital admission is required for the management of gastrointestinal complications after bariatric surgery in clinically unstable patients (Grade D). Surgical management should be pursued for gastrointestinal complications not amenable or responsive to medical therapy (Grade D). However, if not dehydrated, most patients can undergo endoscopic stomal dilation for stricture as an outpatient procedure (Grade D).

R73(163). Revision of a bariatric surgical procedure can be recommended when serious complications related to previous bariatric surgery cannot be managed medically (Grade C; BEL 3).

R74(164). Reversal of a bariatric surgical procedure is recommended when serious complications related to previous bariatric surgery cannot be managed medically and are not amenable to surgical revision (Grade D).

\section{Evidence base}

This evidence base pertains to the updated recommendations and contains 403 citations, of which $33(8.2 \%)$ are EL 1, $131(32.5 \%)$ are EL 2, $170(42.2 \%)$ are EL 3, and $69(17.1 \%)$ are EL 4. There is a relatively high proportion (40.4\%) of strong (EL 1 and 2) studies, compared with only $16.5 \%$ in the 2008 AACE-TOS-ASMBS CPG (7 [EL 4, CPG]). The evidence base, supporting tables, and unrevised recommendations for general information may be found in the 2008 AACE-TOS-ASMBS CPG (7 [EL 4, CPG]). 


\section{Q1. Which patients should be offered bariatric surgery?}

R1(1). The evidence base for recommending bariatric surgery for patients with BMI $\geq 40$ $\mathrm{kg} / \mathrm{m}^{2}$ without coexisting medical problems is enriched with recent EL 1-3 studies demonstrating benefit: mortality (31 [EL 1, MRCT]; 32 [EL 1, RCT]), weight loss (33 [EL 1, MRCT]; 34 [EL 1, MRCT]; 35 [EL 2, PCS]; 36 [EL 2, PCS]), diabetes remission (37 [EL 1, MRCT]; 38 [EL 1, RCT]; 39 [EL 1, RCT]; 40 [EL 1, RCT]); improved beta-cell function (41 [EL 1; RCT]); and improved pulmonary function (42 [EL 3; PCS]). Currently, the WHO classification scheme for obesity, based on BMI, determines diagnostic and therapeutic management. However, BMI is confounded by ethnic differences (43 [EL 2, MNRCT]; 44 [EL 4, NE]) and body composition (44 [EL 4, NE]); (45 [EL 2, CSS], and future improved risk stratification strategies may incorporate other anthropometric measurements, such as waist circumference (46 [EL 3, SS]) or waist-to-hip ratio (43 [EL 2, MNRCT]), comorbidity and functional status assessments (47 [EL 4 NE]), and body composition technologies (45 [EL 3, CSS]). Factors found to be associated with poor outcome include open procedures, male gender, older age, congestive heart failure, peripheral vascular disease, deep venous thrombosis, PE, obstructive sleep apnea, impaired functional status, and chronic kidney disease (48 [EL 2, PCS]; 49 [EL 3, SS]). Therefore, further studies are needed that utilize new clinical risk-stratification systems to optimize patient selection criteria and consequently, patient outcomes.

R2(2/3). Many recent studies demonstrate benefit for bariatric surgery patients with BMI $<35 \mathrm{~kg} / \mathrm{m}^{2}$ in terms of weight loss (10 [EL 1, RCT]; 12 [EL 2, PCS]), diabetes remission, and cardiovascular risk reduction (50 [EL 2, RCT]; 51 [EL 1, RCT]; 52 [EL 2, PCS]; 53 [EL 2 , PCS]). This evidence base is supported by additional, though not as strong, studies and post hoc analyses from diverse ethnicities on weight loss (54 [EL 2, PCS]) and T2D improvement (11 [EL 2; PCS]; 55 [EL 3, SS]; 56 [EL 4, NE review and analysis]; 57 [EL 2, PCS]; 58 [EL 3, SS]; 59 [EL 2; PCS]; 60 [EL 2, NRCT]; 61 [EL 2, PCS]; 62 [EL 2; MNRCT]; 63 [EL 2, PCS]; 64 [EL 2, PCS]). As a result, the United States Food and Drug Administration (FDA) approved the LAP-BAND for patients with a BMI of 30-34.9 kg/m² with an obesity-related co-morbidity. Moreover, the recent comparative effectiveness, randomized, nonblinded, single-center trial, with $34 \%$ of patients with BMI $<35 \mathrm{~kg} / \mathrm{m}^{2}$, represents a highly relevant study, even though it cannot yet be generalizable (39 [EL 2, RCT]). A companion paper by Mingrone et al. (40 [EL 2, RCT]) randomized patients with BMI $\geq 35 \mathrm{~kg} / \mathrm{m}^{2}$ and does not apply to this CPG recommendation. Future, well-designed clinical trials that incorporate longer follow-up periods with demonstration of safety in the surgical group, relevant CVD outcomes, and an intensive medical therapy comparator group associated with weight loss, will clarify this CPG recommendation for patients with BMI $<35 \mathrm{~kg} / \mathrm{m}^{2}$.

$\mathbf{R 3}(4)$. There are no compelling studies to date that support recommending a bariatric surgical procedure for the management of T2D alone, in the absence of obesity (BMI $<30$ $\left.\mathrm{kg} / \mathrm{m}^{2}\right)$. 


\section{Q2. Which bariatric surgical procedure should be offered?}

R4(5/6/7). Two principal determinants since publication of the 2008 AACE-TOS-ASMBS CPG (7 [EL 4; CPG]) have impacted clinical decision making regarding the choice of a specific bariatric surgery procedure (see Fig. 1 for depictions of the 4 common bariatric surgery procedures). First, the emphasis has shifted from weight-loss outcomes to the metabolic effects of bariatric surgery procedures, and second, sufficient data regarding the safety, efficacy, and durability of various procedures, especially the LSG, have been published. The advent of personalized medicine and applicability to obesity genetics and medicine is reviewed by Blakemore and Froguel (65 [EL 4]). Additionally, new procedures have emerged that are still considered investigational but will clearly impact future decision making. The superiority of laparoscopic bariatric surgical procedures, versus open procedures, was further demonstrated by the meta-analysis of Reoch et al. (66 [EL 1, MRCT]).

As the metabolic effects of various bariatric operations become better understood, the traditional classifications of procedures as "restrictive," "malabsorptive," or "combination" procedures have become less functional and less widely accepted. Adjustable gastric banding has clearly been shown to result in improvement or remission of diabetes and metabolic syndrome (50 [EL 2, RCT]), but it appears that these effects may not be related to changes in gut hormones (67 [EL 2, PCS]). The early, weight-independent effects of RYGB, $\mathrm{BPD} / \mathrm{BPDDS}$, and LSG on T2D improvement have led many to refer to these procedures as "metabolic" operations (68 [EL 2, NRCT]; 69 [EL 2, PCS]; 70 [EL 2, NRCT]; 71 [EL 4, $\mathrm{NE}]$ ). In a 2-year period, RYGB was associated with increased achievement of American Diabetes Association (ADA) composite endpoints (38.2\% versus $10.5 \%$ with routine medical management; $P<.001 ; \mathrm{A}_{1 \mathrm{c}}<7.0 \%+$ LDL-cholesterol $<100 \mathrm{mg} / \mathrm{dL}$, and systolic blood pressure [BP] $<130 \mathrm{~mm} \mathrm{Hg})(72$ [EL 3, SS]). In recent follow-up reports of the Swedish Obese Subjects (SOS) study at median follow-up of 14.7 years, bariatric surgery was associated with improved T2D prevention and reduced cardiovascular deaths; these results extend the bariatric surgery benefits on surrogate markers to relevant clinical outcomes (26 [EL 2, PCS]; 73 [EL 2, PCS]). Nevertheless, the durability issue of T2D resolution remains at issue since approximately one third of RYGB patients experience relapse (74 [EL 3, SS]). Elevated GLP-1 levels and various other gut hormone changes favoring satiety and glucose metabolism have been demonstrated after RYGB (75 [EL 2, NRCT]; 76 [EL 2, NRCT], 77 [EL 4, NE]; 78 [EL 1, RCT]), BPD (79 [EL 4, NE]; 80 [EL 2, PCS]; 81 [EL 2, PCS]), and LSG (82 [EL 1, RCT]; 83 [EL 2, PCS]; 84 [EL 2, NRCT]). Exclusion of nutrient flow through the duodenum and proximal bowel (RYGB, BPD, $\mathrm{BPD} / \mathrm{DS}$ ) may also play a role in diabetes remission after these procedures, although the precise mechanism for this effect has not been established and requires further study (85 [EL 4, NE]; 86 [EL 4, NE]). Future therapeutic targets based on the various mechanisms of action of these operations are likely as they become more clearly defined (86 [EL 4, NE]; 87 [EL 4, NE]).

The LSG has become widely accepted as a primary bariatric operation and is no longer considered investigational (see ASMBS statement at http://s3.amazonaws.com/ publicASMBS/GuidelinesStatements/PositionStatement/ASMBS-SLEEVE- 
STATEMENT-2011_10_28.pdf [accessed on May 22, 2012]). The LSG is seldom used as part of a 2-stage risk management strategy for highrisk patients. Because nearly $80 \%$ of the stomach is transected and nutrients rapidly pass through a gastric conduit, increased GLP-1 and PYY 3-36 and decreased ghrelin levels result, producing key metabolic effects (78 [EL 1, RCT]; 82 [EL 1, RCT]; 83 [EL 2, PCS]; 84 [EL 2, NRCT]; 88 [EL 1, RCT]). In addition to many recently published case series reporting the short- and medium- term safety and efficacy (weight loss and glycemic status) of the SG, the majority of which were performed laparoscopically (89 [EL 3, SS]; 90 [EL 3, SS]; 91 [EL 2, PCS]; 92 [EL 3, SS]; 93 [EL 3, SS]; 94 [EL 3, SS]; 95 [EL 2, PCS]; 96 [EL 3, SS]; 97 [EL 2, PCS]; 98 [EL 2, PCS]; 99 [EL 3, SS]; 100 [EL 3, SS]; 101 [EL 3, SS]; 102 [EL 2, PCS]), there are now several comparative studies (103 [EL ]; 104 [EL ]; 105 [EL ]; 106 [EL ]; 107 [EL ]; 108 [EL ]; 109 [EL ]; 110 [EL ]; 111 [EL ]; 112 [EL ]; 113 [EL ]; 114 [EL ]; 115 [EL ]), 6 randomized controlled trials (78 [EL 1, RCT]; 82 [EL 1, RCT]; 116 [EL 1, RCT]; 117 [EL 1, RCT]; 118 [EL 1, RCT]; 119 [EL 1, RCT]), and meta-analyses (120 [EL 2, MNRCT]; 121 [EL 2, MNRCT]) demonstrating equivalency or superiority to other accepted procedures (RYGB and LAGB). Analyses of outcomes from large prospective databases have revealed a risk/ benefit profile for LSG that is positioned between the LAGB and RYGB (122 [EL 3, SS]; 123 [EL 3, SS]). There is also data demonstrating the durability of LSG at 5 to 9 years with acceptable long-term weight loss in the range of 50\%-55\% EWL (124 [EL 2, PCS]; 125 [EL 3, SS]; 126 [EL 3, SS]; 127 [EL 3, SS]; 128 [EL 2, PCS]). However, there are still concerns about the overall durability of the LSG procedure in light of a paucity of long-term ( $>5-10$ year) data, major complication rates (approximately $12.1 \%$ on average), mortality (up to $3.3 \%$ in some studies), and costs (129 [EL 2, MNRCT]).

Gastric plication is an investigational procedure designed to create gastric restriction without the placement of a device or resection of tissue. This procedure is performed laparoscopically and involves infolding the greater curvature of the stomach to tubularize the stomach and create an intraluminal fold. This technique has also been used in combination with a LAGB to help augment early weight loss. There are several short-term studies demonstrating relative safety and effectiveness of greater curvature plication with outcomes intermediate between LAGB and SG (130 [EL 2, PCS]; 131 [EL 2, PCS]; 132 [EL 2, PCS]; 133 [EL 2, PCS]). Notwithstanding the above EL 2 studies, more robust comparative data and conclusive data evaluating the durability of this procedure will be needed before specific recommendations can be made. As new procedures (both surgical and endoscopic) continue to emerge within the field of bariatric surgery, it is important to balance innovation and patient choice with patient safety and demonstrated effectiveness based on clear benchmarks. For now, investigational bariatric procedures should only be recommended within the framework of an institutional review board (IRB), or equivalent, approved clinical research study.

\section{Q3. How should potential candidates for bariatric surgery be managed preoperatively?}

R8(11/12). Informed consent for bariatric surgery is a dynamic process of education and comprehension in addition to the disclosure of risks and benefits (134 [EL 3, NE]; 135 [EL 2, PCS]). Educational objectives, active teaching and learning processes, and assessments are recommended (134 [EL 3, NE]; 136 [EL 4, NE]; 137 [EL 4, NE]) and should be 
communicated at a 6th-8th grade reading level (138 [EL 4, NE]). Multimedia tools for informed consent and patient education show promise for improving comprehension (139 [EL 2, NRCT]). Many programs begin the patients' experience with informational seminars, but education should be ongoing. Promotion of realistic expectations is recommended given the tendency for patients to endorse unrealistic expectancies for weight loss (140 [EL 2, PCS]; 141 [EL 3, SS]; 142 [EL 2, PCS]). As a result, the benefits of a proposed bariatric surgery should not be overstated (138 [EL 4, NE]). Accreditation may be awarded by the Unified National Accreditation Program for Bariatric Surgery Centers by the American College of Surgeons (ACS) and ASMBS (http://www.facs.org/news/2012/ acsasmbs0312.html, accessed on September 17, 2012).

R10(14). Cirrhosis (143 [EL 3, SS]) has been associated with adverse outcome following bariatric surgery, including progression to liver transplantation (144 [EL 3, SS]). Preoperative weight loss (targeting $3 \mathrm{~kg}$ fat loss [over 2 weeks], 5\% excess body weight [EBW] loss, or $10 \%$ total weight loss with energy-restricted diets) has been associated with reduction in hepatic volume (145 [EL 2, PCS]), variable perceived and measured facility in operative technique (beneficial: 146 [EL 2, PCS]; equivocal: 147 [EL 1, RCT]), variable effects on short-term ( $\triangle$ year; beneficial: 148 [EL 3, SS]; 149 [EL 1, RCT]; 150 [EL 2, PCS], 151 [EL 2, PCS]; not beneficial: 152 [EL 3, SS]) complication rates and weight loss, and no conclusive benefit for long-term outcome parameters. Therefore, recommendations to implement an aggressive preoperative weight-loss program to reduce liver volume should not be applied to all patients with hepatomegaly, but rather at the discretion of the bariatric surgery team for a subset of those higher-risk patients (e.g., technically difficult cases, preoperative BMI $>50 \mathrm{~kg} / \mathrm{m}^{2}$, etc.) to improve short-term outcomes. Preoperative weight loss with medical nutrition therapy can improve glycemic control and should therefore be utilized in obese patients with diabetes (153 [EL 4]).

\section{Q4. What are the elements of medical clearance for bariatric surgery?}

R11(15-17). A diabetes comprehensive care plan (DCCP) has been described in the 2011 AACE CPG (153 [EL 4, NE]); EL 1 reports can be found here supporting preoperative and postoperative glycemic control targets). Importantly, a shorter duration and better glycemic control preoperatively is associated with a higher rate of T2D remission after bariatric surgery (154 [EL 2, PCS]). More liberal targets may be used based on clinical judgment. Risk factors contributing to complications and death after RYGB include T2D, in addition to BMI $\Sigma 55 \mathrm{~kg} / \mathrm{m}^{2}$ (main factor), obstructive sleep apnea, and cardiomyopathy (155 EL 2, PCS). Among 468 patients undergoing RYGB, elevated preoperative $A_{1 c}$ was associated with elevated postoperative hyperglycemia. Postoperative hyperglycemia is independently associated with wound infections, acute renal failure, and reduced T2D remission rates (156 [EL 3, SS]). Absolute weight loss is negatively correlated with preoperative treatment for T2D ( $P=.021$; due to weight gain and orectic effects of insulin and insulin secretagogues), but not with preoperative biomarkers of T2D or insulin resistance (fasting BG, fasting insulin, or homeostatic model assessment [HOMA] index) (157 EL 2, PCS). However, T2D remission rates following RYGB were positively correlated with preoperative C-peptide levels, suggesting that this biomarker may be used to assist in the selection of patients with obesity-related T2D (158 [EL 2, PCS]). 
R12(18/19). Severe obesity is associated with increased TSH levels and subclinical hypothyroidism; following bariatric surgery and weight loss, TSH levels decrease (159 [EL 2, PCS]; 160 [EL 2, PCS]; 161 [EL 3, SS]; 162 [EL 2, PCS]; 163 [EL 3, SS]). Nevertheless, routine screening for primary hypothyroidism simply due to the presence of an obese state is not recommended, whereas aggressive case finding is recommended in at-risk patients (164 [EL 4, NE]). In short, obesity appears to be associated with TSH elevation in the absence of a primary thyroid disease. Notwithstanding the above, many insurance companies require TSH testing before bariatric surgery.

R13(20/21). Preoperative triglyceride levels were positively correlated with nonalcoholic steatohepatitis (NASH), and high-density lipoprotein (HDL) levels were negatively correlated with nonalcoholic fatty liver disease (NAFLD), supporting the utility of lipoprotein profiling preoperatively (165 [EL 2, PCS]). Treatment guidelines are provided in the 2012 AACE CPG for management of dyslipidemia and prevention of atherosclerosis (166 [EL 4, CPG).

$\mathbf{R 1 4}(22-24)$. This recommendation is updated based on additional evidence (primary EL 3) related to the harmful effects of various deficiencies (iron, calcium, $\mathrm{B}_{12}$, folic acid, and vitamin D) and teratogens (vitamin A). These studies serve as the basis for position papers (167 [EL 4, position]) and reviews (168 [EL 4, review], 169 [EL 4, review]).

$\mathbf{R 1 8}(29 / 31)$. The evidence base is updated by 2 studies. Cardiopulmonary testing (at least an electrocardiogram and polysomnography) is recommended preoperatively with further testing (echocardiography, spirometry, and arterial blood gases) guided by additional risk factors specific tests (170 [EL 2, PCS]). Continuation of beta-blockers in a cohort comprised of many bariatric surgery patients was associated with fewer cardiac events and improved 90-day mortality rates (171 [EL 3, SS]).

R19(32/33). Obstructive sleep apnea (OSA) is prevalent before bariatric surgery (up to 94\%), with a significant number undiagnosed (38\%) (172 [EL 3, SS]; 173 [EL 3, SS]; 174 [EL 3, CSS]; 175 [EL 3, SS]; 176 [EL 3, SS]; 177 [EL 3, SS]). Moreover, attempts at predictive modeling, although encouraging, do not appear to have sufficient sensitivity and specificity (173 [EL 3, SS]; 175 [EL 3, SS]; 176 [EL 3, SS]; 178 [EL 3, SS]). Moderate to severe OSA is associated with increased risk for all-cause mortality (179 [EL 3, SS]) and in bariatric surgery patients, with adverse outcomes (180 [EL 2, PCS]). Therefore, routine preoperative screening with polysomnography should be considered, with further diagnostic testing and treatment of appropriate at-risk patients (181 [EL 4, CPG]). Standard preoperative management of overweight/obese patients with OSA using continuous positive airway pressure (CPAP) is recommended (182 [EL 4, review]).

R20(34/157). Recent data supports the association of smoking cigarettes with an increased risk of postoperative marginal ulceration (183 [EL 3, SS]) and pneumonia (184 [EL 3, SS]). The relative risk conferred by cigarette smoking on the incidence of infections in postbariatric surgery patients undergoing body contouring abdominoplasty is 14 , with a cutoff of 8.5 pack-years (185 [EL 3, SS]), and undergoing mastopexy is 3.8, with a cutoff of 6.85 pack-years (186 [EL 3, SS]). Smoking cessation has been recommended at least 6 weeks 
before bariatric surgery in the evidence-based best practice guidelines by Schumann et al. (181 [EL 4, CPG]). However, the timing specified by this recommendation-that smoking should be stopped at least 6 weeks preoperatively — was not supported by a meta-analysis (187 [EL 2, MNRCT]). Therefore, all smokers should be advised to stop smoking at any time before bariatric surgery, even if it is within 6 weeks before surgery.

R21(35/36). The Bariatric Outcomes Longitudinal Database prospectively evaluated 73,921 patients undergoing bariatric surgery and analyzed venous thromboembolism (VTE) events within 90 days of surgery (188 [EL 3, SS]). The overall risk of VTE after surgery was .42\%, and $73 \%$ of these events occurred after discharge, most within 30 days after surgery (188 [EL 3, SS]). The risk of VTE was greater in the patients undergoing RYGB than in those undergoing adjustable gastric banding (.55\% versus .16\%) (188 [EL 3, SS]). VTE was more frequent when the procedure was performed using an open, rather than a laparoscopic approach (1.54\% versus .34\%) (188 [EL 3, SS]). Patients with a VTE event were older, had higher BMI, and were more likely to have a history of VTE (16.5\% versus $3.7 \%)$ than patients who did not have a VTE event (188 [EL 3, SS]). The risk of VTE was greater in men (hazard ratio 2.32, 95\% confidence interval 1.81-2.98) and in patients with an inferior vena cava filter (hazard ratio 7.66, 95\% confidence interval 4.55-12.91) (188 [EL 3, SS]). However, there is evidence suggesting that prophylactic IVC filter placement before RYGB does not prevent PE and may lead to additional complications (189 [EL 3, SS]).

R23(38). In a study limited to obese patients in the eastern region of Saudi Arabia, the prevalence of abnormal liver function tests was low and generally due to nonalcoholic fatty liver disease (NAFLD) (190 [EL 3, SS]). Therefore, routine abdominal ultrasonography is not needed to routinely screen for significant liver disease before bariatric surgery.

R24(39). The reported prevalence range for preoperative $\mathrm{H}$ pylori has widened from $8.7 \%$ in a German cohort (191 [EL 2, PCS]) to $85.5 \%$ in a Saudi cohort of bariatric surgery patients (192 [EL 3, SS]), with other series having intermediate values (193 [EL 3, SS]; 194 [EL 3, SS]; 195 [EL 3, SS]). In 1 retrospective review, preoperative treatment following H pylori screening resulted in reduced incidence of viscus perforation (196 [EL 3, SS]). In another retrospective review of 560 patients undergoing RYGB, flexible upper endoscopy, testing for $\mathrm{H}$ pylori followed by treatment of patients with positive results, was associated with a lower incidence of postoperative marginal ulcers (2.4\%), compared with those who did not undergo such screening (6.8\%) (197 [EL 3, SS]). However, in a PCSA, Yang et al. (198 [EL 2, PCS]) conclude that gastric ulcers in symptomatic patients following laparoscopic bariatric surgery are related to the surgical procedure and not exposure to $\mathrm{H}$ pylori infection. This finding was corroborated by the results of Loewen et al. (199 [EL 3, CCS]). The issue of $\mathrm{H}$ pylori screening before bariatric surgery will require a well- designed RCT, but until then, the evidence does not support routine screening (200 [EL 4, opinion]), but aggressive case finding in high-risk patients may be reasonable.

$\mathbf{R 2 5}(40)$. In a retrospective, multicenter study of 411 RYGB patients, 7 of 21 with a history of gout suffered an acute gouty attack postoperatively (201 [EL 3, SS]). 
R27(42/43). The psychosocial evaluation identifies potential contraindications to surgical intervention, such as substance abuse or poorly controlled psychiatric illness, and identifies interventions that can enhance long-term weight management (202 [EL 4, review]). Even though there are published recommendations regarding the structure and content of mental health evaluations (203 [EL 2, PCS]; 204 [EL 4, CPG]; 205 [EL 2, PCS]), consensus guidelines have yet to be established. Psychologists, psychiatrists, or other mental health professionals typically perform these evaluations, which rely on clinical interviews, as well as questionnaire measures of psychiatric symptoms and/or objective tests of personality or psychopathological conditions (206 [EL 3, SS]). More comprehensive evaluations assess the bariatric surgery knowledge, weight history, eating and physical activity habits, potential obstacles, and resources that may influence postoperative outcomes (203 [EL 2, PCS]; 204 [EL 4, CPG]). Approximately $90 \%$ of bariatric surgery programs require their surgical candidates to undergo a mental health evaluation preoperatively (207 [EL 3, SS]; 208 [EL 3]). A substantial proportion of bariatric surgery candidates present themselves in an overly favorable light during the psychological evaluation (209 [EL 3, SS]), and there is low congruence between clinically derived and research-based diagnoses (210 [EL 3, SS]), which may impact accurate assessment.

A lifetime history of substance abuse disorder is more likely in bariatric surgery candidates compared with the general population (211 [EL 3, SS]). In contrast, current alcohol and substance abuse in bariatric surgery candidates is low compared with the general population (211 [EL 3, SS]). The LABS study demonstrated that certain groups including those with regular preoperative alcohol consumption, alcohol use disorder, recreational drug use, smokers, and those undergoing RYGB had a higher risk of postoperative alcohol use disorder (212 [EL 2, PCS]). A web-based questionnaire study indicated that $83 \%$ of respondents continued to consume alcohol after RYGB, with $28.4 \%$ indicating a problem controlling alcohol (213 [EL 3, SS]). In a prospective study with 13- to 15-year follow-up after RYGB, there was an increase in alcohol abuse (2.6\% presurgery to $5.1 \%$ postsurgery) but a decrease in alcohol dependence (10.3\% presurgery versus $2.6 \%$ postsurgery) (214 [EL 2, PCS]). In a survey 6-10 years after RYGB, $7.1 \%$ of patients had alcohol abuse or dependence before surgery, which was unchanged postoperatively, whereas $2.9 \%$ admitted to alcohol dependence after surgery but not before surgery (215 [EL 3, SS]). Finally, in a retrospective review of a large electronic database, $2 \%-6 \%$ of bariatric surgery admissions were positive for a substance abuse history (216 [EL 3, SS]). Interestingly, 2 studies have demonstrated better weight loss outcomes among patients with a past substance abuse history compared with those without past alcohol or other substance abuses (217 [EL ]; 218 [EL 3, SS]).

The pharmacokinetic changes following RYGB include accelerated alcohol absorption (shorter time to reach maximum concentration) (219 [EL 2, NRCT]), higher maximum alcohol concentration (219 [EL 2, NRCT]; 220 [EL 2, PCS]; 221 [EL 2, PCS]), and longer time to eliminate alcohol (220 [EL 2, PCS]; 221 [EL 2, PCS]). In a recent prospective crossover study of RYGB patients, blood alcohol content (BAC) was measured preoperatively and 3 and 6 months postoperatively after $5 \mathrm{oz}$ of red wine to determine peak BAC and time until sober (221 [EL 2, PCS]). The peak BAC in patients at 6 months (.088\%) 
was greater than the preoperative baseline (.024\%) with varying intoxication symptoms (221 [EL 2, PCS]). Similar findings have been demonstrated in patients after LSG (222 [EL 2, PCS]). Weight loss and rapid emptying of a gastric pouch contribute to the higher BAC (219 [EL 2, NRCT]) and faster alcohol absorption and lower metabolic clearance (220 [EL 2, PCS]), respectively, for each drink consumed. Overall, from the existing evidence base, it is unclear how long an individual should be abstinent from alcohol, or other substances with abuse potential, before bariatric surgery.

R28(44). Binge eating disorder (BED), night eating syndrome, grazing, and other loss-ofcontrol eating patterns are quite common in bariatric surgery candidates (223 [EL 2, PCS]; 224 [EL 3, SS]; 225 [EL 2, PCS]). Several studies have linked preoperative BED with less excess body weight lost or weight regain during the 2-year postoperative period (226 [EL 3, SS]; 227 [EL 4, NE]; 228 [EL 3, CSS]; 229 [EL 2, PCS]; 230 [EL 3, SS]) Other studies have not found significant differences in weight loss outcomes when comparing patients with and without preoperative BED (231 [EL 2, PCS]; 232 [EL 2, PCS]; 233 [EL 3, SS]). These conflicting findings may be due in part to the wide variation in methodology for determining BED in the studies (234 [EL 4, NE]). However, loss-of-control eating and grazing appear to be linked to weight loss outcomes (223 [EL 2, PCS]; 224 [EL 3, SS]; 235 [EL 3, SS]; 236 [EL 2, PCS]). Perioperative behavioral strategies to improve adherence with lifestyle modification include long-term patient-provider contact, actual physical activity interventions (enrolling patients in programs), concrete and specific recommendations, and mechanisms to facilitate impulse control and improve mood (237 [EL 4, opinion]).

Notwithstanding the above, preoperative interventions have had mixed results (238 [EL 2, PCS]; 239 [EL 2, PCS]). Bulimia nervosa is rare among bariatric surgery candidates and should be considered a contraindication to these surgical procedures (http:// www.behavioralhealthce.com/index.php/component/courses/?task=view\&cid=70).

R29(45). The EL 3 evidence base supporting the high prevalence rates and need for systematic preoperative assessment and treatment of nutrient insufficiencies/deficiencies is primarily represented by surveillance studies, case series, and case reports. Additions to this evidence base since the 2008 AACE-TOS-ASMBS CPG (7 [EL 4, CPG]) support this recommendation (240 [EL 3, SS]; 241 [EL 3]; 242 [EL 3, SS]; 243 [EL 3, SS]; 244 [EL 3, SS]; 245 [EL 3, SS]; 246 [EL 3, SS]; 247 [EL 3, SS]; 248 [EL 3, SS]; 249 [EL 3, SS]; 250 [EL 3, SS]; 251 [EL 3, SS]; 252 [EL 3, SS]). The length of intestinal bypass is directly related to the extent of risk for nutritional deficiencies (253 [EL 1, RCT]).

R30 (NEW). Obesity is a risk factor for certain malignancies (e.g., endometrial, renal, gallbladder, breast, colon, pancreatic, and esophageal) (254 [EL 4, review], 255 [EL 3, SS], 256 [EL 4, review], 257 [EL 3, SS], 258 [EL 3, SS]), adversely affects clinical outcomes (259 [EL 2, PCS]), and therefore prompts age-and risk-appropriate cancer screening before bariatric surgery. Gagné et al. (260 [EL 3, SS]) found that among 1,566 undergoing bariatric surgery, $36(2.3 \%)$ had a history of malignancy, $4(.3 \%)$ were diagnosed during the preoperative evaluation, $2(.1 \%)$ were diagnosed intraoperatively, and another $16(1 \%)$ were diagnosed postoperatively. However, the authors commented that a finding of malignancy per se was not a contraindication to bariatric surgery as long as the life expectancy was reasonable. Subsequently, limited clinical series have described the benefit of preoperative 
screening for specific cancer histiotypes (261 [EL 3, CCS]) and the protective effect of bariatric surgery (262 [EL 4, review]). Unfortunately, despite this clinical association, awareness and implementation are still lacking (263 [EL 3, SS]).

\section{Q5. How can early postoperative care be optimized?}

R31 (46-53/90/91). In an RCT by Sarwer et al. (264 [EL 1, RCT]), regular postoperative dietary counseling by an RD was associated with greater weight loss at 4 and 24 months compared with the control group. Although none of these weight loss differences reached statistical significance, the dietary counseling group reported greater improvements in eating behavior (264 [EL 1, RCT]). The role of the RD in postoperative care is further reviewed by Kulick et al. (265 [EL 4, position]) and Ziegler et al. (266 [EL 4, consensus]).

Recommendations for protein intake are variable but studies suggest higher protein levels (80-90 g/d) are associated with reduced loss of lean body mass (267 [EL 4, NE]; 268 [EL 2, PCS]; 269 [EL 3, SS]). Protein intake is generally reduced following surgery (270 [EL 2, PCS]), and adequate intake can be facilitated through the use of protein supplements, though a causal effect of protein supplement use and favorable body composition change has not been demonstrated (271 [EL 2, PCS]). A review of healthy eating principles after RYGB is provided by Moize et al. (272 [EL 4, review]). Medication absorption depends on the a variety of drug-specific factors, but in general rapid- or immediate-release preparations, in liquid form or crushed to facilitate tolerance, are preferable to extended release or entericcoated preparations (273 [EL 4, review]; 274 [EL 4, review]).

R32(54/89/93). Many patients will require additional micronutrient supplementation in addition to 2 daily multivitamins recommended (275 [EL 2, PCS]; 276 [EL 4, CPG]). The extent and severity of micronutrient undernutrition is related to the extent and severity of disruption of normal gastrointestinal anatomy and physiology (277 [EL 4, review]). Guidelines for treating iron deficiency in bariatric surgery patients are reviewed by Munoz et al. (278 [EL 4, review]). Guidelines for folic acid and $\mathrm{B}_{12}$ are based on maintenance of biochemical and functional markers (e.g., homocysteine, RBC folate, and methylmalonic acid) within target ranges (279 [EL 2, PCS]; 280 [EL 3, SCR]). Calcium intake primarily in the form of food is advocated in LAGB given recent reports linking calcium supplementation with increased incidence of MI risk in postoperative women (281 [EL 2, PCS])). Vitamin D dosages of at least and as high as $6000 \mathrm{IU} / \mathrm{d}$ are safe and necessary in many postbariatric surgery patients to achieve target blood levels (282 [EL 1, RCT]; 283 [EL 4, position]). The broad recommendation concerning micronutrient undernutrition and management was designated as Grade A based on expert consensus, even though EL 1 studies are lacking for all relevant vitamins and minerals.

R34(56/92). The Nutrition Risk Score 2002 is a validated instrument to identify patients who would benefit from nutrition support (284 [EL 3, SS]). PN is reserved for those patients requiring nutrition support but unable to meet their needs enterally. The timing of nutrition support initiation is based on the clinical setting and has been discussed in various recent CPG (285 [EL 4, CPG]; 286 [EL 4, NE]; 287 [EL 4, CPG]). The application of these evidence-based CPG recommendations in the bariatric surgery patient has been derived from extrapolations from obesity patients in the ICU (288 [EL 4, review]) and limited reviews and 
case reports, primarily involving postoperative leaks (289 [EL 4, review]; 290 [EL 4, NE]; $291[$ EL 3, SS]).

R35(57). This recommendation is consistent with the 2011 AACE DCCP CPG (153 [EL 4, CPG]).

R36(58-61). Recent changes in the recommendations for inpatient and outpatient glycemic control targets are provided in the 2011 AACE DCCP CPG (153 [EL 4, CPG]) and the review by Schlienger et al. (292 [EL 4, review]). An initial tight glycemic control protocol in the hospital following bariatric surgery can be safely implemented, but outcome studies are lacking so no formal recommendation can be made at this time (293 [EL 3, SS]). Metformin may be considered to manage hyperglycemia in the postoperative patient, but caution should be exercised in patients with reduced glomerular filtration rate (GFR) due to a potential increase for lactic acidosis (153 [EL 4, CPG]; 294 [EL 2, PCS]; 295 [EL 2, $\mathrm{NRCT}]$ ). There are insufficient data regarding the use of incretin-based therapies in the postoperative setting, but they may assist in achieving glycemic and weight targets (296 [EL $3, \mathrm{SCR}])$.

R38(64). Postoperative CPAP improves arterial blood gas and reduces the need for intubation (297 [EL 4, review]). NSQIP data from 2006-2008 recently published also reports that postoperative pulmonary complications (pneumonia and respiratory failure) can be predicted by various risk factors, accounted for one-fifth of complications and significantly increased 30-day mortality after bariatric surgery (298 [EL 3, SS]). Singleinstitution retrospective series have demonstrated that CPAP after gastric bypass does not result in an increased anastomotic leak rate (299 [EL 3, SS]).

R39(65/66). Although strong evidence is lacking, there is demonstrable benefit with posthospital discharge extended chemoprophylaxis for selected high-risk patients; this strategy should be considered based on individual patient risk factors, including VTE, activity level at the time of discharge, and bleeding complications (300 [EL 4, CPG]; 301 [EL 3, SS]; 302 [EL 2, PCS]). The BOLD data demonstrated that $73 \%$ of VTE events occurred after hospital discharge (303 [EL 3, SS]). The time frame of 24 hours adheres with the Surgical Care Improvement Project (SCIP; http://www.jointcommission.org/ surgical_care_improvement_project/).

The use of prophylactic IVC filters is controversial and there are data that prophylactic IVC filters do not prevent thromboembolic events in postbariatric patients and may lead to additional complications. The Michigan Bariatric Collaborative study ( $\mathrm{N}=542 \mathrm{RYGB}$ patients) found that prophylactic IVC filter placement was not associated with a decrease in VTE-related complications, serious complications, or death (OR $=2.49 ; 95 \%$ CO .99-6.26) (304 [EL 3, SS]). There was no subgroup of patients in whom IVC filters improved outcomes, and $57 \%$ of patients who died or had permanent disability had a fatal PE or IVCrelated complication (304 [EL 3, SS]). Additionally, the BOLD data reported that the risk of VTE was greater in patients with an IVC filter (hazard ratio 7.66, 95\% confidence interval 4.55-12.91) (303 [EL 3, SS]). 
R40(67-71). The principal update concerns leaks following LSG (305 [EL 3, CCS]; 306 [EL 3, SS]; 307 [EL 2, MNRCT]; 308 [EL 3, CCS]; 309 [EL 4, review]; 310 [EL 4, NE]; 311 [EL 4, position]). The varying prevalence of this complication ( $0 \%-12 \%$; increased risk associated with smaller bougie size and higher BMI) in the reports cited represents a key factor in the clinical decision making regarding choice of bariatric procedure, technique and setting. There are new reviews regarding the clinical management of leaks but aspects of suspicion, diagnosis, and early exploration have not changed. Recently, an elevated Creactive protein (CRP) on day 2 following RYGB was associated with intestinal leak (312 [EL 3, SS]). CT imaging provides information regarding the gastric remnant staple line and the jejunojejunostomy that is not obtained with UGI (305 [EL 3, CCS]; 313 [EL 3, SS]; 314 [EL 3, SS]).

R41(72-75). The incidence of postoperative rhabdomyolysis (RLM; CK >1000 IU/L) ranges from 7-30.4\% (315 [EL 2, PCS]; 316 [EL 1, RCT]; 317 [EL 2, PCS]), and even though IVF is an effective treatment, this has not been shown to be an effective preventive measure (316 [EL 1, RCT]). Increased BMI $\left(>55-60 \mathrm{~kg} / \mathrm{m}^{2}\right)$ and bypass $>$ banding were associated with increased RLM incidence (315 [EL 2, PCS]; 261 [EL 2, PCS]) and patients in these higher risk categories may benefit from routine postoperative CK testing (316 [EL 1, RCT]; 317 [EL 2, PCS]).

\section{Q6. How can optimal follow-up of bariatric surgery be achieved?}

R42(78-83/85/88). Adherence with follow-up visits (missing <25\% of appointments, cf. $>25 \%$ ) was associated with greater loss of EBW for LAGB but not RYGB patients (318 [EL $3, \mathrm{SS}])$. This corroborated findings by Shen et al. (319 [EL 3, SS]) that the association of follow-up frequency impacted weight loss success to a greater degree in LAGB patients, compared with RYGB patients. Dixon et al. (320 [EL 3, SS]) found that a follow-up frequency less than 13 times in 2 years for LAGB patients, especially males, was associated with less weight loss (\% excess BMI loss); similar findings were noted when patients were motivated by appearance (especially young females) but there were no associations with "readiness-to-change." In another retrospective review of LAGB patients, Weichman et al. (321 [EL 3, SS]) found that $<7$ follow-up visits per year was associated with less loss of EBW than with $\geq 7$ follow-up visits per year.

Binge eating disorder (BED) and grazing are associated with inadequate weight loss or weight regain after RYGB (322 [EL 3, SS]). In a prospective study, Rutledge et al. (323 [EL 2 , PCS]) found that the presence of $\geq 2$ psychiatric conditions was associated with inadequate weight loss or weight regain after LAGB or RYGB. Efforts should be made to anticipate inadequate weight loss or weight regain by detecting risk factors such as continued disordered eating and psychiatric co-morbidity and then implementing a selfmonitoring strategy in higher-risk patients (324 [EL 3, SS]). Nutritional management of weight regain after RYGB may be successful (low glycemic load, $45 \%$ carbohydrate/35\% protein $/ 20 \%$ fat [about $16 \mathrm{kcal} / \mathrm{kg} / \mathrm{d}$ ], 3 servings $/ \mathrm{d}$ dairy product, $15 \mathrm{~g} / \mathrm{d}$ fiber supplement, and micronutrient supplements to avoid deficiencies) (325 [EL 2, PCS]). Though different mechanisms may ultimately account for inadequate weight loss or weight regain after LAGB procedures, conversion to a RYGB appears efficacious for both indications, at least 
short term (within 12 months) (326 [EL 2, PCS]). In patients with weight regain after RYGB, revisional surgery is most successful if performed within 5 years after the primary procedure (327 [EL 3, SS]). A recent review of revisional bariatric surgery is provided by Kellogg (328 [EL 4, review]). Additional reviews on nutritional and metabolic follow-up strategies are provided by Ziegler et al. (329 [EL 4, review]) and Koch and Finelli (330 [EL 4 , review]).

R43(84). Updated algorithms for the evaluation and treatment of postprandial hypoglycemia after bariatric surgery are provided by Ceppa et al. (331 [EL 3, CCS]) and Cui et al. (332 [EL 3, CCS]). The discriminants used in these algorithms include specific hypoglycemic and dumping symptoms, vasomotor and glycemic responses to oral glucose challenge, and formal insulinoma and 72 hour prolonged fasting tests (331 [EL 3, CCS]); (332 [EL 3, CCS]). Interventions for noninsulinoma pancreatogenous hypoglycemia syndrome (NIPHS) include pharmacological therapy (octreotide [332 [EL 3, CCS]; 333 [EL 3, SCR]), diazoxide (332 [EL 3, CCS]; 334 [EL 3, SCR]), acarbose (333 [EL 3, SCR]) and calcium channel antagonists (332 [EL 3, CCS]; 335 [EL 3, SCR]) and surgical procedures (gastric restriction 280 [EL 2, PCS]) and pancreatectomy (336 [EL 2, PCS]; 337 [EL 3, SCR]).

R44(86). Many bariatric surgery patients have negative beliefs and cognitions regarding physical activity; these should be addressed and the benefits and types of physical activity before and after bariatric surgery reinforced (338 [EL 2, PCS]; 339 [EL 2, PCS]). In a retrospective study of 148 RYGB patients, postoperative physical activity was associated with greater EWL loss (OR 3.5; $P<.01)(340$ [EL 3, SS]). These results were corroborated by Hatoum et al. (341 [EL 2, PCS]). In a nonrandomized trial of 15 patients post-RYGB, an exercise program of 75 minutes cardiovascular warmup $\times$ strength training $\times$ endurance training, 3 times a week for 12 weeks prevented the reduction in static and dynamic muscle strength observed in control patients (342 [EL 2, NRCT]). In a RCT of 21 patients postRYGB, 12 weeks of aerobic exercise training was associated with improved cardiac autonomic function and pulmonary functional capacity (343 [EL 1, RCT]). In another RCT of 33 patients post-RYGB or gastric banding, 12 weeks of a high-volume exercise (up to 1 $\mathrm{hr} / \mathrm{d}$ moderate physical activity with increases in additional light physical activity) was associated with increased resting energy expenditure, improved glucose tolerance, and enhanced physical fitness (344 [EL 1, RCT]).

In 1 meta-analysis, Egberts et al. (345 [EL 2, MNRCT]) found that postbariatric surgery patients participating in an exercise program experienced a standardized mean of $3.62 \mathrm{~kg}$ greater weight loss compared with minimal exercise groups. In another meta-analysis, Livhits et al. (346 [EL 2, MNRCT]) demonstrated the salutary effects of postoperative exercise, with many of the study designs analyzed incorporating $>30 \mathrm{~min} / \mathrm{d}$ of moderate physical activity. These findings are consistent with the meta-analysis of Jacobi et al. (347 [EL 2, MNRCT]).

R45(87). A number of empirical studies and a meta-analysis demonstrate improved weightloss outcomes in patients who attend support groups following weight-loss surgery (348 [EL 2, MNRCT]; 349 [EL 3, SS]). The positive relationship between support group attendance and weight loss has been found in RYGB (340 [EL 3, SS]; 350 [EL 3, SS]) and LAGB (351 
[EL 3, SS]) patients. One study has shown a linear relationship between numbers of groups attended and weight loss after controlling for baseline BMI in LAGB patients (352 [EL 3, SS]).

R47(96). In a cross-sectional study of 2 cohorts (before and 12 months after RYGB), Gomez et al. (353 [EL 3, CSS]) found that bone mineral density (BMD) was positively correlated with lean mass preoperatively and postoperatively and with fat mass preoperatively. However, the authors point out that causal mechanisms among body composition, BMD, and neurohumoral axes remain complex and require further study. Even with the bone loss in the hip after bariatric surgery, the data and limitations of dual energy $x$-ray absorptiometry (DXA) are not conclusive that there is an increased incidence of osteoporosis and increased fracture risk (354 [EL 4, review]). These limitations are compounded further by the weight constraints of most DXA tables (250-275 pounds), although newer and larger machines can accommodate up to 450 pounds (355 [EL 4, review]). Forearm BMD determinations remain an option for preoperative screening and postoperative surveillance.

R49(101/102). Enteric hyperoxaluria is observed after RYGB and BPDDS and related to fat malabsorption (356 [EL 2, PCS]). Therapeutic strategies to manage hyperoxalaturia in bariatric surgery patients include calcium supplementation, increased hydration, limiting dietary oxalate, and adhering with a low-fat diet (356 [EL 2, PCS]). Sakhaee et al. (357 [EL 1, RCT]) performed a placebo-controlled RCT in RYGB patients demonstrating that potassium $(40 \mathrm{mEq})$ calcium $(800 \mathrm{mg})$ citrate $(100 \mathrm{mEq})$ supplementation inhibited calcium oxalate agglomeration. Certain probiotics (e.g., VSL\#3) have also been found to lower GI oxalate absorption in bariatric surgery patients (358 [EL 2, PCS]), as well as reduce bacterial overgrowth, increase $B_{12}$ availability, and perhaps by altering the intestinal microbiome, increase weight loss (359 [EL 1, RCT]).

R54(113-116). A meta-analysis of RCT to treat $\mathrm{B}_{12}$ deficiency concluded that oral $\mathrm{B}_{12}$ therapy (1000-2000 $\mathrm{mg} / \mathrm{d})$ was as effective as intramuscular administration in achieving short-term hematological and neurological responses (360 [EL 1, MRCT]).

R58(122-123). Approximately 9\% of patients have a zinc deficiency before bariatric surgery and $42 \%$ (RYGB) to $92 \%$ (BPDDS) after surgery, depending on procedure type (361 [EL 3, SS]). There are abnormalities in zinc (and iron) absorption markers following RYGB, reinforcing the need to monitor these analytes in this setting (251 [EL 3, SS]; 253 [EL 3, SS]; 362 [EL 2, PCS]).

R59(NEW). Approximately 51\%-68\% of BPD patients demonstrate low copper levels up to 4 years postoperatively (251 [EL 3, SS]; 253 [EL 3, SS]). This contrasts with approximately $4 \%$ of RYGB patients postoperatively up to 5 years (253 [EL 3, SS]). Shorter-term (5 years) hypocupremia was associated with reduced leukocyte and granulocyte counts but not with clinical evidence of hematological or neurological disorders (253 [EL 3, SS]).

R60(124-129). Chronic nausea and emesis are associated with thiamine deficiency in bariatric surgery patients. However, Lakhani et al. (363 [EL 3, SS]) found that among RYGB patients developing thiamine deficiency, they also had evidence of small intestine 
bacterial overgrowth (SIBO), which responded to thiamine $100 \mathrm{mg}$ PO BID for 2 months (on average) and antibiotics (metronidazole, amoxicillin, or rifaximin for 7-10 days each month for 2 months on average). The authors concluded that SIBO impairs the absorption of thiamine, as well as other nutrients.

R61(130). Improvements in serum lipid levels after bariatric surgery have been well documented and are multifactorial in nature (GI absorption, altered dietary patterns, and not weight loss per se). The continued need for lipid-lowering medication, especially statins, unless overtly unnecessary or not possible due to GI symptoms, is emphasized, though the evidence base is fairly limited (364 [EL 3, SS]).

R62(131). Reductions in systolic and diastolic BP can occur within weeks of RYGB and continue up a year (365 [EL 2, PCS]). A nonmatched PCS with 3.4 years follow-up demonstrated significant improvement (RR .59) in metabolic syndrome components, including hypertension in a bariatric surgery group, compared with a medical weight-loss program group (366 [EL 2, PCS]). Notwithstanding these results, the determinants of BP changes with obesity and bariatric surgery are complex. Similar to the above R61 for statins, postoperative antihypertensives should also not be discontinued unless found to be overtly unnecessary (72 [EL 3, SS]). The SOS (367 [EL 2, PCS]) study and recent RCTs (38 [EL 1, $\mathrm{RCT}$ ]; 39 [EL 2; RCT]; 40 [EL 1, RCT]; 41 [EL 1, RCT]) have failed to demonstrate major or durable improvements in BP (368 [EL 4, NE]). In addition, certain determinants of BPmuscle sympathetic nerve activity and plasma rennin activity-fall with negative energy balance but rebound with weight stability (369 [EL 2, PCS]).

R63(132-135/138). Among 290 bariatric surgery patients, loose stool, and malodorous flatus were most frequent after BPD > RYGB, and constipation most frequent after LAGB (370 [EL 3, SS]).

R64(136/137). Nonsteroidal antiinflammatory drugs are associated with gastric and marginal ulcer perforations after RYGB (371 [EL 3, SS]; 372 [EL 3, SS]).

$\mathbf{R 6 5}(139-141)$. Endoscopy is study of choice for chronic abdominal pain after bariatric surgery and foreign body removal can be successful $(71 \%$ with immediate symptomatic improvement in 1 study; 373 [EL 3, SS]). There is no evidence regarding $\mathrm{H}$ pylori testing postoperatively to evaluate GI symptoms or complications.

R66(142). Retrospective series and single case reports have demonstrated the effectiveness of revisional surgery for problems related to nonpartitioned stomach after primary RYGB (gastrogastric fistula, staple line disruption) (374 [EL 3, SS]; 375 [EL 3, SS]; 376 [EL 3, SS]; 377 [EL 3, SCR]; 378 [EL 3, SCR]; 379 [EL 3, SCR]). Endoluminal procedures, such as endoscopic plicating and suturing, can be effective treatment for gastrogastric fistulas and staple line failures in selected cases and are less risky than surgical revision. The technology required and endoscopic skill set needed to accomplish these endoluminal procedures, though, are not widely available and are considered as investigational at this time. (380 [EL 3, SS]; 381 [EL 3, SS]; 382 [EL 3, CCS]; 383 [EL 3, SCR], 384 [EL 3, SCR]). 
$\mathbf{R 6 8}(145 / 146)$. Ultrasound is conventionally utilized to assess gallstone formation in the postbariatric surgery patient (385 [EL 4, review]). In a comparative cohort study, prophylactic cholecystectomy was feasible in preventing gallbladder complications after RYGB (386 [EL 2, PCS]). A meta-analysis of 5 RCTs, including 521 patients, concluded that ursodeoxycholic acid (300-1200 mg/d) significantly reduces gallstone formation after bariatric surgery (387 [EL 1, MRCT]).

R69(147/148). Rifaximin therapy provides symptom relief in irritable bowel syndrome and may be considered in post-BPD patients with symptoms related to bacterial overgrowth (388 [EL 1, RCT]). Probiotics can reduce bacterial overgrowth and promote weight loss in RYGB patients (359 [EL 1, RCT]).

R70(R149-152). Deferral of definitive repair of an symptomatic hernia depends on the surgeon's judgement based on the patient's clinical status and ease of repair. In 1 study, concomitant ventral hernia repair and RYGB was associated with small bowel obstruction and/or greater length of hospital stay (389 [EL 3, SS]). Whereas in a later study, concomitant mesh repair for ventral hernias and RYGB or LSG was found to be safe (390 [EL 3, SS]). The diagnostic challenges for internal hernias and small bowel obstructions following RYGB are related to vague symptom reporting and reduced yield with imaging, both as a result of altered GI anatomy (391 [EL 3, SS]).

R71(R153-156). Body contouring procedures after bariatric surgery are associated with improved well-being and quality of life (392 [EL 3, SS]). However, there is a $21 \%$ overall complication rate with abdominoplasty after bariatric surgery (393 [EL 3, SS]). There are alternatives to the traditional amputation-type panniculectomy for skin laxity after bariatric surgery. The potentially longer fleurde-lis procedure has been reported to have a lower complication rate and improved symptom/cosmetic outcome (394 [EL 3, SS]). A modification to this procedure with high lateral incisions has been used in those patients who still have a BMI $>30 \mathrm{~kg} / \mathrm{m}^{2}$ (395 [EL 3, SS]). Circumferential abdominoplasty is another safe and effective body contouring procedure after bariatric surgery (396 [EL 3, SS]). Mastopexy is also indicated in nearly all female postbariatric surgery patients (397 [EL 3, SS]). In a retrospective review, van der Beek et al. (398 [EL 3, SS]) found that a stable weight for 3 months that is close to normal, typically requiring 12-18 months postoperatively, was associated with a low complication rate.

R72(158-162). The hospital readmission rate is $5.8 \%$ for RYGB and $1.2 \%$ for banding procedures within 30 days after discharge; the greatest predictors are prolonged length of stay (LOS) (OR 2.3), open surgery (OR 1.8), and pseudotumor cerebri (OR 1.6) for RYGB and prolonged LOS (OR 2.1), history of DVT or PE (OR 2.1), asthma (OR 1.5), and OSA (OR 1.5) (399 [EL 2, PCS]). In another study, publicly funded insurance, wound infections, malaise, and technical complications were associated with readmission after RYGB (400 [EL 3]).

R73(163). The overall incidence of revisional bariatric surgery ranges from 5\%-50\% with leak rates around 30\% (401 [EL 4, review]). As an example, revisional RYGB after LAGB is safe and effective but with less weight loss, on average, compared with primary RYGB 
procedures (402 [EL 3, SS]). There are many other case reports and small clinical series but, at present, no RCTs to guide decision making for revisional bariatric surgery.

R74(164). Brolin and Asad (396 [EL 3, SS]) conducted a retrospective review of 2,573 primary and 252 revisional bariatric surgeries with 13 undergoing reversals. Rationale for the reversals were intractable vomiting or diarrhea, substance abuse, and severe metabolic complications (403 [EL 3, SS]). Reversal could be obviated in about $50 \%$ of patients with patient education and follow-up (403 [EL 3, SS]).

\section{Acknowledgments}

Robin Blackstone, MD: Immediate Past President, ASMBS; George Blackburn, MD, PhD: Co-Chair, Harvard Medical School, Beth Israel Deaconess Medical Center, Boston, MA; Alan Garber, MD: Departments of Medicine, Biochemistry and Molecular Medicine and Molecular and Cellular Biology, Baylor College of Medicine, Houston, TX; David B. Sarwer, PhD: Professor of Psychology, Departments of Psychiatry and Surgery and Director, Clinica Services, Center for Weight and Eating Disorders, Perelman School of Medicine at the University of Pennsylvania, Philadelphia, PA; Bruce Wolfe, MD: Professor of Surgery, Oregon Health and Science University, Portland, OR; Christopher D. Still, DO: Medical Director, Center for Nutrition \& Weight Management; Director, Geisinger Obesity Institute, Geisinger Health Care System, Danville, PA

\section{ABBREVIATIONS}

$\begin{array}{ll}\text { AACE } & \text { American Association of Clinical Endocrinologists } \\ \text { ACS } & \text { American College of Surgery } \\ \text { ASMBS } & \text { American Association of Metabolic and Bariatric Surgery } \\ \text { BAC } & \text { blood alcohol content } \\ \text { BED } & \text { binge eating disorder } \\ \text { BEL } & \text { best evidence level } \\ \text { BMI } & \text { body mass index } \\ \text { BPD-DS } & \text { biliopancreatic diversion with duodenal switch } \\ \text { CCS } & \text { clinical case series } \\ \text { CK } & \text { creatine kinase } \\ \text { CPAP } & \text { continuous positive airway pressure } \\ \text { CPG } & \text { clinical practice guidelines } \\ \text { CSS } & \text { cross-sectional study } \\ \text { CT } & \text { computerized tomography } \\ \text { CVD } & \text { cardiovascular disease } \\ \text { DCCP } & \text { diabetes comprehensive care plan } \\ \text { DVT } & \text { deep venous thrombosis } \\ \text { DXA } & \text { dual-energy x-ray absorptiometry } \\ \text { EL } & \text { evidence level }\end{array}$


EN enteral nutrition

FDA U.S. Food and Drug Administration

GERD gastrointestinal reflux disease

HDL high-density lipoprotein

ICU intensive care unit

LABS longitudinal assessment of bariatric surgery

LAGB laparoscopic adjustable gastric band

LDL low-density lipoprotein

LSG laparoscopic sleeve gastrectomy

MI myocardial infarction

MNRCT meta-analysis of nonrandomized controlled trials

MRCT meta-analysis of randomized controlled trials

NAFLD nonalcoholic fatty liver disease

NASH nonalcoholic steatohepatitis

NE

no evidence

NIH National Institutes of Health

OHS obesity hypoventilation syndrome

OSA obstructive sleep apnea

OS-MRS obesity surgery mortality risk score

PTH parathyroid hormone

PCOS polycystic ovary syndrome

PCS prospective cohort study

PE pulmonary embolism

PN parenteral nutrition

PPI proton pump inhibitor

RCT randomized controlled trial

RML rhabdomyolysis

RYGB Roux-en-Y gastric bypass

SCR single case report

SG sleeve gastrectomy

SOS Swedish Obesity Subjects

SS surveillance survey 
type 2 diabetes mellitus

TOS

The Obesity Society

TSH

thyroid-stimulating hormone

UGI

upper gastrointestinal

VTE

venous thromboembolism

\section{References}

1. Ogden CL, Carroll MD, Kit BK, et al. Prevalence of obesity in the United States, 2009-2020. NCHS Data Brief. 2012; 82:1-8. EL 3, SS. [PubMed: 22617494]

2. Berrington de Gonzalez A, Hartge P, Cerhan JR, et al. Body-mass index and mortality among 1.46 million white adults. N Engl J Med. 2010; 363:2211-2219. Erratum in: N Engl J Med 2011, 365, 869 EL 3, SS. [PubMed: 21121834]

3. Mechanick JI, Garber AJ, Handelsman Y, et al. American Association of Clinical Endocrinologists (AACE) position paper on obesity and obesity medicine. Endocr Pract. 2012; 18:642-648. EL 4, NE position. [PubMed: 23047927]

4. Ryan DH, Johnson WD, Myers VH, et al. Nonsurgical weight loss for extreme obesity in primary care settings: results of the Louisiana Obese Subjects Study. Arch Intern Med. 2010; 170:146-154. EL 1, RCT. [PubMed: 20101009]

5. Livingston EH. The incidence of bariatric surgery has plateaued in the U.S. Am J Surg. 2010; 200:3781-385. EL 3, SS.

6. American Society for Metabolic \& Bariatric Surgery. [Accessed August 8, 2009] Metabolic \& Bariatric Surgery. Fact Sheet. Available at: http://www.asbs.org/Newsite07/media/ asmbs_fs_surgery.pdfEL 3, SS

7. Mechanick JI, Kushner RF, Sugerman HJ, et al. American Association of Clinical Endocrinologists, The Obesity Society, and the American Society for Metabolic \& Bariatric Surgery medical guidelines for clinical practice for the perioperative nutritional, metabolic, and nonsurgical support of the bariatric surgery patient. Endocr Pract. 2008; 14(Suppl 1):1-83. EL 4, CPG. [PubMed: 18723418]

8. American Society for Metabolic \& Bariatric Surgery. [Accessed April 22, 2012] Updated position statement on sleeve gastrectomy as a bariatric procedure. revised 10/28/2011. Available at: http:// www.thinnertimesforum.com/topic/65864-october-2011-sleeve-gastrectomy-position-statementfrom-asmbs/EL 4, NE position

9. Hutter MM, Schirmer BD, Jones DB, et al. First report from the American College of Surgeons Bariatric Surgery Center Network: laparoscopic sleeve gastrectomy has morbidity and effectiveness positioned between the band and the bypass. Ann Surg. 2011; 254:410-420. EL 2, PCS. [PubMed: 21865942]

10. O’Brien PE, Dixon JB, Laurie C, et al. Treatment of mild to moderate obesity with laparoscopic adjustable gastric banding or an intensive medical program: a randomized trial. Ann Intern Med. 2006; 144:625-633. EL 1, RCT. [PubMed: 16670131]

11. Sultan S, Parikh M, Youn H, et al. Early U.S. outcomes after laparoscopic adjustable gastric banding in patients with a body mass index less than 35kg/m2. Surg Endosc. 2009; 23:1569-1573. EL 2, PCS. [PubMed: 19263156]

12. Parikh M, Duncombe J, Fielding GA. Laparoscopic adjustable gastric banding for patients with body mass index ofr35 kg/m². Surg Obes Relat Dis. 2006; 2:518-522. EL 2, PCS. [PubMed: 17015204]

13. Angrisani L, Favretti F, Furbetta F, et al. Italian group for Lap-Band system: results of multicenter study on patients with BMI $235 \mathrm{~kg} / \mathrm{m}^{2}$. Obes Surg. 2004; 14:415-418. EL 3, SS. [PubMed: 15072665] 
14. U.S. Food and Drug Administration. [Accessed April 22, 2012] FDA expands use of banding system for weight loss. Available at: http://www.fda.gov/NewsEvents/Newsroom/ PressAnnouncements/ucm245617.htmEL 4, NE position

15. Dixon JB, Zimmet P, Alberti KG. Bariatric surgery: an IDF statement for obese Type 2 diabetes. Diabet Med. 2011; 28:628-642. EL 4, NE position. [PubMed: 21480973]

16. Sjöström L, Lindroos AK, Peltonen M. Lifestyle, diabetes, and cardiovascular risk factors 10 years after bariatric surgery. N Engl J Med. 2004; 351:2683-2693. EL 2, PCS. [PubMed: 15616203]

17. Adams TD, Davidson LE, Litwin SE, et al. Health benefits of gastric bypass surgery after 6 years. JAMA. 2012; 308:1122-1131. EL 2, PCS. [PubMed: 22990271]

18. NIH conference. Gastrointestinal surgery for severe obesity. Consensus Development Conference Panel. Ann Intern Med. 1991; 115:956-961. EL 4, NE consensus. [PubMed: 1952493]

19. Tsai WS. Bariatric Surgery in Adolescents: recent national trends in use and in-hospital outcome. Arch Pediatr Adolesc Med. 2007; 161:217-221. EL 3, SS. [PubMed: 17339501]

20. Nguyen NT, Karipineni F, Masoomi H. Increasing utilization of laparoscopic gastric banding in the adolescent: data from academic medical centers, 2002-2009. Am Surg. 2011; 11:1510-1504. EL 3, SS. [PubMed: 22196666]

21. Livingston EH, Huerta S, Arthur D. Male gender is a predictor of morbidity and age a predictor of mortality for patients undergoing gastric bypass surgery. Ann Surg. 2002; 236:576-582. EL 3, SS. [PubMed: 12409663]

22. Dorman RB, Abraham AA, Al-Refaie WB. Bariatric Surgery Outcomes in the Elderly: An ACS NSQIP Study. J Gastrointest Surg. 2012; 16:35-44. EL 3, SS. [PubMed: 22038414]

23. DeMaria EJ, Murr M, Byrne TK. Validation of the obesity surgery mortality risk score in a multicenter study proves it stratifies mortality risk in patients undergoing gastric bypass for morbid obesity. Ann Surg. 2007; 246:578-582. EL 3, SS. [PubMed: 17893494]

24. DeMaria EJ, Portenier D, Wolfe L. Obesity surgery mortality risk score: Proposal for a clinically useful score to predict mortality risk in patients undergoing gastric bypass. Surg Obes Relat Dis. 2007; 3:134-140. EL 3, SS. [PubMed: 17386394]

25. The Longitudinal Assessment of Bariatric Surgery (LABS) Consortium. Perioperative Safety in the Longitudinal Assessment of Bariatric Surgery. N Engl J Med. 2009; 361:445-454. EL 2, PCS. [PubMed: 19641201]

26. Sjöström L, Peltonen M, Jacobson P. Bariatric surgery and long- term cardiovascular events. JAMA. 2012; 307:56-65. EL 2, PCS. [PubMed: 22215166]

27. Adams TD, Gress RE, Smith SC, et al. Long-term mortality after gastric bypass surgery. N Engl J Med. 2007; 357:753-761. EL 2, RCCS. [PubMed: 17715409]

28. Winters BD, Gurses AP, Lehmann H, et al. Clinical review: checklists-translating evidence into practice. Crit Care. 2009; 13:210-220. EL 4, review. [PubMed: 20064195]

29. Agency for Healthcare research and Quality (AHRQ). [Accessed December 29, 2011] National Guideline Clearinghouse. Available at: http://www.guideline.gov/content.aspx? $\mathrm{id}=13022 \&$ search=bariatric + aaceEL $4, \mathrm{NE}$ cpg

30. Mechanick JI, Camacho PM, Cobin RH, et al. American Association of Clinical Endocrinologists protocol for standardized production of clinical practice guidelines-2010 update. Endocr Pract. 2010; 16:270-283. EL 4, NE cpg. [PubMed: 20350905]

31. Pontiroli AEW, Morabito A. Long-term prevention of mortality in morbid obesity through bariatric surgery. A systematic review and meta-analysis of trials performed with gastric banding and gastric bypass. Ann Surg. 2011; 253:484-487. [PubMed: 21245741]

32. Buchwald H, Rudser KD, Williams SE, et al. Overall mortality, incremental life expectancy, and cause of death at 25 years in the program on the surgical control of the hyperlipidemias. Ann Surg. 2010; 251:1034-1040. EL 1; RCT. [PubMed: 20485136]

33. Padwal R, Klarenbach S, Wiebe N, et al. Bariatric surgery: a systematic review and network metaanalysis of randomized trials. Obes Rev. 2011; 12:602-621. EL 1; MRCT. [PubMed: 21438991]

34. Garb J, Welch G, Zagarins S, et al. Bariatric surgery for the treatment of morbid obesity: a metaanalysis of weight loss outcomes for laparoscopic adjustable gastric banding and laparoscopic gastric bypass. Obes Surg. 2009; 19:1447-1455. EL 1; MRCT. [PubMed: 19655209] 
35. Valezi AC, Mali J Junior, de Menezes MA, et al. Weight loss outcome after silastic ring Roux-en Y gastric by-pass: 8 years of follow-up. Obes Surg. 2010; 20:1491-1495. EL 2; PCS. [PubMed: 20811958]

36. Toouli J, Kow L, Ramos AC, et al. International multicenter study of safety and effectiveness of Swedish Adjustable Gastric Band in 1-, 3-, and 5-year follow-up cohorts. Surg Obes Relat Dis. 2009; 5:598-609. EL 2; PCS. [PubMed: 19656740]

37. Buchwald H, Estok R, Fahrbach K, et al. Weight and type 2 diabetes after bariatric surgery: systemic review and meta-analysis. Am J Med. 2009; 122:248-256. EL 1; MRCT. [PubMed: 19272486]

38. Hofs $\varnothing$ D, Nordstrand N, Johnson LK, et al. Obesity-related cardiovascular risk factors after weight loss: a clinical trial comparing gastric bypass surgery and intensive lifestyle intervention. Eur J Endocrinol. 2010; 163:735-745. EL 1; RCT. [PubMed: 20798226]

39. Schauer PR, Kashyap S, Wolski K, et al. Bariatric surgery versus intensive medical therapy in obese diabetic patients. N Engl J Med. 2012; 366:1567-1576. EL 1; RCT (nonblinded, nongeneralizable). [PubMed: 22449319]

40. Mingrone G, Panunzi S, De Gaetano A, et al. Bariatric surgery versus conventional medical therapy for type 2 diabetes. N Engl J Med. 2012; 366:1577-1585. EL 1; RCT (nonblinded, nongeneralizable). [PubMed: 22449317]

41. Hofs $\varnothing$ D, Jenssen T, Bollerslev J, et al. Beta cell function after weight loss: a clinical trial comparing gastric bypass surgery and intensive lifestyle intervention. Eur J Endocrinol. 2011; 164:231-238. EL 1; RCT. [PubMed: 21078684]

42. Lumachi F, Marzano B, Fanti G, et al. Hypoxemia and hypoventilation syndrome improvement after laparoscopic bariatric surgery in patients with morbid obesity. In Vivo. 2010; 24:329-331. EL 3; PCS (small sample size). [PubMed: 20555008]

43. Ashwell M, Gunn P, Gibson S. Waist-to-height ratio is a better screening tool than waist circumference and BMI for adult cardiometabolic risk factors: systematic review and metaanalysis. Obes Rev. 2012; 13:275-286. EL 2, MNRCT. [PubMed: 22106927]

44. Pories WJ, Dohm LG, Mansfield CJ. Beyond the BMI: the search for better guidelines for bariatric surgery. Obesity. 2010; 18:865-871. EL 4, NE opinion. [PubMed: 20150899]

45. De Lorenzo A, Bianchi A, Maroni P, et al. Adiposity rather than BMI determines metabolic risk. Int J Cardiol. [Epub 2011 Nov 14.] EL 3, CSS.

46. Katzmarzyk PT, Bray GA, Greenway FL, et al. Ethnic-specific BMI and Waist circumference thresholds. Obesity. 2011; 19:1272-1278. EL 3, SS. [PubMed: 21212770]

47. Sharma AM, Kushner RF. A proposed clinical staging system for obesity. Int J Obes (Lond). 2009; 33:289-295. EL 4; NE theory. [PubMed: 19188927]

48. Flum DR, Belle SH, King WC, et al. Perioperative safety in the longitudinal assessment of bariatric surgery. N Engl J Med. 2009; 361:445-454. EL 2, PCS (large prospective cohort). [PubMed: 19641201]

49. Nguyen NT, Masoomi H, Laugenour K, et al. Predictive factors of mortality in bariatric surgery: data from the Nationwide Inpatient Sample. Surgery. 2011; 150:347-351. EL 3, SS (large database). [PubMed: 21801970]

50. Dixon JB, O'Brien PE, Playfair J, et al. Adjustable gastric banding and conventional therapy for type 2 diabetes. JAMA. 2008; 299:316-323. EL 2; RCT (nonblinded). [PubMed: 18212316]

51. Lee WJ, Chong K, Ser KH, et al. Gastric bypass vs. sleeve gastrectomy for type 2 diabetes mellitus. Arch Surg. 2011; 146:143-148. EL 1; RCT. [PubMed: 21339423]

52. Lee WJ, Wang W, Lee YC, et al. Effect of laparoscopic mini-gastric bypass for type 2 diabetes mellitus: comparison of BMI >35 and <35. J Gastrointest Surg. 2008; 12:945-852. EL 2; PCS. [PubMed: 17940829]

53. Cohen RV, Pinheiro JC, Schiavon CA, et al. Effects of gastric bypass surgery in patients with type 2 diabetes and only mild obesity. Diabetes Care. 2012; 35:1420-1428. EL 2; PCS. [PubMed: 22723580]

54. Choi J, Digiorgi M, Milone L, et al. Outcomes of laparoscopic adjustable gastric banding in patients with low body mass index. Surg Obes Relat Dis. 2010; 6:367-371. EL 2; PCS. [PubMed: 20185374] 
55. Serrot FJ, Dorman RB, Miller CJ, et al. Comparative effectiveness of bariatric surgery and nonsurgical therapy in adults with type 2 diabetes mellitus and body mass indexo35 $\mathrm{kg} / \mathrm{m}^{2}$. Surgery. 2011; 150:684-691. EL 3; SS. [PubMed: 22000180]

56. Fried M, Ribaric G, Buchwald JN, et al. Metabolic surgery for the treatment of type 2 diabetes in patients with BMI $<35 \mathrm{~kg} / \mathrm{m}^{2}$ : an integrative review of early studies. Obes Surg. 2010; 20:776790. EL 4, NE review and analysis. [PubMed: 20333558]

57. Lee WJ, Chong K, Chen CY, et al. Diabetes remission and insulin secretion after gastric bypass in patients with body mass index $035 \mathrm{~kg} / \mathrm{m}^{2}$. Obes Surg. 2011; 21:889-895. EL 2; PCS. [PubMed: 21499957]

58. Demaria EJ, Winegar DA, Pate VW, et al. Early postoperative outcomes of metabolic surgery to treat diabetes from sites participating in the ASMBS bariatric surgery center of excellence program as reported in the Bariatric Outcomes Longitudinal Database. Ann Surg. 2010; 252:559566. EL 3; SS. [PubMed: 20739857]

59. Lee WJ, Ser KH, Chong K, et al. Laparoscopic sleeve gastrectomy for diabetes treatment in nonmorbidly obese patients: efficacy and change of insulin secretion. Surgery. 2010; 147:664669. EL 2; PCS. [PubMed: 20004451]

60. Geloneze B, Geloneze SR, Fiori C, et al. Surgery for nonobese type 2 diabetic patients: an interventional study with duodenal-jejunal exclusion. Obes Surg. 2009; 19:1077-1083. EL 2; NRCT. [PubMed: 19475464]

61. Ramos AC, Galv ao Neto MP, et al. Laparoscopic duodenal-jejunal exclusion in the treatment of type 2 diabetes mellitus in patients with BMI $<30 \mathrm{~kg} / \mathrm{m}^{2}$ (LBMI). Obes Surg. 2009; 19:307-312. EL 2; PCS. [PubMed: 18987919]

62. Li Q, Chen L, Yang Z, et al. Metabolic effects of bariatric surgery in type 2 diabetic patients with body mass indexo35 kg/m². Diabetes Obes Metab. 2012; 14:262-270. EL 2; MNRCT. [PubMed: 22051116]

63. Huang CK, Shabbir A, Lo CH, et al. Laparoscopic Rouxen-Y gastric bypass for the treatment of type II diabetes mellitus in Chinese patients with body mass index of 25-35. Obes Surg. 2011; 21:1344-1349. EL 2, PCS. [PubMed: 21479764]

64. Shah SS, Todkar JS, Shah PS, et al. Diabetes remission and reduced cardiovascular risk after gastric bypass in Asian Indians with body mass indexo35 kg/m². Surg Obes Relat Dis. 2010; 6:332-338. EL 2, PCS. [PubMed: 19846351]

65. Blakemore AI, Froguel P. Investigation of Mendelian forms of obesity holds out the prospect of personalized medicine. Ann NY Acad Sci. 2010; 1214:180-189. EL 4, review. [PubMed: 21175686]

66. Reoch J, Mottillo S, Shimony A, et al. Safety of laparoscopic vs open bariatric surgery: a systematic review and meta-analysis. Arch Surg. 2011; 146:1314-1322. EL 1, MRCT. [PubMed: 22106325]

67. Korner J, Inabnet W, Febres G, et al. Prospective study of gut hormone and metabolic changes after adjustable gastric banding and Roux-en-Y gastric bypass. Int J Obes (Lond). 2009; 33:786795. EL 2, PCS. [PubMed: 19417773]

68. Laferrere B, Teixeira J, McGinty J, et al. Effect of weight loss by gastric bypass surgery versus hypocaloric diet on glucose and incretin levels in patients with type 2 diabetes. J Clin Endocrinol Metab. 2008; 93:2479-2485. EL 2, NRCT. [PubMed: 18430778]

69. Bose M, Teixeira J, Olivan B, et al. Weight loss and incretin responsiveness improve glucose control independently after gastric bypass surgery. J Diabetes. 2010; 2:47-55. EL 2, PCS. [PubMed: 20676394]

70. Vidal J, Ibarzabal A, Romero F, et al. Type 2 diabetes mellitus and the metabolic syndrome following sleeve gastrectomy in severely obese subjects. Obes Surg. 2008; 18:1077-1082. EL 2, NRCT. [PubMed: 18521701]

71. Schulman AP, del Genio F, Sinha N, Rubino F. "Metabolic" surgery for treatment of type 2 diabetes mellitus. Endocr Pract. 2009; 15:624-631. EL 4, NE Review. [PubMed: 19625245]

72. Leslie DB, Dorman RB, Serrot FJ, et al. Efficacy of the Roux-en-Y gastric bypass compared to medically managed controls in meeting the American Diabetes Association composite end point 
goals for management of type 2 diabetes mellitus. Obes Surg. 2012; 22:367-374. EL 3, SS. [PubMed: 21918925]

73. Carlsson LM, Peltonen M, Ahlin S, et al. Bariatric surgery and prevention of type 2 diabetes in Swedish obese subjects. N Engl J Med. 2012; 367:695-704. EL 2, PCS. [PubMed: 22913680]

74. Arterburn DE, Bogart A, Sherwood NE, et al. A multisite study of long-term remission and relapse of type 2 diabetes mellitus following gastric bypass. Obes Surg. 2013; 23:93-102. EL 3, SS. [PubMed: 23161525]

75. Laferrere B. Effect of gastric bypass surgery on the incretins. Diabetes Metab. 2009; 35:513-517. EL 2, NRCT. [PubMed: 20152736]

76. Kashyap SR, Daud S, Kelly KR, et al. Acute effects of gastric bypass versus gastric restrictive surgery on beta-cell function and insulinotropic hormones in severely obese patients with type 2 diabetes. Int J Obes (Lond). 2009; 34:462-471. EL 2, NRCT. [PubMed: 20029383]

77. Cummings DE. Endocrine mechanisms mediating remission of diabetes after gastric bypass surgery. Int J Obes (Lond). 2009; 33(Suppl 1):S33-40. EL 4, NE opinion. [PubMed: 19363506]

78. Peterli R, Wolnerhanssen B, Peters T, et al. Improvement in glucose metabolism after bariatric surgery: comparison of laparoscopic Roux-en-Y gastric bypass and laparoscopic sleeve gastrectomy: a prospective randomized trial. Ann Surg. 2009; 250:234-241. EL 1, RCT (small sample size). [PubMed: 19638921]

79. Mingrone G, Castagneto-Gissey L. Mechanisms of early improvement/resolution of type 2 diabetes after bariatric surgery. Diabetes Metab. 2009; 35:518-523. EL 4, NE review. [PubMed: 20152737]

80. Briatore L, Salani B, Andraghetti G, et al. Beta-cell function improvement after biliopancreatic diversion in subjects with type 2 diabetes and morbid obesity. Obesity (Silver Spring). 2010; 18:932-936. EL 2, PCS. [PubMed: 20186136]

81. Briatore L, Salani B, Andraghetti G, et al. Restoration of acute insulin response in T2DM subjects 1 month after biliopancreatic diversion. Obesity (Silver Spring). 2008; 16:77-81. EL 2, PCS. [PubMed: 18223616]

82. Karamanakos SN, Vagenas K, Kalfarentzos F, Alexandrides TK. Weight loss, appetite suppression, and changes in fasting and postprandial ghrelin and peptide-YY levels after Roux-enY gastric bypass and sleeve gastrectomy: a prospective, double blind study. Ann Surg. 2008; 247:401-407. EL 1, RCT (small sample size). [PubMed: 18376181]

83. Basso N, Capoccia D, Rizzello M, et al. First-phase insulin secretion, insulin sensitivity, ghrelin, GLP-1, and PYY changes $72 \mathrm{~h}$ after sleeve gastrectomy in obese diabetic patients: the gastric hypothesis. Surg Endosc. 2011; 25:3540-3550. EL 2, PCS. [PubMed: 21638183]

84. Valderas JP, Irribarra V, Rubio L, et al. Effects of sleeve gastrectomy and medical treatment for obesity on glucagon-like peptide 1 levels and glucose homeostasis in non-diabetic subjects. Obes Surg. 2011; 21:902-909. EL 2, NRCT. [PubMed: 21347823]

85. Rubino F, Kaplan LM, Schauer PR, Cummings DE. The Diabetes Surgery Summit consensus conference: recommendations for the evaluation and use of gastrointestinal surgery to treat type 2 diabetes mellitus. Ann Surg. 2010; 251:399-405. EL 4, NE consensus. [PubMed: 19934752]

86. Rubino F, Schauer PR, Kaplan LM, Cummings DE. Metabolic surgery to treat type 2 diabetes: clinical outcomes and mechanisms of action. Annu Rev Med. 2010; 61:393-411. EL 4, NE review. [PubMed: 20059345]

87. Laferrere B. Diabetes remission after bariatric surgery: is it just the incretins? Int J Obes (Lond). 2011; 35(Suppl 3):S22-25. EL 4, NE review. [PubMed: 21912382]

88. Lee WJ, Chen CY, Chong K, Lee YC, Chen SC, Lee SD. Changes in postprandial gut hormones after metabolic surgery: a comparison of gastric bypass and sleeve gastrectomy. Surg Obes Relat Dis. 2011; 7:683-690. EL 1, RCT (follow-up study; small sample size). [PubMed: 21996600]

89. Behrens C, Tang BQ, Amson BJ. Early results of a Canadian laparoscopic sleeve gastrectomy experience. Can J Surg. 2011; 54:138-143. EL 3, SS. [PubMed: 21251414]

90. Bellanger DE, Greenway FL. Laparoscopic sleeve gastrectomy, 529 cases without a leak: shortterm results and technical considerations. Obes Surg. 2011; 21:146-150. EL 3, SS. [PubMed: 21132397] 
91. Bobowicz M, Lehmann A, Orlowski M, Lech P, Michalik M. Preliminary Outcomes 1 Year after Laparoscopic Sleeve Gastrectomy Based on Bariatric Analysis and Reporting Outcome System (BAROS). Obes Surg. 2011; 21:1843-1848. EL 2, PCS. [PubMed: 21491136]

92. Breznikar B, Dinevski D. Bariatric surgery for morbid obesity: pre- operative assessment, surgical techniques and postoperative monitoring. J Int Med Res. 2009; 37:1632-1645. EL 3, SS.

[PubMed: 19930873]

93. Chowbey PK, Dhawan K, Khullar R, et al. Laparoscopic sleeve gastrectomy: an Indian experiencesurgical technique and early results. Obes Surg. 2010; 20:1340-1307. EL 3, SS. [PubMed: 19787412]

94. Gadiot RP, Biter LU, Zengerink HJ, et al. Laparoscopic sleeve gastrectomy with an extensive posterior mobilization: Technique and Preliminary Results. Obes Surg. 2012; 22:320-329. EL 3, SS. [PubMed: 21826582]

95. Kiriakopoulos A, Varounis C, Tsakayannis D, Linos D. Laparoscopic sleeve gastrectomy in morbidly obese patients. Technique and short term results. Hormones (Athens). 2009; 8:138-143. EL 2, PCS. [PubMed: 19570741]

96. Lewis CE, Dhanasopon A, Dutson EP, Mehran A. Early experience with laparoscopic sleeve gastrectomy as a single-stage bariatric procedure. Am Surg. 2009; 75:945-949. EL 3, SS. [PubMed: 19886141]

97. Magee CJ, Barry J, Arumugasamy M, Javed S, Macadam R, Kerrigan DD. Laparoscopic sleeve gastrectomy for high-risk patients: weight loss and comorbidity improvement-short-term results. Obes Surg. 2011; 21:547-550. EL 2, PCS. [PubMed: 20623202]

98. Menenakos E, Stamou KM, Albanopoulos K, Papailiou J, Theodorou D, Leandros E. Laparoscopic sleeve gastrectomy performed with intent to treat morbid obesity: a prospective single- center study of 261 patients with a median follow-up of 1 year. Obes Surg. 2010; 20:276-282. EL 2, PCS. [PubMed: 19636644]

99. Ramalingam G, Anton CK. Our 1-Year Experience in Laparoscopic Sleeve Gastrectomy. Obes Surg. 2011; 21:1828-1833. EL 3, SS. [PubMed: 21818646]

100. Rice RD, Simon TE, Seery JM, Frizzi JD, Husain FA, Choi YU. Laparoscopic sleeve gastrectomy: outcomes at a military training center. Am Surg. 2010; 76:835-840. EL 3, SS. [PubMed: 20726413]

101. Sammour T, Hill AG, Singh P, Ranasinghe A, Babor R, Rahman H. Laparoscopic sleeve gastrectomy as a single-stage bariatric procedure. Obes Surg. 2010; 20:271-275. EL 3, SS. [PubMed: 19997786]

102. Stroh C, Birk D, Flade-Kuthe R, et al. Status of bariatric surgery in Germany-results of the nationwide survey on bariatric surgery 2005-2007. Obes Facts. 2009; 2(Suppl 1):2-7. EL 2, PCS. [PubMed: 20124768]

103. Benaiges D, Goday A, Ramon JM, Hernandez E, Pera M, Cano JF. Laparoscopic sleeve gastrectomy and laparoscopic gastric bypass are equally effective for reduction of cardiovascular risk in severely obese patients at one year of follow-up. Surg Obes Relat Dis. 2011; 7:575-580. EL 2, PCS. [PubMed: 21546321]

104. Benedix F, Westphal S, Patschke R, et al. Weight loss and changes in salivary ghrelin and adiponectin: comparison between sleeve gastrectomy and Roux-en-Y gastric bypass and gastric banding. Obes Surg. 2011; 21:616-624. EL 2, NRCT. [PubMed: 21331503]

105. Chouillard EK, Karaa A, Elkhoury M, Greco VJ. Laparoscopic Roux-en-Y gastric bypass versus laparoscopic sleeve gastrectomy for morbid obesity: case-control study. Surg Obes Relat Dis. 2011; 7:500-505. EL 2, RCCS. [PubMed: 21459682]

106. Iannelli A, Anty R, Schneck AS, Tran A, Gugenheim J. Inflammation, insulin resistance, lipid disturbances, anthropometrics, and metabolic syndrome in morbidly obese patients: a case control study comparing laparoscopic Roux-en-Y gastric bypass and laparoscopic sleeve gastrectomy. Surgery. 2011; 149:364-370. EL 2, RCCS. [PubMed: 20932542]

107. Leyba JL, Aulestia SN, Llopis SN. Laparoscopic Rouxen-Y gastric bypass versus laparoscopic sleeve gastrectomy for the treatment of morbid obesity. A prospective study of 117 patients. Obes Surg. 2011; 21:212-216. EL 2, PCS. [PubMed: 20835778] 
108. Nocca D, Guillaume F, Noel P, et al. Impact of laparoscopic sleeve gastrectomy and laparoscopic gastric bypass on $\mathrm{HbA}_{1 \mathrm{c}}$ blood level and pharmacological treatment of type 2 diabetes mellitus in severe or morbidly obese patients. Results of a multicenter prospective study at 1 year. Obes Surg. 2011; 21:738-743. EL 2, PCS. [PubMed: 21468625]

109. Abbatini F, Rizzello M, Casella G, et al. Long-term effects of laparoscopic sleeve gastrectomy, gastric bypass, and adjustable gastric banding on type 2 diabetes. Surg Endosc. 2010; 24:10051010. EL 3, SS. [PubMed: 19866235]

110. de Gordejuela AG, Pujol Gebelli J, Garcia NV, Alsina EF, Medayo LS, Masdevall Noguera C. Is sleeve gastrectomy as effective as gastric bypass for remission of type 2 diabetes in morbidly obese patients? Surg Obes Relat Dis. 2011; 7:506-509. EL 3, SS. [PubMed: 21411376]

111. Garrido-Sanchez L, Murri M, Rivas-Becerra J, et al. Bypass of the duodenum improves insulin resistance much more rapidly than sleeve gastrectomy. Surg Obes Relat Dis. 2012; 8:145-150. EL 2, NRCT. [PubMed: 21570362]

112. Lakdawala MA, Bhasker A, Mulchandani D, Goel S, Jain S. Comparison between the results of laparoscopic sleeve gastrectomy and laparoscopic Roux-en-Y gastric bypass in the Indian population: a retrospective 1 year study. Obes Surg. 2010; 20:1-6. EL 2, RCCS. [PubMed: 19802646]

113. Marantos G, Daskalakis M, Karkavitsas N, Matalliotakis I, Papadakis JA, Melissas J. Changes in metabolic profile and adipoinsular axis in morbidly obese premenopausal females treated with restrictive bariatric surgery. World J Surg. 2011; 35:2022-2030. EL 2, NRCT. [PubMed: 21691870]

114. Omana JJ, Nguyen SQ, Herron D, Kini S. Comparison of comorbidity resolution and improvement between laparoscopic sleeve gastrectomy and laparoscopic adjustable gastric banding. Surg Endosc. 2010; 24:2513-2517. EL 3, SS. [PubMed: 20339873]

115. Topart P, Becouarn G, Ritz P. Comparative early outcomes of three laparoscopic bariatric procedures: sleeve gastrectomy, Roux-en-Y gastric bypass, and biliopancreatic diversion with duodenal switch. Surg Obes Relat Dis. 2012; 8:250-254. EL 3, SS. [PubMed: 21803660]

116. Kehagias I, Karamanakos SN, Argentou M, Kalfarentzos F. Randomized clinical trial of laparoscopic Roux-en-Y gastric bypass versus laparoscopic sleeve gastrectomy for the management of patients with BMI $<50 \mathrm{~kg} / \mathrm{m}^{2}$. Obes Surg. 2011; 21:1650-1656. EL 1, RCT. [PubMed: 21818647]

117. Himpens J, Dapri G, Cadiere GB. A prospective randomized study between laparoscopic gastric banding and laparoscopic isolated sleeve gastrectomy: results after 1 and 3 years. Obes Surg. 2006; 16:1450-1456. EL 1, RCT. [PubMed: 17132410]

118. Lee WJ, Chong K, Ser KH, et al. Gastric bypass vs sleeve gastrectomy for type 2 diabetes mellitus: a randomized controlled trial. Arch Surg. 2011; 146:143-148. EL 1, RCT. [PubMed: 21339423]

119. Woelnerhanssen B, Peterli R, Steinert RE, Peters T, Borbely Y, Beglinger C. Effects of postbariatric surgery weight loss on adipokines and metabolic parameters: comparison of laparoscopic Roux-en-Y gastric bypass and laparoscopic sleeve gastrectomy-a prospective randomized trial. Surg Obes Relat Dis. 2011; 7:561-568. EL 1, RCT (small sample size). [PubMed: 21429816]

120. Brethauer SA, Hammel JP, Schauer PR. Systematic review of sleeve gastrectomy as staging and primary bariatric procedure. Surg Obes Relat Dis. 2009; 5:469-475. EL 2, MNRCT. [PubMed: 19632646]

121. Gill RS, Birch DW, Shi X, et al. Sleeve gastrectomy and type 2 diabetes mellitus: a systematic review. Surg Obes Relat Dis. 2010; 6:707-713. EL 2, MNRCT. [PubMed: 20947447]

122. Hutter MM, Schirmer BD, Jones DB, et al. First report from the American College of Surgeons Bariatric Surgery Center Network: laparoscopic sleeve gastrectomy has morbidity and effectiveness positioned between the band and the bypass. Ann Surg. 2011; 254:410-420. discussion 20-2. EL 3, SS. [PubMed: 21865942]

123. Birkmeyer NJ, Dimick JB, Share D, et al. Hospital complication rates with bariatric surgery in Michigan. JAMA. 2010; 304:435-442. EL 3, SS. [PubMed: 20664044] 
124. Bohdjalian A, Langer FB, Shakeri-Leidenmuhler S, et al. Sleeve gastrectomy as sole and definitive bariatric procedure: 5-year results for weight loss and ghrelin. Obes Surg. 2010; 20:535-540. EL 2, PCS. [PubMed: 20094819]

125. D'Hondt M, Vanneste S, Pottel H, Devriendt D, Van Rooy F, Vansteenkiste F. Laparoscopic sleeve gastrectomy as a single-stage procedure for the treatment of morbid obesity and the resulting quality of life, resolution of comorbidities, food tolerance, and 6-year weight loss. Surg Endosc. 2011; 25:2498-2504. EL 3, SS. [PubMed: 21359900]

126. Himpens J, Dobbeleir J, Peeters G. Long-term results of laparoscopic sleeve gastrectomy for obesity. Ann Surg. 2010; 252:319-324. EL 3, SS. [PubMed: 20622654]

127. Sarela AI, Dexter SP, O'Kane M, Menon A, McMahon MJ. Long- term follow-up after laparoscopic sleeve gastrectomy: 8-9-year results. Surg Obes Relat Dis. 2012; 8:679-684. EL 3, SS. [PubMed: 21890430]

128. Weiner RA, Weiner S, Pomhoff I, Jacobi C, Makarewicz W, Weigand G. Laparoscopic sleeve gastrectomy_influence of sleeve size and resected gastric volume. Obes Surg. 2007; 17:12971305. EL 2, PCS. [PubMed: 18098398]

129. Shi X, Karmali S, Sharma AM, et al. A review of laparoscopic sleeve gastrectomy for morbid obesity. Obes Surg. 2010; 20:1171-1177. EL 2, MNRCT. [PubMed: 20379795]

130. Talebpour M, Amoli BS. Laparoscopic total gastric vertical plication in morbid obesity. J Laparoendosc Adv Surg Tech A. 2007; 17:793-798. EL 2, PCS. [PubMed: 18158812]

131. Skrekas G, Antiochos K, Stafyla VK. Laparoscopic gastric greater curvature plication: results and complications in a series of 135 patients. Obes Surg. 2011; 21:1657-1663. EL 2, PCS. [PubMed: 21898042]

132. Ramos A, Galvao Neto M, Galvao M, Evangelista LF, Campos JM, Ferraz A. Laparoscopic greater curvature plication: initial results of an alternative restrictive bariatric procedure. Obes Surg. 2010; 20:913-918. EL 2, PCS. [PubMed: 20407932]

133. Brethauer SA, Harris JL, Kroh M, et al. Laparoscopic gastric plication for treatment of severe obesity. Surg Obes Relat Dis. 2011; 7:15-22. EL 2, PCS. [PubMed: 21144804]

134. Gould J, Ellsmere J, Fanelli R, et al. Panel report: best practices for the surgical treatment of obesity. Surg Endosc. 2011; 25:1730-1740. EL 3, NE consensus. [PubMed: 21136099]

135. Eaton L, Walsh C, Magnuson T, et al. On-line bariatric surgery information session as effective as in-person information session. Surg Obes Relat Dis. 2012; 8:225-229. EL 2, PCS. [PubMed: 22178563]

136. Sabin J, Fanelli R, Flaherty H, et al. Best practice guidelines on informed consent for weight loss surgery patients. Obes Res. 2005; 13:250-253. EL 4, NE technical review. [PubMed: 15800281]

137. Wee CC, Pratt JS, Fanelli R, et al. Best practice updates for informed consent and patient education in weight loss surgery. Obesity. 2009; 17:885-888. EL 4, NE technical review. [PubMed: 19396067]

138. Raper SE, Sarwer DB. Informed consent issues in the conduct of bariatric surgery. Surg Obes Relat Dis. 2008; 4:60-68. EL 4, NE review. [PubMed: 17974497]

139. Eggers C, Obliers R, Koerfer A, et al. A multimedia tool for the informed consent of patients prior to gastric banding. Obesity. 2007; 15:2866-2873. EL 2, NRCT. [PubMed: 18070779]

140. Heinberg LJ, Keating K, Simonelli L. Discrepancy between ideal and realistic goal weights in three bariatric procedures: who is likely to be unrealistic? Obes Surg. 2010; 20:148-153. EL 2, PCS. [PubMed: 19789932]

141. Kaly P, Orellana S, Torrella T, et al. Unrealistic weight loss expectations in candidates for bariatric surgery. Surg Obes Rel Dis. 2008; 4:6-10. EL 3, SS.

142. White MA, Masheb RM, Rothschild BS, et al. Do patients' unrealistic weight goals have prognostic significance for bariatric surgery? Obes Surg. 2007; 17:74-81. EL 2, PCS. [PubMed: 17355772]

143. Mosko JD, Nguyen GC. Increased perioperative mortality following bariatric surgery among patients with cirrhosis. Clin Gastroenterol Hepatol. 2011; 9:897-901. EL 3, SS. [PubMed: 21782772] 
144. Geerts A, Darius T, Chapelle T, et al. The multicenter Belgian survey on liver transplantation for hepatocellular failure after bariatric surgery. Transplant Proc. 2010; 42:4395-8. EL 3, SS. [PubMed: 21168706]

145. Fris RJ. Preoperative low energy diet diminishes liver size. Obes Surg. 2004; 14:1165-1170. EL 2, PCS. [PubMed: 15527628]

146. Edholm D, Kullberg J, Haenni A, et al. Preoperative 4-week low- calorie diet reduces liver volume and intrahepatic fat, and facilitates laparoscopic gastric bypass in morbidly obese. Obes Surg. 2011; 21:345-350. EL 2, PCS. [PubMed: 21181291]

147. Nieuwnhove YV, Dambrauskas Z, Campillo-Soto A, et al. Preoperative very low-calorie diet and operative outcome after laparoscopic gastric bypass. Arch Surg. 2011; 146:1300-1305. EL 1, RCT (multicenter, single-blinded). [PubMed: 22106323]

148. Alvarado R, Alami RS, Hsu G, et al. The impact of preoperative weight loss in patients undergoing laparoscopic Roux-en-Y gastric bypass. Obes Surg. 2005; 15:1282-1286. EL 3, SS. [PubMed: 16259888]

149. Alami RS, Morton JM, Schuster R, et al. Is there a benefit to preoperative weight loss in gastric bypass patients? A prospective randomized trial. Surg Obes Rel Dis. 2007; 3:141-146. EL 1, RCT.

150. Frutos MD, Morales MD, Lujan J, et al. Intragastric balloon reduces liver volume in super-obese patients, facilitating subsequent laparoscopic gastric bypass. Obes Surg. 2007; 17:150-154. EL 2, PCS. [PubMed: 17476864]

151. Collins J, McCloskey C, Titchner R, et al. Preoperative weight loss in high-risk superobese bariatric patients: a computed tomography-based analysis. Surg Obes Rel Dis. 2011; 7:480-485. EL 2, PCS.

152. Becouarn G, Topart P, Ritz P. Weight loss prior to bariatric surgery is not a pre-requisite of excess weight loss outcomes in obese patients. Obes Surg. 2010; 20:574-577. EL 3, SS. [PubMed: 20174885]

153. Handelsman Y, Mechanick JI, Blonde L, et al. American Association of Clinical Endocrinologists Medical Guidelines for Clinical Practice for Developing a Diabetes Mellitus Comprehensive Care Plan. Endocr Pract. 2011; 17(Suppl 2):1-52. EL 4, NE CPG. [PubMed: 21474420]

154. Hall TC, Pellen MGC, Sedman PC, et al. Preoperative factors predicting remission of type 2 diabetes mellitus after Roux-en-Y gastric bypass surgery for obesity. Obes Surg. 2010; 20:12451250. EL 2, PCS. [PubMed: 20524158]

155. Martins-Filho ED, Camara-Neto JB, Ferraz AAB, et al. Evaluation of risk factors in superobese patients submitted to conventional Fobi- Capella surgery. Arq Gastroenterol. 2008; 45:3-10. EL 2, PCS. [PubMed: 18425221]

156. Perna M, Romagnuolo J, Morgan K, et al. Preoperative hemoglobin $A_{1 c}$ and postoperative glucose control in outcomes after gastric bypass for obesity. Surg Obes Relat Dis. 2012; 6:686690. EL 3, SS.

157. Coupaye M, Sabate JM, Castel B, et al. Predictive factors of weight loss 1 year after laparoscopic gastric bypass in obese patients. Obes Surg. 2010; 20:1671-1677. EL 2, PCS. [PubMed: 20396991]

158. Lee W-J, Chong K, Ser K-H, et al. C-peptide predicts the remission of type 2 diabetes after bariatric surgery. Obes Surg. 2012; 2:293-298. EL 2, PCS. [PubMed: 22139820]

159. Moulin de Moraes CM, Mancini MC, Edna de Melo M, et al. Prevalence of subclinical hypothyroidism in a morbidly obese population and improvement after weight loss induced by Roux- en-Y gastric bypass. Obes Surg. 2005; 15:1287-1291. EL 2, PCS. [PubMed: 16259889]

160. Raftopoulos Y, Gagne DJ, Papasavas P, et al. Improvement of hypothyroidism after laparoscopic Rouxen-Y gastric bypass for morbid obesity. Obes Surg. 2004; 14:509-513. EL 2, PCS. [PubMed: 15130228]

161. Chikunguwo S, Brethauer S, Nirujogi V, et al. Influence of obesity and surgical weight loss on thyroid hormone levels. Surg Obes Relat Dis. 2007; 3:631-636. EL 3, SS. [PubMed: 18023816]

162. Fierabracci P, Pinchera A, Marinelli S, et al. Prevalence of endocrine diseases in morbidly obese patients scheduled for bariatric surgery: beyond diabetes. Obes Surg. 2011; 21:54-60. EL 2, PCS. [PubMed: 20953730] 
163. Jankovic D, Wolf P, Anderwald C-H, et al. Prevalence of endocrine disorders in morbidly obese patients and the effects of bariatric surgery on endocrine and metabolic parameters. Obes Surg. 2012; 22:62-69. EL 3, SS. [PubMed: 22052199]

164. Garber J, Cobin RH, Gharib H, et al. Clinical practice guidelines for hypothyroidism in adults: cosponsored by American Association of Clinical Endocrinologists and the American Thyroid Association. Endocr Pract. 2012; 11:1-207. EL 4, NE CPG.

165. Kashyap SR, Kiab DL, Baker AR, et al. Triglyceride levels and not adipokine concentrations are closely related to severity of nonalcoholic fatty liver disease in an obesity surgery cohort. Obesity. 2009; 17:1696-1701. EL 2, PCS. [PubMed: 19360015]

166. Jellinger PS, Smith DA, Mehta AE, et al. American Association of Clinical Endocrinologists' guidelines for management of dyslipidemia and prevention of atherosclerosis. Endocr Pract. 2012; 18(Suppl 1):1-78. EL 4, NE CPG. [PubMed: 22522068]

167. American College of Obstetricians and Gynecologists. ACOG Practice Bulletin no. 105: bariatric surgery and pregnancy. Obstet Gynecol. 2009; 113:1405-1413. EL 4, position. [PubMed: 19461456]

168. Kominiarek MA. Pregnancy after bariatric surgery. Obstet Gynecol Clin North Am. 2010; 37:305-320. EL 4, review. [PubMed: 20685555]

169. Magdaleno R, Pereira BG, Chaim EA, et al. Pregnancy after bariatric surgery: a current view of maternal, obstetrical and perinatal challenges. Arch Gynecol Obstet. 2012; 285:559-566. EL 4, review. [PubMed: 22205187]

170. Catheline JM, Bihan H, Le Quang T, et al. Preoperative cardiac and pulmonary assessment in bariatric surgery. Obes Surg. 2008; 18:271-277. EL 2, PCS. [PubMed: 18204992]

171. Kwon S, Thompson R, Florence M, et al. b-blocker continuation after noncardiac surgery: a report from the surgical care and outcomes assessment program. Arch Surg. 2012; 147:467-473. EL 3, SS. [PubMed: 22249847]

172. Rasmussen JJ, Fuller WD, Ali MR. Sleep apnea syndrome is significantly underdiagnosed in bariatric surgical patients. Surg Obes Relat Dis. 2012; 5:569-573. EL 3, SS. [PubMed: 21925966]

173. Kolotkin RL, LaMonte MJ, Walker JM, Cloward TV, Davidson LE, Crosby RD. Predicting sleep apnea in bariatric surgery patients. Surg Obes Relat Dis. 2011; 7:605-610. EL 3, SS. [PubMed: 21684219]

174. Daltro C, Gregorio PB, Alves E, et al. Prevalence and severity of sleep apnea in a group of morbidly obese patients. Obes Surg. 2007; 17:809-814. EL 3, CSS. [PubMed: 17879582]

175. Palla A, Digiorgio M, Carpene N, et al. Sleep apnea in morbidly obese patients: prevalence and clinical predictivity. Respiration. 2009; 78:134-40. EL 3, SS. [PubMed: 18936534]

176. Sareli AE, Cantor CR, Williams NN, et al. Obstructive sleep apnea in patients undergoing bariatric surgery-a tertiary center experience. Obes Surg. 2009; 21:316-327. EL 3, SS. [PubMed: 19669842]

177. Lee YH, Johan A, Wong KK, et al. Prevalence and risk factors for obstructive sleep apnea in a multiethnic population of patients presenting for bariatric surgery in Singapore. Sleep Med. 2009; 10:226-232. EL 3, SS. [PubMed: 18387341]

178. Dixon JB, Schachter LM, O'Brien PE. Predicting sleep apnea and excessive day sleepiness in the severely obese: indicators for polysomnography. Chest. 2003; 123:1134-1141. EL 3, SS modeling. [PubMed: 12684304]

179. Marshall NS, Wong KK, Liu PY, et al. Sleep apnea as an independent risk factor for all-cause mortality: the Busselton Health Study. Sleep. 2008; 31:1079-1085. EL 3, SS. [PubMed: 18714779]

180. Flum DR, Belle SH, King WC, et al. Perioperative safety in the longitudinal assessment of bariatric surgery. N Engl J Med. 2009; 361:445-454. EL 2, PCS. [PubMed: 19641201]

181. Schumann R, Jones SB, Cooper B, et al. Update on best practice recommendations for anesthetic perioperative care and pain management in weight loss surgery, 2004-2007. Obesity (Silver Spring). 2009; 17:889-894. EL 4, NE CPG. [PubMed: 19396068] 
182. Fritscher LG, Mottin CC, Canani S, et al. Obesity and obstructive sleep apnea-hypopnea syndrome: the impact of bariatric surgery. Obesity Surgery. 2007; 17:95-99. EL 4, review. [PubMed: 17355775]

183. Felix EL, Kettelle J, Mobley E, Swartz D. Perforated marginal ulcers after laparoscopic gastric bypass. Surg Endosc. 2008; 22:2128-2132. EL 3, SS. [PubMed: 18553197]

184. Gupta PK, Gupta H, Kaushik M, et al. Predictors of pulmonary complications after bariatric surgery. Surg Obes Relat Dis. 2012; 8:574-581. EL 3, SS. [PubMed: 21719358]

185. Gravante G, Araco A, Sorge R, et al. Wound infections in post- bariatric patients undergoing body contouring abdominoplasty: the role of smoking. Obes Surg. 2007; 17:1325-1331. EL 3, SS. [PubMed: 18000726]

186. Gravante G, Araco A, Sorge R, et al. Wound infections in body contouring mastopexy with breast reduction after laparoscopic adjustable gastric bandings: the role of smoking. Obes Surg. 2008; 18:721-727. EL 3, SS. [PubMed: 18365296]

187. Myers K, Hajek P, Hinds C, et al. Stopping smoking shortly before surgery and postoperative complications: a systematic review and meta-analysis. Arch Intern Med. 2011; 171:983-989. EL 2, MNRCT. [PubMed: 21403009]

188. Winegar DA, Sherif B, Pate V, DeMaria EJ. Venous thromboembolism after bariatric surgery performed by Bariatric Surgery Center of Excellence Participants: analysis of the Bariatric Outcomes Longitudinal Database. Surg Obes Relat Dis. 2011; 7:181-188. EL 3, SS. [PubMed: 21421182]

189. Birkmeyer NJ, Share D, Baser O, et al. Preoperative placement of inferior vena cava filters and outcomes after gastric bypass surgery. Ann Surg. 2010; 252:313-318. EL 3, SS. [PubMed: 20622663]

190. Al Akwaa A, El Zubier A, Al Shehri M. Pattern of liver function tests in morbidly obese Saudi patients undergoing bariatric surgery. Saudi J Gastroenterol. 2011; 17:252-255. EL 3, SS. [PubMed: 21727731]

191. Kuper MA, Kratt T, Kramer KM, et al. Effort, safety, and findings of routine preoperative endoscopic evaluation of morbidly obese patients undergoing bariatric surgery. Surg Endosc. 2010; 24:1996-2001. EL 2, PCS. [PubMed: 20135170]

192. Al-Akwaa AM. Prevalence of Helicobacter pylori infection in a group of morbidly obese Saudi patients undergoing bariatric surgery: a preliminary report. Saudi J Gastroenterol. 2010; 16:264267. EL 3, SS. [PubMed: 20871190]

193. Csendes A, Burgos AM, Smok G, et al. Endoscopic and histologic findings of the foregut in 426 patients with morbid obesity. Obes Surg. 2007; 17:28-34. EL 3, SS. [PubMed: 17355765]

194. Erim T, Cruz-Correa MR, Szomstein S, et al. Prevalence of Helicobacter pylori seropositivity among patients undergoing bariatric surgery: a preliminary study. World J Surg. 2008; 32:20212025. EL 3, SS. [PubMed: 18581170]

195. de Moura Almeida A, Cotrim HP, Santos AS, et al. Preoperative upper gastrointestinal endoscopy in obese patients undergoing bariatric surgery: is it necessary? Surg Obes Relat Dis. 2008:144149. EL 3, SS. [PubMed: 18294926]

196. Hartin CW, ReMine DS, Lucktong TA. Preoperative bariatric screening and treatment of Helicobacter pylori. Surg Endosc. 2009; 23:2531-4. EL 3, SS. [PubMed: 19444517]

197. Schirmer B, Erenoglu C, Miller A. Flexible endoscopy in the management of patients undergoing Roux-en-Y gastric bypass. Obes Surg. 2002; 12:634-638. EL 3, SS. [PubMed: 12448383]

198. Yang CS, Lee WJ, Wang HH, et al. The influence of Helicobacter pylori infection on the development of gastric ulcer in symptomatic patients after bariatric surgery. Obes Surg. 2006; 16:735-739. EL 2, PCS. [PubMed: 16756734]

199. Loewen M, Giovanni J, Barba C. Screening endoscopy before bariatric surgery: a series of 448 patients. Surg Obes Relat Dis. 2008; 4:709-712. EL 3, CCS. [PubMed: 18514584]

200. Gould J. Prevalence of Helicobacter pylori infection among patients undergoing bariatric surgery: a preliminary study. World J Surg. 2008; 32:2026-2027. EL 4, NE opinion. [PubMed: 18536991]

201. Friedman JE, Dallal RM, Lord JL. Gout attacks occur frequently in postoperative gastric bypass patients. Surg Obes Relat Dis. 2008; 4:11-13. EL 3, SS. [PubMed: 18065292] 
202. Pull CB. Current psychological assessment practices in obesity surgery programs: what to assess and why. Curr Opin Psychiatry. 2010; 23:30-36. EL 4, NE review. [PubMed: 19926994]

203. Heinberg LJ, Ashton K, Windover A. Moving beyond dichotomous psychological evaluation: The Cleveland Clinic Behavioral Rating System for Weight Loss Surgery. Surg Obes Relat Dis. 2010; 6:185-190. EL 2, PCS. [PubMed: 20096644]

204. Greenberg I, Sogg S, Perna FM. Behavioral and psychological care in weight loss surgery: Best practice update. Obesity. 2009; 17:880-884. EL 4, NE CPG. [PubMed: 19396066]

205. Mahony D. Psychological assessments of bariatric surgery patients. Development, reliability, and exploratory factor analysis of the PsyBari. Obes Surg. 2011; 21:1395-1406. EL 2, PCS. [PubMed: 20306154]

206. Fabricatore AN, Crerand CE, Wadden TA, et al. How do mental health professionals evaluate candidates for bariatric surgery? Survey results. Obes Surg. 2005; 15:567-573. EL 3, SS. [PubMed: 15946440]

207. Peacock JC, Zizzi SJ. An assessment of patient behavioral requirements pre- and post-surgery at accredited weight loss surgical centers. Obes Surg. 2011; 21:1950-1957. EL 3, SS. [PubMed: 21337000]

208. Bauchowitz AU, Gonder-Frederick LA, Olbrisch ME, et al. Psychosocial evaluation of bariatric surgery candidates: a survey of present practices. Psychosom Med. 2005; 67:825-832. EL 3, SS. [PubMed: 16204445]

209. Ambwani S, Boeka AG, Brown JD, et al. Socially desirable responding by bariatric surgery candidates during psychological assessment. Surg Obes Relat Dis. [Epub 2011 Jul 18.] EL 3, SS.

210. Mitchell JE, Steffen KJ, de Zwaan M, et al. Congruence between clinical and research-based psychiatric assessment in bariatric surgical candidates. Surg Obes Relat Dis. 2010; 6:628-634. EL 3, SS. [PubMed: 20727837]

211. Kalarchian MA, Marcus MD, Levine MD, et al. Psychiatric disorders among bariatric surgery candidates: relationship to obesity and functional health status. Am J Psychiatry. 2007; 164:328334. EL 3, SS. [PubMed: 17267797]

212. King WC. Prevalence of Alcohol Use Disorders Before and After Bariatric Surgery. JAMA. 2012; 307:2515-2525. EL 2, PCS.

213. Buffington CK. Alcohol use and health risks: survey results. Bariatric Times. 2007; 4:21-23. EL $3, \mathrm{SS}$.

214. Mitchell JE, Lancaster KL, Burgard MA, et al. Long-term follow-up of patients' status after gastric bypass. Obes Surg. 2001; 11:464-648. EL 2, PCS. [PubMed: 11501356]

215. Ertelt TW, Mitchell JE, Lancaster K, et al. Alcohol abuse and dependence before and after bariatric surgery: a review of the literature and report of a new data set. Surg Obes Relat Dis. 2008; 4:647-650. EL 3, SS. [PubMed: 18420465]

216. Saules KK, Wiedemann A, Ivezaj V, et al. Bariatric surgery history among substance abuse treatment patients: prevalence and associated features. Surg Obes Relat Dis. 2010; 6:615-621. EL 3, SS. [PubMed: 20207591]

217. Clark MM, Balsiger BM, Sletten CD, et al. Psychosocial Factors and 2-Year Outcome Following Bariatric Surgery for Weight Loss. Obes Surg. 2003; 13:739-745. EL 2, PCS. [PubMed: 14627469]

218. Heinberg LJ, Ashton K. History of substance abuse relates to improved postbariatric body mass index outcomes. Surg Obes Relat Dis. 2010; 6:417-421. EL 3, SS. [PubMed: 20655025]

219. Klockhoff H, Naslund I, Jones AW. Faster absorption of ethanol and higher peak concentration in women after gastric bypass surgery. Br J Clin Pharm. 2002; 54:587-591. EL 2, NRCT.

220. Hagedorn JC, Encarnacion B, Brat GA, et al. Does gastric bypass alter alcohol metabolism? Surg Obes Rel Dis. 2007; 3:543-548. EL 2, PCS.

221. Woodard GA, Downey J, Hernandez-Boussard T, et al. Impaired alcohol metabolism after gastric bypass surgery: a case-crossover trial. J Am Coll Surg. 2011; 212:209-214. EL 2, PCS (crossover design). [PubMed: 21183366]

222. Maluenda F, Csendes A, De Aretxabala X, et al. Alcohol absorption modification after a laparoscopic sleeve gastrectomy. Obes Surg. 2010; 20:744-748. EL 2, PCS. [PubMed: 20358306] 
223. Colles SL, Dixon JB, O'Brien PE. Grazing and loss of control related to eating: two high-risk factors following bariatric surgery. Obesity. 2008; 16:615-22. EL 2, PCS. [PubMed: 18239603]

224. Kofman MD, Lent MR, Swencionis C. Maladaptive eating patterns, quality of life and weight outcomes following gastric bypass: Results on an internet survey. Obesity. 2010; 18:1938-1943. EL 3, SS. [PubMed: 20168309]

225. Kruseman M, Leimgruber A, Zumbach F, et al. Dietary, weight, and psychological changes among patients with obesity, 8 years after gastric bypass. J Am Diet Assoc. 2010; 110:527-534. EL 2, PCS. [PubMed: 20338278]

226. deZwaan M, Mitchell JE, Howell LM, et al. Characteristics of morbidly obese patients before gastric bypass surgery. Compr Psychiatry. 2003; 44:428-434. EL 3, SS. [PubMed: 14505305]

227. Hsu LK, Benotti PN, Dwyer JW, et al. Nonsurgical factors that influence the outcome of bariatric surgery: A review. Psychosomatic Med. 1998; 60:338-346. EL 4, NE review.

228. Guisado Macias JA, Vaz Leal FJ. Psychopathological differences between morbidly obese binge eaters and non-binge eaters after bariatric surgery. Eat Weight Dis. 2003; 8:315-318. EL 3, CSS.

229. Sabbioni ME, Dickson MH, Eychmueller S, et al. Intermediate results of health related quality of life after vertical banded gastroplasty. Int J Obes Relat Metab Disord. 2002; 26:277-280. EL 2, PCS. [PubMed: 11850762]

230. Toussi R, Fujioka K, Coleman KJ. Pre-and postsurgery behavioral compliance, patient health, and postbariatric surgical weight loss. Obesity. 2009; 17:966-1002. EL 3, SS.

231. Alger-Mayer S, Rosati C, Polimeni JM, et al. Preoperative binge eating status and gastric bypass surgery: A long-term outcome study. Obes Surg. 2009; 19:139-145. EL 2, PCS. [PubMed: 18478306]

232. White MA, Mashed RM, Rothschild BS, et al. The prognostic significance of regular binge eating in extremely obese gastric bypass patients: 12-month postoperative outcomes. J Clin Psychiatry. 2006; 67:1928-1935. EL 2, PCS. [PubMed: 17194271]

233. Fujioka K, Yan E, Wang HJ, et al. Evaluating preoperative weight loss, binge eating disorder, and sexual abuse history on Roux-en Y gastric bypass outcome. Surg Obes Relat Dis. 2008; 4:137143. EL 3, SS. [PubMed: 18359454]

234. Sarwer DB, Wadden TA, Fabricatore AN. Psychosocial and behavioral aspects of bariatric surgery. Obes Res. 2005; 13:639-648. EL 4, NE review. [PubMed: 15897471]

235. de Zwaan M, Hilbert A, Swan-Kremeier L, et al. Comprehensive interview assessment of eating behavior 18-35 months after gastric bypass surgery for morbid obesity. Surg Obes Relat Dis. 2010; 6:79-87. EL 3, SS. [PubMed: 19837012]

236. White MA, Kalarchian M, Masheb RM, et al. Loss of control over eating predicts outcomes in bariatric surgery patients: a prospective, 24-month follow-up study. J Clin Psychiatry. 2010; 71:175-184. EL 2, PCS. [PubMed: 19852902]

237. Sarwer DB, Dilks RJ, West-Smith L. Dietary intake and eating behavior after bariatric surgery: Threats to weight loss maintenance and strategies for success. Surg Obes Rel Dis. 2011; 7:644651. EL 4, NE opinion.

238. Ashton K, Heinberg L, Windover A, et al. Positive response to binge eating intervention enhances postsurgical weight loss and adherence. Surg Obes Relat Dis. 2011; 7:315-320. EL 2, PCS. [PubMed: 21295526]

239. Wadden TA, Faulconbridge LF, Jones-Corneille LR, et al. Binge eating disorder and the outcome of bariatric surgery at one year: A prospective, observational study. Obesity. 2011; 19:122012208. EL 2, PCS. [PubMed: 21253005]

240. de Luis DA, Pacheco D, Izaola O, et al. Micronutrient status in morbidly obese women before bariatric surgery. Surg Obes Relat Dis. [Epub 2011 Sep 29.] EL 3, SS.

241. Schweiger C, Weiss R, Berry E, et al. Nutritional deficiencies in bariatric surgery candidates. Obes Surg. 2010; 20:193-197. EL 3, SS. [PubMed: 19876694]

242. Ernst B, Thurnheer M, Schmid SM, et al. Evidence for the necessity to systematically assess micronutrient status prior to bariatric surgery. Obes Surg. 2009; 19:66-73. EL 3, SS. [PubMed: 18491197]

243. Nicoletti CF, Lima TP, Donadelli SP, et al. New look at nutritional care for obese patient candidates for bariatric surgery. Surg Obes Relat Dis. [Epub 2011 Aug 28.] EL 3, SS. 
244. Toh SY, Zarshenas N, Jorgensen J. Prevalence of nutrient deficiencies in bariatric patients. Nutrition. 2009; 25:1150-1156. EL 3, SS. [PubMed: 19487104]

245. Alasfar F, Ben-Nakhi M, Khoursheed M, et al. Selenium is significantly depleted among morbidly obese female patients seeking bariatric surgery. Obes Surg. 2011; 21:1710-1713. EL 3, SS. [PubMed: 21633821]

246. Moizé V, Deulofeu R, Torres F, et al. Nutritional intake and prevalence of nutritional deficiencies prior to surgery in a Spanish morbidly obese population. Obes Surg. 2011; 21:1382-1388. EL 3, SS. [PubMed: 21298509]

247. Fish E, Beverstein G, Olson D, et al. Vitamin D status of morbidly obese bariatric surgery patients. J Surg Res. 2010; 164:198-202. EL 3, SS. [PubMed: 20850786]

248. Signori C, Zalesin KC, Franklin B, et al. Effect of gastric bypass on vitamin D and secondary hyperparathyroidism. Obes Surg. 2010; 20:949-952. EL 3, SS. [PubMed: 20443152]

249. Pereira S, Saboya C, Chaves G, et al. Class III obesity and its relationship with the nutritional status of vitamin A in pre- and postoperative gastric bypass. Obes Surg. 2009; 19:738-744. EL 3, SS. [PubMed: 18392900]

250. de Luis DA, Pacheco D, Izaola O, et al. Zinc and copper serum levels of morbidly obese patients before and after biliopancreatic diversion: 4 years of follow-up. J Gastrointest Surg. 2011; 15:2178-2181. EL 3, SS. [PubMed: 21826547]

251. Botella Romero F, Milla Tobarra M, Alfaro Martínez JJ, et al. Bariatric surgery in duodenal switch procedure: weight changes and associated nutritional deficiencies. Endocrinol Nutr. 2011; 58:214-218. EL 3, SS. [PubMed: 21524947]

252. Balsa JA, Botella-Carretero JI, Gómez-Martín JM, et al. Copper and zinc serum levels after derivative bariatric surgery: differences between Roux-en-Y gastric bypass and biliopancreatic diversion. Obes Surg. 2011; 21:744-750. EL 3, SS. [PubMed: 21442375]

253. Aasheim ET, Björkman S, Søvik TT, et al. Vitamin status after bariatric surgery: a randomized study of gastric bypass and duodenal switch. Am J Clin Nutr. 2009; 90:15-22. Erratum in: Am J Clin Nutr, 2010, 91, 239, 240EL 1, RCT. [PubMed: 19439456]

254. Carroll K. Obesity as a risk factor for certain types of cancer. Lipids. 1998; 33:1055-1059. EL 4, NE review. [PubMed: 9870899]

255. Bergstrom A, Pisani P, Tenet V, et al. Overweight as an avoidable cause of cancer in Europe. Int J Cancer. 2001; 91:421-430. Erratum, Int J Cancer, 2001, 92, 927 EL 3, SS meta-analysis of published epidemiological data. [PubMed: 11169969]

256. Peto J. Cancer epidemiology in the last century and the next decade. Nature. 2001; 411:390-395. EL 4, NE review. [PubMed: 11357148]

257. Chow W-H, Blot WJ, Vaughan TL, et al. Body mass index and risk of adenocarcinomas of the esophagus and gastric cardia. J Natl Cancer Inst. 1998; 90:150-155. EL 3, SS. [PubMed: 9450576]

258. Vaughan TL, Davis S, Kristal A, Thomas DB. Obesity, alcohol, and tobacco as risk factors for cancers of the esophagus and gastric cardia: adenocarcinoma versus squamous cell carcinoma. Cancer Epidemiol Biomarkers Prev. 1995; 4:85-92. EL 3, SS. [PubMed: 7742727]

259. Calle EE, Rodriguez C, Walker-Thurmond K, et al. Overweight, obesity, and mortality from cancer in a prospectively studied cohort of U.S. adults. N Engl J Med. 2003; 348:1625-1638. EL 2, PCS. [PubMed: 12711737]

260. Gagné DJ, Papasavas PK, Maalout M, et al. Obesity surgery and malignancy: our experience after 1500 cases. Surg Obes Relat Dis. 2009; 5:160-164. EL 3, SS. [PubMed: 18849199]

261. Pilone V, Tramontano S, Formato A, et al. Role of bariatric surgery in early detection of renal cell carcinoma: report of two cases and review of the literature. Chir Ital. 2008; 60:703-709. EL 3, CCS. [PubMed: 19062493]

262. Ashrafian H, Ahmed K, Rowland SP, et al. Metabolic surgery and cancer: protective effects of bariatric procedures. Cancer. 2011; 117:1788-1199. EL 4, NE review. [PubMed: 21509756]

263. Winfree LE, Henretta MS, Hallowell PT, et al. Preoperative gynecologic evaluation of bariatric surgery patients: improving cancer detection in a high-risk population. J Am Coll Surg. 2010; 211:256-262. EL 3, SS. [PubMed: 20670865] 
264. Sarwer DB, Moore RH, Spitzer JC, et al. A pilot study investigating ther efficacy of postoperative dietary counseling to improve outcomes after bariatric surgery. Surg Obes Relat Dis. 2012; 8:561-568. EL 1, RCT. [PubMed: 22551576]

265. Kulick D, Hark L, Deen D. The bariatric surgery patient: a growing role for registered dietitians. J Am Diet Assoc. 2010; 110:593-599. EL 4, NE position. [PubMed: 20338285]

266. Ziegler O, Sirveaux MA, Brunaud L, et al. Medical follow up after bariatric surgery: nutritional and drug issues. General recommendations for the prevention and treatment of nutritional deficiencies. Diabetes Metab. 2009; 35:544-557. EL 4, NE consensus. [PubMed: 20152742]

267. Faria SL. Dietary protein intake and bariatric surgery. Obes Surg. 2011; 21:1798-1805. EL 4, NE review. [PubMed: 21590346]

268. Raftopoulos I. Protein intake compliance with morbidly obese patients undergoing bariatric surgery and its effect on weight loss and biochemical parameters. Surg Obes Relat Dis. 2011; 7:733-742. EL 2, PCS. [PubMed: 21925961]

269. Billy, H.; Okerson, T. Changes in body composition following gastric bypass or gastric banding. AACE 21st Annual Scientific and Clinical Congress; May 23-27, 2012; Philadelphia, Pennslyvania. Abstract \#1315. EL 3, SS

270. Bavaresco M, Paganini S, Pereira Lima T, et al. Nutritional course of patients submitted to bariatric surgery. Obes Surg. 2010; 20:716-721. EL 2, PCS. [PubMed: 18931884]

271. Andreu A, Moize V, Rodriguez L, et al. Protein intake, body composition, and protein status following bariatric surgery. Obes Surg. 2010; 20:1509-1515. EL 2, PCS. [PubMed: 20820937]

272. Moize VL, Pi-Sunyer X, Mochari H, et al. Nutritional pyramid for post-gastric bypass patients. Obes Surg. 2010; 20:1133-1141. EL 4, NE review. [PubMed: 20401543]

273. Padwal R, Brocks D, Sharma AM. A systematic review of drug absorption following bariatric surgery and its theoretical implications. Obes Rev. 2010; 11:41-50. EL 4, review. [PubMed: 19493300]

274. Miller AD, Smith KM. Medication and nutrient administration considerations after bariatric surgery. Am J Health Syst Pharm. 2006; 63:1852-1857. EL 4, review. [PubMed: 16990631]

275. Donadelli SP, Junqueira-Franco MV, de Mattos Donadelli CA, et al. Daily vitamin supplementation and hypovitaminosis after obesity surgery. Nutrition. 2012; 28:391-396. EL 2, PCS. [PubMed: 22055480]

276. Aills L, Blankenship J, Buffington C, et al. ASMBS Allied Health Nutritional Guidelines for the Surgical Weight Loss Patient Surgery for Obesity and Related Diseases. Surg Obes Relat Dis. 2008:S73-S108. EL 4, NE CPG. [PubMed: 18490202]

277. Malone M. Recommended nutritional supplements for bariatric surgery patients. Ann Pharmacother. 2008; 42:1851-1858. EL 4, NE review. [PubMed: 19017827]

278. Munoz M, Botella-Romero F, Gomez-Ramirez S, et al. Iron deficiency and anemia in bariatric surgical patients: causes, diagnosis and proper management. Nutr Hosp. 2009; 24:640-654. EL 4, NE review. [PubMed: 20049366]

279. Ledoux S, Coupaye M, Bogard C, et al. Determinants of hyperhomocysteinemia after gastric bypass surgery in obese subjects. Obes Surg. 2011; 21:78-86. EL 2, PCS. [PubMed: 20814760]

280. Vieira C, Cosmo C, Lucena R. The importance of methylmalonic acid dosage on the assessment of patients with neurological manifestations following bariatric surgery. Obes Surg. 2011; 21:1971-1974. EL 3, SCR. [PubMed: 21688116]

281. Li K, Kaaks R, Linseisen J, et al. Associations of dietary calcium intake and calcium supplementation with myocardial infarction and stroke risk and overall cardiovascular mortality in the Heidelberg cohort of the European Prospective Investigation into Cancer and Nutrition study (EPIC-Heidelberg). Heart. 2012; 98:920-925. EL 2, PCS. [PubMed: 22626900]

282. Goldner WS, Stoner JA, Lyden E, et al. Finding the optimal dose of vitamin D following Rouxen-Y gastric bypass: a prospective, randomized pilot clinical trial. Obes Surg. 2009; 19:173-179. EL 1, RCT. [PubMed: 18795378]

283. Holick MF, Binkley NC, Bischoff-Farrari HA, et al. Guidelines on vitamin D deficiency. J Clin Endocrinol Metab. 2011; 96:1911-1930. EL 4, NE position. [PubMed: 21646368] 
284. Kondrup J, Rasmussen HH, Hamberg O, et al. Nutritional risk screening (NRS 2002): a new method based on an analysis of controlled clinical trials. Clin Nutr. 2003; 22:321-336. EL 3, SS. [PubMed: 12765673]

285. Martindale RG, McClave SA, Vanek VW, et al. Guidelines for the provision and assessment of nutrition support therapy in the adult critically ill patient: Society of Critical Care Medicine and American Society for Parenteral and Enteral Nutrition: Executive Summary. Crit Care Med. 2009; 37:277-316. EL 4, NE CPG.

286. Singer P, Berger MM, Van den Berghe G, et al. ESPEN guidelines on parenteral nutrition: intensive care. Clin Nutr. 2009; 28:387-400. EL 4, NE CPG. [PubMed: 19505748]

287. Heyland DK, Dhaliwal R, Drover JW, et al. Canadian clinical practice guidelines for nutrition support in mechanically ventilated, critically ill adult patients. J Parenter Enteral Nutr. 2003; 27:355-373. EL 4, NE CPG.

288. Martindale RG, DeLegge M, McClave S, et al. Nutrition delivery for obese ICU patients: delivery issues, lack of guidelines, and missed opportunities. J Parenter Enteral Nutr. 2011; 35(Suppl 1): 80S-87. S. EL 4, NE review.

289. Morales MP, Miedema BW, Scott JS, et al. Management of postsurgical leaks in the bariatric patient. Gastrointest Endoscopy Clin N Am. 2011; 21:295-304. EL 4, NE review.

290. Segaran E. Symposium 7: Downsize me. Provision of nutritional support to those experiencing complications following bariatric surgery. Proceedings Nutr Soc. 2010; 69:536-542. EL 4, NE review.

291. Hamilton C, Dasari V, Shatnawei A, et al. Hypocaloric home parenteral nutrition and nutrition parameters in patients following bariatric surgery. Nutr Clin Pract. 2011; 26:577-582. EL 3, SS. [PubMed: 21947640]

292. Schlienger J-L, Pradignac A, Luca F, et al. Medical management of diabetes after bariatric surgery. Diab Metab. 2009; 35:558-561. EL 4, NE review.

293. Joseph B, Genaw J, Carlin A, et al. Perioperative tight glycemic control: the challenge of bariatric surgery patients and the fear of hypoglycemic events. Permanente J. 2007; 11:36-39. EL 3, SS.

294. Aberle J, Reining F, Dannheim V, et al. Metformin after bariatric surgery-an acid problem. Exp Clin Endocrinol Diabetes. 2012; 120:152-153. EL 2, PCS. [PubMed: 21915819]

295. Padwal RS, Gabr RQ, Sharma AM, et al. Effect of gastric bypass surgery on the absorption and bioavailability of metformin. Diabetes Care. 2011; 34:1295-1300. EL 2, NRCT. [PubMed: 21478461]

296. Rothkopf MM, Bilof ML, Haverstick LP, et al. Synergistic weight loss and diabetes resolution with exenatide administration after laparoscopic gastric banding. Surg Obes Relat Dis. 2009; 5:128-131. EL 3, SCR. [PubMed: 18996762]

297. Chiumello D, Chevallard G, Gregoretti C. Non-invasive ventilation in postoperative patients: a systematic review. Intensive Care Med. 2011; 37:918-929. EL 4, NE review. [PubMed: 21424246]

298. Gupta PK, Gupta H, Kaushik M, et al. Predictors of pulmonary complications after bariatric surgery. Surg Obes Relat Dis. 2012; 8:574-581. EL 3, SS. [PubMed: 21719358]

299. Ramirez A, Lalor PF, Szomstein S, et al. Continuous positive airway pressure in immediate postoperative period after laparoscopic Roux- en-Y gastric bypass: is it safe? Surg Obes Relat Dis. 2009; 5:544-546. EL 3, SS. [PubMed: 19640798]

300. Geerts WH, Bergqvist D, Pineo GF, et al. Prevention of venous thromboembolism: American College of Chest Physicians Evidence- Based Clinical Practice Guidelines (8th Edition). Chest. 2008; 133:381S-453. S. EL 4, NE CPG. [PubMed: 18574271]

301. Magee CJ, Barry J, Javed S, et al. Extended thromboprophylaxis reduces incidence of postoperative venous thromboembolism in laparoscopic bariatric surgery. Surg Obes Relat Dis. 2010; 6:322-325. EL 3, SS. [PubMed: 20510295]

302. Raftopoulos I, Martindale C, Cronin A, et al. The effect of extended post-discharge chemical thromboprophylaxis on venous thromboembolism rates after bariatric surgery: a prospective comparison trial. Surg Endosc. 2008; 22:2384-2391. EL 2, PCS. [PubMed: 18622558] 
303. Winegar DA, Sherif B, Pate V, et al. Venous thromboembolism after bariatric surgery performed by Bariatric Surgery Center of Excellence Participants: analysis of the Bariatric Outcomes Longitudinal Database. Surg Obes Relat Dis. 2011; 7:181-188. EL 3, SS. [PubMed: 21421182]

304. Birkmeyer NJ, Share D, Baser O, et al. Preoperative placement of inferior vena cava filters and outcomes after gastric bypass surgery. Ann Surg. 2010; 252:313-318. EL 3, SS. [PubMed: 20622663]

305. de Aretxabala X, Leon J, Wiedmaier G, et al. Gastric leak after sleeve gastrectomy: analysis of its management. Obes Surg. 2011; 21:1232-1237. EL 3, CCS (small sample size; N=9). [PubMed: 21416198]

306. Bellanger DE, Greenway FL. Laparoscopic sleeve gastrectomy, 529 cases without a leak: shortterm results and technical considerations. Obes Surg. 2011; 21:146-150. EL 3, SS. [PubMed: 21132397]

307. Aurora AR, Khaitan L, Saber AA. Sleeve gastrectomy and the risk of leak: a systematic analysis of 4,888 patients. Surg Endosc. 2012; 26:1509-1515. EL 2, MNRCT. [PubMed: 22179470]

308. Triantafyllidis G, Lazoura O, Sioka E, et al. Anatomy and complications following laparoscopic sleeve gastrectomy: radiological evaluation and imaging pitfalls. Obes Surg. 2011; 21:473-478. EL 3, CCS. [PubMed: 20652760]

309. Marquez MF, Ayza MF, Lozano RB, et al. Gastric leak after laparoscopic sleeve gastrectomy. Obes Surg. 2010; 20:1306-1311. EL 4, NE review. [PubMed: 20574787]

310. Gagner M. Leaks after sleeve gastrectomy are associated with smaller bougies: prevention and treatment strategies. Surg Laparosc Endosc Percutan Tech. 2010; 20:166-169. EL 4, NE opinion. [PubMed: 20551815]

311. The ASMBS Clinical Issues Committee. ASMBS Guideline on the prevention and detection of gastrointestinal leak after gastric bypass including the role of imaging and surgical exploration. Surg Obes Relat Dis. 2009; 5:293-296. EL 4, NE, position. [PubMed: 19356997]

312. Warschkow R, Tarantino I, Folie P, et al. C-reactive protein 2 days after laparoscopic gastric bypass surgery reliably indicates leaks and moderately predicts morbidity. J Gastrointest Surg. 2012; 16:1128-1135. EL 3, SS. [PubMed: 22528569]

313. Lyass S, Khalili TM, Cunneen S, et al. Radiological studies after laparoscopic Roux-en-Y gastric bypass: routine or selective? Am Surg. 2004; 70:918-921. EL 3, SS. [PubMed: 15529851]

314. Carussi LR, Turner MA, Conklin RC, et al. Roux-en-Y gastric bypass surgery for morbid obesity: evaluation of postoperative extraluminal leaks with upper gastrointestinal series. Radiology. 2006; 238:119-127. EL 3, SS. [PubMed: 16373763]

315. Mognol P, Vignes SM, Chosidow D, et al. Rhabdomyolysis after pararoscopic bariatric surgery. Obes Surg. 2004; 14:91-94. EL 2, PCS. [PubMed: 14980040]

316. Wool DB, Lemmens HJ, Brodsky JB, et al. Intraoperative fluid replacement and postoperative creatine phosphokinase levels in laparoscopic bariatric patients. Obes Surg. 2010; 20:698-701. EL 1, RCT (single-blinded). [PubMed: 20198451]

317. Youssef T, Abd-Elaal I, Zakaria G, et al. Bariatric surgery: Rhabdomyolysis after open Roux-enY gastric bypass: a prospective study. Int J Surg. 2010; 8:484-488. EL 2, PCS. [PubMed: 20624497]

318. El Chaar M, McDeavitt K, Richardson S, et al. Does patient compliance with preoperative bariatric office visits affect postoperative excess weight loss? Surg Obes Relat Dis. 2011; 7:743748. EL 3, SS. [PubMed: 21256092]

319. Shen R, Dugay G, Rajaram K, et al. Impact of patient follow-up on weight loss after bariatric surgery. Obes Surg. 2004; 14:514-519. EL 3, SS. [PubMed: 15130229]

320. Dixon JB, Laurie CP, Anderson ML, et al. Motivation, readiness to change, and weight loss following adjustable gastric band surgery. Obesity (Silver Spring). 2009; 17:698-705. EL 3, SS. [PubMed: 19148126]

321. Weichman K, Ren C, Kurian M, et al. The effectiveness of adjustable gastric banding: a retrospective 6-year U.S. follow-up study. Surg Endosc. 2011; 25:397-403. EL 3, SS. [PubMed: 20574855] 
322. Kofman MD, Lent MR, Swencionis C. Maladaptive eating patterns, quality of life, and weight outcomes following gastric bypass: results of an internet survey. Obesity. 2010; 18:1938-43. EL 3, SS. [PubMed: 20168309]

323. Rutledge T, Groez LM, Savu M. Psychiatric factors and weight loss patterns following gastric bypass surgery in a veteran population. Obes Surg. 2011; 21:29-35. EL 2, PCS. [PubMed: 19847571]

324. Odom J, Zalesin KC, Washington TL. Behavioral Predictors of Weight Regain after Bariatric Surgery. Obes Surg. 2010; 20:349-356. EL 3, SS. [PubMed: 19554382]

325. Faria SL, de Olivera Kelly E, Lins RD. Nutritional Management of Weight Regain After Bariatric Surgery. Obes Surg. 2010; 20:135-139. EL 2, PCS. [PubMed: 18575942]

326. Langer FB, Bohdjalian A, Shakeri-Manesch S. Inadequate Weight Loss vs Secondary Weight Regain: Laparoscopic Conversion from Gastric Banding to Rouxen-Y Gastric Bypass. Obes Surg. 2008; 18:1381-1386. EL 2, PCS. [PubMed: 18438619]

327. Yimcharoen P, Heneghan HM, Singh M. Endoscopic findings and outcomes of revisional procedures for patients with weight recidivism after gastric bypass. Surg Endosc. 2011; 25:33453352. EL 3, SS. [PubMed: 21533520]

328. Kellogg TA. Revisional Bariatric Surgery. Surg Clin N Am. 2011; 91:1353-1371. EL 4, NE review. [PubMed: 22054158]

329. Ziegler O, Sirveaux MA, Brunaud L, et al. Medical followup after bariatric surgery: nutritional and drug issues. Diab Metab. 2009; 35:544-557. EL 4, NE review.

330. Koch TR, Finelli FC. Postoperative metabolic and nutritional complications of bariatric surgery. Gastroenterol Clin N Am. 2010; 39:109-124. EL 4, NE review.

331. Ceppa EP, Ceppa DP, Omotosho PA, Dickerson JA 2nd, Park CW, Portenier DD. Algorithm to diagnose etiology of hypoglycemia after Roux-en-Y gastric bypass for morbid obesity: case series and review of the literature. Surg Obes Relat Dis. 2012; 8:641-647. EL 3, CCS. [PubMed: 21982939]

332. Cui Y, Elahi D, Andersen DK. Advances in the etiology and management of hyperinsulinemic hypoglycemia after Roux-en-Y gastric bypass. J Gastrointest Surg. 2011; 15:1879-1888. EL 3, CCS. [PubMed: 21671112]

333. Bernard B, Kline GA, Service FJ. Hypoglycemia following upper gastrointestinal surgery: case report and review of the literature. BMC Gastroenterology. 2010; 10:77-80. EL 3, SCR. [PubMed: 20615254]

334. Spanakis E, Gragnoli C. Successful medical management of status post-Roux-en-Y-gastricbypass hyperinsulinemic hypoglycemia. Obes Surg. 2009; 19:1333-1334. EL 3, SCR. [PubMed: 19551453]

335. Moreira RO, Moreira RBM, Machado NAM, et al. Postprandial hypoglycemia after bariatric surgery: pharmacological treatment with verapamil and acarbose. Obes Surg. 2008; 18:16181621. EL 3, SCR. [PubMed: 18566871]

336. Z'graggen K, Guweidhi A, Steffen R, et al. Severe recurrent hypoglycemia after gastric bypass surgery. Obes Surg. 2008; 18:981-988. EL 2, PCS (small study; N=12). [PubMed: 18438618]

337. Abellan P, Camara R, Merino-Torres JF, et al. Severe hypoglycemia after gastric bypass surgery for morbid obesity. Diab Res Clin Pract. 2008; 79:e7-9. EL 3, SCR.

338. Wouters EJ, Larsen JK, Zijlstra H, et al. Physical activity after surgery for severe obesity: the role of exercise cognitions. Obes Surg. 2011; 21:1894-1899. EL 2, PCS. [PubMed: 20835924]

339. Josbeno DA, Kalarchian M, Sparto PJ, et al. Physical activity and physical function in individuals post-bariatric surgery. Obes Surg. 2011; 21:1243-1249. EL 2, PCS. [PubMed: 21153567]

340. Livhits M, Mercado C, Yermilov I, et al. Behavioral factors associated with successful weight loss after gastric bypass. Am Surg. 2010; 76:1139-1142. EL 3, SS. [PubMed: 21105629]

341. Hatoum IJ, Stein HK, Merrifield BF, et al. Capacity for physical activity predicts weight loss after Roux-en-Y gastric bypass. Obesity. 2008; 17:92-99. EL 2, PCS. [PubMed: 18997674]

342. Stegen S, Derave W, Calders P, et al. Physical fitness in morbidly obese patients: effet of gastric bypass surgery and exercise training. Obes Surg. 2011; 21:61-70. EL 2, NRCT. [PubMed: 19997987] 
343. Castello V, Simoes P, Bassi D, et al. Impact of aerobic exercise training on heart rate variability and functional capacity in obese women after gastric bypass surgery. Obes Surg. 2011;21:17391749. EL 1, RCT (findings limited by generalizability and relevance of dysautonomia on overall outcomes). [PubMed: 21104041]

344. Shah M, Snell PG, Rao S, et al. High-volume exercise program in obese bariatric surgery patients: a randomized, controlled trial. Obesity. 2011; 19:1826-1834. EL 1, RCT (findings limited by methodological flaws in exercise program and individual dietary counseling rather than group counseling). [PubMed: 21681226]

345. Egberts K, Brown WA, Brennan L, et al. Does exercise improve weight loss after bariatric surgery? A systematic review. Obes Surg. 2012; 22:335-341. EL 2, MNRCT. [PubMed: 22038571]

346. Livhits M, Mercado C, Yermilov I, et al. Exercise following bariatric surgery: systematic review. Obes Surg. 2010; 20:657-665. EL 2, MNRCT. [PubMed: 20180039]

347. Jacobi D, Ciangura C, Couet C, et al. Physical activity and weight loss following bariatric surgery. Obes Rev. 2011; 12:366-377. EL 2, MNRCT. [PubMed: 20331508]

348. Livhits M, Mercado C, Yermilov I, et al. Is social support associated with greater weight loss after bariatric surgery?: a systematic review. Obes Reviews. 2011; 12:142-148. EL 2, MNRCT.

349. Orth WS, Madan AK, Taddeucci RJ, et al. Support group meeting attendance is associated with better weight loss. Obes Surg. 2008; 18:391-394. EL 3, SS. [PubMed: 18286346]

350. Song Z, Reinhardt K, Busdon M, et al. Association between support group attendance and weight loss after Roux-en-Y gastric bypass. Surg Obes Relat Dis. 2008; 4:100-103. EL 3, SS. [PubMed: 17400030]

351. Elakkary E, Elhorr A, Aziz F, et al. Do support groups play a role in weight loss after laparoscopic adjustable gastric banding? Obes Surg. 2006; 16:331-334. EL 3, SS. [PubMed: 16545165]

352. Kaiser KA, Franks SF, Smith AB. Positive relationship between support group attendance and one-year postoperative weight loss in gastric banding patients. Surg Obes Relat Dis. 2011; 7:8993. EL 3, SS. [PubMed: 20947449]

353. Gómez JM, Vilarrasa N, Masdevall C, et al. Regulation of bone mineral density in morbidly obese women: a cross-sectional study in two cohorts before and after by-pass surgery. Obes Surg. 2009; 19:345-350. EL 3, CSS. [PubMed: 18443887]

354. Scibora LM, Ikramuddin S, Buchwald H, et al. Examining the link between bariatric surgery, bone loss, and osteoporosis: a review of bone density studies. Obes Surg. 2012; 22:654-667. EL 4, NE review. [PubMed: 22271358]

355. Williams SE. Metabolic bone disease in bariatric surgery patients. J Obes. 2011; 2011:634614. EL 4, NE review. [PubMed: 21274274]

356. Kumar R, Lieske JC, Collazo-Clavell ML, et al. Fat malabsorption and increased oxalate absorption are common after roux-en-Y gastric bypass surgery. Surgery. 2011; 149:654-661. EL 2, PCS. [PubMed: 21295813]

357. Sakhaee K, Griffith C, Pak CY. Biochemical control of bone loss and stone-forming propensity by potassium-calcium citrate after bariatric surgery. Surg Obes Relat Dis. 2012; 8:67-72. EL 1, RCT (2-phase, crossover, blinding not mentioned). [PubMed: 21703942]

358. Okombo J, Liebman M. Probiotic-induced reduction in gastrointestinal oxalate absorption in healthy subjects. Urol Res. 2010; 38:169-178. EL 2, PCS. [PubMed: 20224931]

359. Woodward GA, Encarnacion B, Downey JR, et al. Probiotics improve outcomes after Roux-en-Y gastric bypass surgery: a prospective randomized trial. J Gastrointest Surg. 2009; 13:1198-1204. EL 1, RCT ( $=$ 41, double-blinded). [PubMed: 19381735]

360. Butler C, Vidal-Alaball J, Cannings-John R, et al. Oral vitamin b12 versus intramuscular vitamin B12 for b12 deficiency: a systematic review of randomized controlled trials. Fam Pract. 2006; 23:279-285. EL 1, MRCT. [PubMed: 16585128]

361. Salle A, Demarsy D, Poirier AL, et al. Zinc deficiency: a frequent and underestimated complication after bariatric surgery. Obes Surg. 2010; 20:1660-1670. EL 3, SS. [PubMed: 20706804] 
362. Rosa FT, de Oliveira-Penaforte FR, de Arruda Leme I, et al. Altered plasma response to zinc and iron tolerance test after Roux-en-Y gastric bypass. Surg Obes Relat Dis. 2011; 7:309-314. EL 2, PCS. [PubMed: 21429817]

363. Lakhani SV, Shah HN, Alexander K, et al. Small intestinal bacterial overgrowth and thiamine deficiency after Roux-en-Y gastric bypass surgery in obese patients. Nutr Res. 2008; 28:293298. EL 3, SS. [PubMed: 19083422]

364. Perna M, Baker M, Byrne TK, et al. Statins and the bariatric patient: characterization and perioperative effects of statin therapy in the gastric bypass patient. Am Surg. 2011; 77:44-47. EL 3, SS. [PubMed: 21396304]

365. Ahmed AR, Rickards G, Coniglio D, et al. Laparoscopic Roux-en-Y gastric bypass and its early effect on blood pressure. Obes Surg. 2009; 19:845-849. EL 2, PCS. [PubMed: 18758869]

366. Batsis JA, Romero-Corral A, Collazo-Clavell ML, et al. Effect of bariatric surgery on the metabolic syndrome: a population-based, long-term controlled study. Mayo Clin Proc. 2008; 83:897-907. EL 2, PCS (non-matched. [PubMed: 18674474]

367. Delling L, Karason K, Olbers T, et al. Feasibility of bariatric surgery as a strategy for secondary prevention in cardiovascular disease: a report from the Swedish obese subjects trial. J Obes. 2010; 2010 pii: 102341. EL 2, PCS.

368. Straznicky N, Grassi G, Esler M, et al. European Society of Hypertension Working Group on Obesity anti-hypertensive effects of weight loss: myth or reality? J Hypertens. 2010; 28:637-643. EL 4, NE consensus. [PubMed: 20125037]

369. Straznicky NE, Grima MT, Eikelis N, et al. The effects of weight loss versus weight loss maintenance on sympathetic nervous system activity and metabolic syndrome components. J Clin Endocrinol Metab. 2011; 96:E503-508. EL 2, PCS. [PubMed: 21177786]

370. Potoczna N, Harfmann S, Steffen R, et al. Bowel habits after bariatric surgery. Obesity Surg. 2008; 18:1287-1296. EL 3, SS.

371. Felix EL, Kettelle J, Mobley E, et al. Perforated marginal ulcers after laparoscopic gastric bypass. Surg Endosc. 2008; 22:2128-2132. EL 3, SS. [PubMed: 18553197]

372. Sasse KC, Ganser J, Kozar M, et al. Seven cases of gastric perforation in Roux-en-Y gastric bypass patients: what lessons can we learn? Obes Surg. 2008; 18:530-534. EL 3, SS. [PubMed: 18324450]

373. Ryou M, Mogabgab O, Lautz DB, et al. Endoscopic foreign body removal for treatment of chronic abdominal pain in patients after Roux-en-Y gastric bypass. Surg Obes Relat Dis. 2010; 6:526-531. EL 3, SS. [PubMed: 20870185]

374. Deylgat BD, Hondt M, Pottel H, et al. Indications, safety, and feasibility of conversion of failed bariatric surgery to Roux-en-Y gastric bypass: a retrospective comparative study with primary laparoscopic Roux-en-Y gastric bypass. Surg Endosc. 2012; 26:1997-2002. EL 3, SS (56 revisional procedures for RYGB). [PubMed: 22258299]

375. Morales MP, Wheeler AA, Ramaswamy A, et al. Laparoscopic revisional surgery after Roux-enY gastric bypass and sleeve gastrectomy. Surg Obes Relat Dis. 2010; 6:485-490. EL 3, SS (23 revisional procedures for RYGB). [PubMed: 20870181]

376. Salimath J, Rosenthal RJ, Szomstein S. Laparoscopic remnant gastrectomy as a novel approach for treatment of gastrogastric fistula. Surg Endosc. 2009; 23:2591-2595. EL 3, SS (22 revisional procedures for RYGB). [PubMed: 19462204]

377. Tucker ON, Escalante-Tattersfield T, Szomstein S, et al. Laparoscopic management of chronic gastric pouch fistula after laparoscopic gastric bypass. Surg Obes Relat Dis. 2009; 5:278-9. EL 3, SCR. [PubMed: 19026597]

378. Madan AK, Dhawan N, Ternovits CA, et al. Laparoscopic repair of a staple-line disruption after an open uncut Rouxen-Y gastric bypass. Obes Surg. 2008; 18:340-344. EL 3, SCR. [PubMed: 18219542]

379. Hil MW, Clarke NE, Hopkins GH. Gastrogastric herniation: an unusual complication following greater curve plication for the treatment of morbid obesity. Ann R Coll Surg Engl. 2012; 94:e7678. EL 3, SCR. [PubMed: 22391359] 
380. Lautz, Flicker MS.; Thompson, CC. Endoscopic management of gastrogastric fistulae does not increase complications at bariatric revision surgery. J Gastrointest Surg. 2011; 15:1736-1742. EL 3, SS. [PubMed: 21479671]

381. Bhardwaj A, Cooney RN, Wehrman A, et al. Endoscopic repair of small symptomatic gastrogastric fistulas after gastric bypass surgery: a single center experience. Obes Surg. 2010; 20:1090-1095. EL 3, SS. [PubMed: 20440578]

382. Spaun GO, Marinec DV, Kennedy TJ, et al. Endoscopic closure of gastrogastric fistulas by using a tissue apposition system (with videos). Gastrointest Endosc. 2010; 71:606-611. EL 3, CCS. [PubMed: 20018279]

383. Fernandez-Esparrach G, Lautz DB, Thompson CC. Endoscopic repair of gastrogastric fistula after Roux-en-Y gastric bypass: a less-invasive approach. Surg Obes Relat Dis. 2010; 6:282-288. EL 3, SCR. [PubMed: 20510291]

384. deWolfe MA, Bower CE. Using the StomaphyX $\mathrm{X}^{\mathrm{TM}}$ endoplicator to treat a gastric bypass complication. JSLS. 2011; 15:109-113. EL 3, SCR. [PubMed: 21902955]

385. Kothari SN. Bariatric surgery and postoperative imaging. Surg Clin N Am. 2011; 91:155-172. EL 4, review. [PubMed: 21184906]

386. Taratino I, Warschkow R, Steffen T, et al. Is routine cholecystectomy justified in severely obese patients undergoing a laparoscopic Roux-en-Y gastric bypass procedure? A comparative cohort study. Obes Surg. 2011; 21:1870-1878. EL 2, PCS. [PubMed: 21863228]

387. Uy MC, Talingdan-Te MC, Espinosa WZ, et al. Ursodeoxycholic acid in the prevention of gallstone formation after bariatric surgery: a meta-analysis. Obes Surg. 2008; 18:1532-1538. EL 1, MRCT. [PubMed: 18574646]

388. Pimentel M, Lembo A, Chey WD, et al. Rifaximin therapy for patients with irritable bowel syndrome without constipation. N Engl J Med. 2011; 364:22-32. EL 1, RCT (no bariatric surgery patients). [PubMed: 21208106]

389. Datta T, Eid G, Nahmias N, et al. Management of ventral hernias during laparoscopic gastric bypass. Surg Obes Relat Dis. 2008; 4:754-747. EL 3, SS. [PubMed: 18514585]

390. Praveen Raj P, Senthiinathan P, Kumaravel R, et al. Concomitant laparoscopic ventral hernia mesh repair and bariatric surgery: a retrospective study from a tertiary care center. Obes Surg. 2012; 22:685-689. EL 3, SS. [PubMed: 22328097]

391. Husain S, Ahmed AR, Johnson J, et al. Small-bowel obstruction after laparoscopic Roux-en-Y gastric bypass: etiology, diagnosis, and management. Arch Surg. 2007; 142:988-993. EL 3, SS. [PubMed: 17938313]

392. van der Beek ES, Te Riele W, Specken TF, et al. The impact of reconstructive procedures following bariatric surgery on patient well-being and quality of life. Obes Surg. 2010; 20:36-41. EL 3, SS. [PubMed: 19688408]

393. Breiting LB, Lock-Andersen J, Matzen SH, et al. Increased morbidity in patients undergoing abdominoplasty after laparoscopic gastric bypass. Dan Med Bull. 2011; 58:A4251. EL 3, SS. [PubMed: 21466761]

394. O’Brien JA, Broderick GB, Hurwitz ZM, et al. Fleur-delis panniculectomy after bariatric surgery: our experience. Ann Plast Surg. 2012; 68:74-78. EL 3, SS. [PubMed: 21587047]

395. Moya AP, Sharma D. A modified technique combining vertical and high lateral incisions for abdominal-to-hip contouring following massive weight loss in persistently obese patient. J Plast Reconstr Aesthet Surg. 2009; 62:56-64. EL 3, SS. [PubMed: 18023630]

396. Vico PG, De Vooght A, Nokerman B. Circumferential body contouring in bariatric and nonbariatric patient. J Plast Reconstr Aesthet Surg. 2010; 63:814-819. EL 3, SS. [PubMed: 19345658]

397. Hamdi M, Van Landuyt K, Blondeel P, et al. Autologous breast augmentation with the lateral intercostal artery perforator flap in massive weight loss patients. J Plast Reconstr Aesthet Surg. 2009; 62:65-70. EL 3, SS. [PubMed: 18054303]

398. Van der Beek ES, van der Molen AM, van Ramshorst B. Complications after body contouring surgery in post-bariatric patients: the importance of a stable weight close to normal. Obes Facts. 2011; 4:61-66. EL 3, SS. [PubMed: 21372612] 
399. Dorman RB, Miller CJ, Leslie DB, et al. Risk for hospital readmission following bariatric surgery. PLoS One. 2012; 7:e32506. EL 2, PCS. [PubMed: 22412881]

400. Hong B, Stanley E, Reinhardt S, et al. Factors associated with readmission after laparoscopic gastric bypass surgery. Surg Obes Relat Dis. 2011; 8:691-695. EL 3, SS. [PubMed: 21978746]

401. Kellogg TA. Revisional bariatric surgery. Surg Clin N Am. 2011; 91:1353-1371. EL 4, NE review. [PubMed: 22054158]

402. Stegtenhorst BR, van der Harst E, Demirkiran A, et al. Effect of primary versus revisional Rouxen-Y gastric bypass: inferior weight loss of revisional surgery after gastric banding. Surg Obes Relat Dis. [Epub 2012 Mar 7.] EL 3, SS.

403. Brolin RE, Asad M. Rationale for reversal of failed bariatric operations. Surg Obes Relat Dis. 2009; 5:673-676. EL 3, SS. [PubMed: 19796997] 


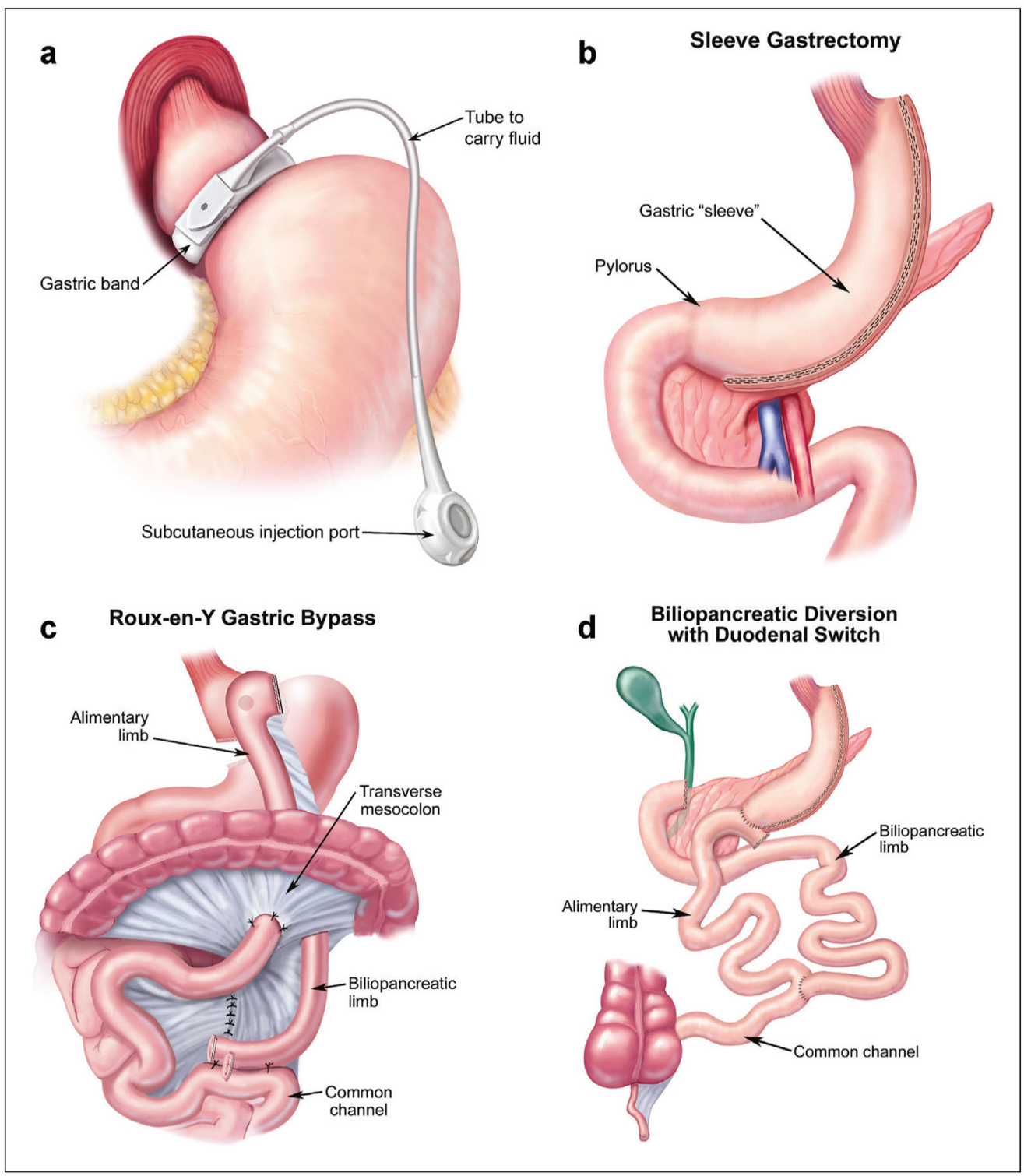

Fig. 1.

Common types of bariatric surgery procedures. (A) Adjustable gastric band; $(B)$ sleeve gastrectomy; $(C)$ Roux-en-Y gastric bypass; $(D)$ biliopancreatic diversion with duodenal switch. (Illustrations reprinted with permission from Atlas of Metabolic and Weight Loss Surgery, Jones et al. Cine-Med, 2010. Copyright of the book and illustrations are retained by Cine-Med.) 


\section{Table 1}

2010 American Association of Clinical Endocrinologists Protocol for Production of Clinical Practice Guidelines-Step I: Evidence Rating*

\begin{tabular}{|c|l|}
\hline Numerical descriptor (evidence level) & Semantic descriptor (reference methodology) \\
\hline 1 & Meta-analysis of randomized controlled trials (MRCT) \\
\hline 1 & Randomized controlled trial (RCT) \\
\hline 2 & Meta-analysis of nonrandomized prospective or case-controlled trials (MNRCT) \\
\hline 2 & Nonrandomized controlled trial (NRCT) \\
\hline 2 & Prospective cohort study (PCS) \\
\hline 2 & Retrospective case-control study (RCCS) \\
\hline 3 & Cross-sectional study (CSS) \\
\hline 3 & Surveillance study (registries, surveys, epidemiologic study) (SS) \\
\hline 3 & Consecutive case series (CCS) \\
\hline 3 & Single case reports (SCR) \\
\hline 4 & No evidence (theory, opinion, consensus, or review) (NE) \\
\hline
\end{tabular}

* 1 = strong evidence $; 2$ = intermediate evidence 3 = weak evidence $; 4=$ no evidence. 
Table 2

A2010 American Association of Clinical Endocrinologists Protocol for Production of Clinical Practice Gudielines-Step II: Evidence Analysis and Subjective Factors

\begin{tabular}{|l|l|l|}
\hline Study design & Data analysis & Interpretation of results \\
\hline Premise correctness & Intent-to- treat & Generalizability \\
\hline Allocation concealment (randomization) & Appropriate statistics & Logical \\
\hline Selection bias & & Incompleteness \\
\hline Appropriate blinding & & Validity \\
\hline Using surrogate end points (especially in "first-in-itsclass" intervention) & & \\
\hline Sample size (beta error) & & \\
\hline Null hypothesis versus Bayesian statistics & & \\
\hline
\end{tabular}


Table 3

A 2010 American Association fo Clinical Endocrinologists Protocol for Production of Clinical Practice Guidelines-Step III: Grading of Recommendations; How Different Evidence Levels can be Mapped to the Same Recommendation Grade*

\begin{tabular}{|l|l|l|l|l|}
\hline Best evidence level & Subjective factor impact & Two-thirds consensus & Mapping & Recommendation grade \\
\hline 1 & None & Yes & Direct & A \\
\hline 2 & Positive & Yes & Adjust up & A \\
\hline 2 & None & Yes & Direct & B \\
\hline 1 & Negative & Yes & Adjust down & B \\
\hline 3 & Positive & Yes & Adjust up & B \\
\hline 3 & None & Yes & Direct & C \\
\hline 2 & Negative & Yes & Adjust down & C \\
\hline 4 & Positive & Yes & Adjust up & C \\
\hline 4 & None & Yes & Direct & D \\
\hline 3 & Negative & Yes & Adjust down & D \\
\hline $1,2,3,4$ & NA & No & Adjust down & D \\
\hline
\end{tabular}

* Starting with the left column, best evidence levels (BEL), subjective factors, and consensus map to recommendation grades in the right column. When subjective factors have little or no impact ("none"), then the BEL is directly mapped to recommendation grades. When subjective factors have a strong impact, then recommendation grades may be adjusted up ("positive" impact) or down ("negative" impact). If a two-thirds consensus cannot be reached, then the recommendation grade is D. NA = not applicable (regardless of the presence or absence of strong subjective factors, the absence of a two-thirds consensus mandates a recommendation grade D). 
Table 4

2010 American Association of Clinical Endocrinologists Protocol for Production of Clinical Practice Guidelines-Step IV: Examples of Qualifiers That May Be Appended to Recommendations

\begin{tabular}{|l|}
\hline Cost-effectiveness \\
\hline Risk-benefit analysis \\
\hline Evidence gaps \\
\hline Alternative physician preferences (dissenting opinions) \\
\hline Alternative recommendations ("cascades") \\
\hline Resource availability \\
\hline Cultural factors \\
\hline Relevance (patient-oriented evidence that matters) \\
\hline
\end{tabular}




\section{Table 5}

\section{Preoperative Checklist for Bariatric Surgery*}

Complete H \& P (obesity-related co-morbidities, causes of obesity, weight BMI, weight loss history, commitment, and exclusions related
to surgical risk)

$\checkmark \quad$ Routine labs (including fasting blood glucose and lipid panel, kidney function, liver profile, lipid profile, urine analysis, prothrombin time/ INR, blood type, CBC)

$\checkmark \quad$ Nutrient screening with iron studies, $\mathrm{B}_{12}$ and folic acid (RBC folate, homocysteine, methylmalonic acid optional), and 25-vitamin D (vitamins A and E optional); consider more extensive testing in patients undergoing malabsorptive procedures based on symptoms and risks

$\checkmark$ Cardiopulmonary evaluation with sleep apnea screening (ECG, CXR, echocardiography if cardiac disease or pulmonary hypertension suspected; DVT evaluation if clinically indicated)

$\checkmark$ GI evaluation (H pylori screening in high-prevalence areas; gallbladder evaluation and upper endoscopy if clinically indicated)

$\checkmark$ Endocrine evaluation $\left(\mathrm{A}_{1 \mathrm{c}}\right.$ with suspected or diagnosed prediabetes or diabetes; TSH with symptoms or increased risk of thyroid disease; androgens with PCOS suspicion (total/bioavailable testosterone, DHEAS, $\Delta_{4}$-androstenedione); screening for Cushing's syndrome if clinically suspected (1 mg overnight dexamethasone test, 24-hour urinary free cortisol, 11 PM salivary cortisol)

$\checkmark \quad$ Clinical nutrition evaluation by RD

$\checkmark$ Psychosocial-behavioral evaluation

$\checkmark \quad$ Document medical necessity for bariatric surgery

$\checkmark \quad$ Informed consent

$\checkmark \quad$ Provide relevant financial information

$\checkmark \quad$ Continue efforts for preoperative weight loss

$\checkmark \quad$ Optimize glycemic control

$\checkmark \quad$ Pregnancy counseling

$\checkmark \quad$ Smoking cessation counseling

$\checkmark \quad$ Verify cancer screening by primary care physician 


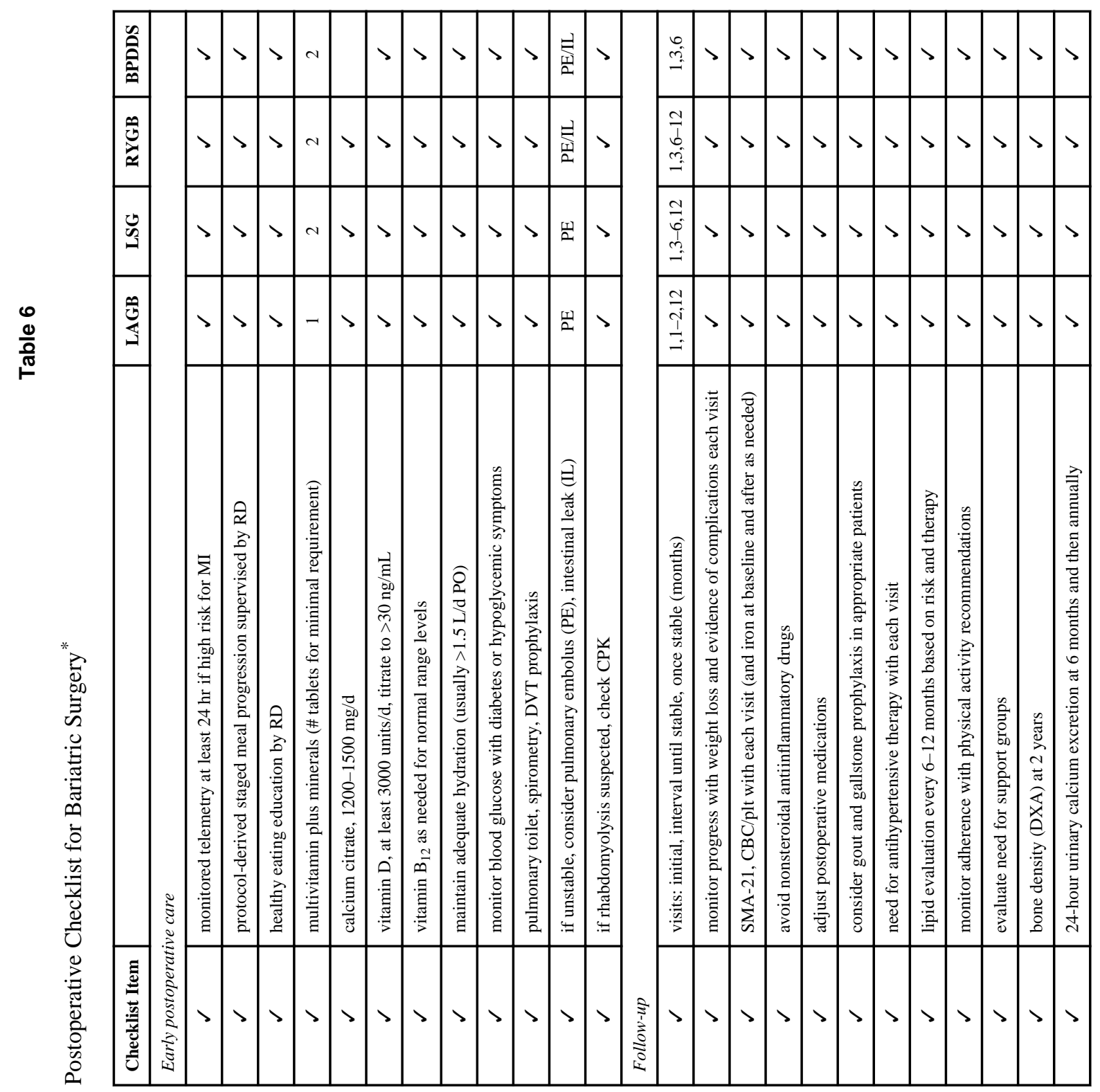

Endocr Pract. Author manuscript; available in PMC 2014 August 21. 
